\author{
Hélio Rubens Victorino Imbimbo
}

\title{
AVALIAÇÃO DA QUALIDADE AMBIENTAL, UTILIZANDO INVERTEBRADOS BENTÔNICOS, NOS RIOS ATIBAIA, ATIBAINHA E CACHOEIRA, SP.
}

São Paulo

2006 
Hélio Rubens Victorino Imbimbo

\section{AVALIAÇÃO DA QUALIDADE AMBIENTAL, UTILIZANDO INVERTEBRADOS BENTÔNICOS, NOS RIOS ATIBAIA, ATIBAINHA E CACHOEIRA, SP.}

Tese apresentada ao Instituto de Biociências da Universidade de São Paulo, para a obtenção de Título de Doutor em Ciências, na Área de Ecologia

Orientadora: Dra. Gisela Yuka Shimizu

São Paulo

2006 
Ficha Catalográfica

Imbimbo, Hélio Rubens Victorino

AVALIAÇÃO DA QUALIDADE AMBIENTAL, UTILIZANDO INVERTEBRADOS BENTÔNICOS, NOS RIOS ATIBAIA, ATIBAINHA E CACHOEIRA, SP.

$$
75 \text { p.+ anexos }
$$

Tese (Doutorado) - Instituto de Biociências da Universidade de São Paulo. Departamento de Ecologia.

1. Ephemeroptera 2. Plecoptera 3. Trichoptera. 4. Qualidade ambiental Universidade de São Paulo. Instituto de Biociências.

Departamento de Ecologia.

Comissão Julgadora:

$\operatorname{Prof}(a)$. Dr(a).

$\operatorname{Prof}(a)$. Dr(a).

$\operatorname{Prof}(a)$. Dr(a).

$\operatorname{Prof}(a) . \operatorname{Dr}(a)$

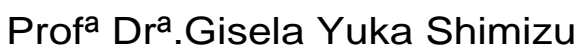

Orientadora 
Aos meus pais. 


\section{AGRADECIMENTOS}

Mais uma vez, à Gisela, por sua amizade, confiança e orientação.

À amiga Mônica, pelo incentivo e dedicação e "ouvido amigo".

À amiga Helena, coma qual compartilhei minhas "lamentações".

Ao Emerson, Vanessa e Mirela, que dividiram comigo a árdua tarefa de triagem das amostras.

À Maira, por seu amor e compreensão nos momentos críticos.

Aos Prof. Dr. Roberto M. Shimizu, pela receptividade e esclarecimentos prestados.

Ao Dr. Carlos Molineri e Dr. Leandro Gonçalves Oliveira, pela gentileza da confirmação de alguns gêneros.

Aos colegas da CETESB que participaram das atividades de campo.

Aos colegas do DAIA, pelo incentivo nas horas de crise.

Aos meus pais, a quem devo muito por ter chegado até aqui.

E aos demais colegas que direta ou indiretamente colaboraram para a realização deste trabalho. 


\section{ÍNDICE}

RESUMO/ABSTRACT 2

1.INTRODUÇÃO 3

$\begin{array}{ll}1.1 \text { Objetivos } & 8\end{array}$

2. MATERIAL E MÉTODOS

2.1 Área de estudo 9

$\begin{array}{ll}\text { 2.1.1. Locais e períodos de amostragem } & 10\end{array}$

2.2. Coleta das amostras

2.2.1. Água 14

$\begin{array}{ll}\text { 2.2.2. Sedimento } & 14\end{array}$

2.2.3. Dados bióticos $\quad 15$

2.3. Análise dos dados

$\begin{array}{ll}\text { 2.3.1 Físicos e químicos } & 17\end{array}$

$\begin{array}{lr}\text { 2.3.2. Bióticos } & 17\end{array}$

3. RESULTADOS E DISCUSSÃO

$\begin{array}{lr}\text { 3.1. Variáveis físicas e químicas } & 18\end{array}$

3.2. Dados Bióticos 39

4. CONCLUSÕES 61

5. RECOMENDAÇÕES

6. REFERÊNCIAS BIBLIOGRÁFICAS 62

ANEXO 


\title{
RESUMO
}

As fases imaturas dos insetos das Ordens Ephemeroptera, Plecoptera e Trichoptera (EPT) são consideradas membros sensíveis da comunidade macrobentônica dos ecossistemas lóticos. Portanto, são freqüentemente utilizados como indicadores de perturbações ambientais como a poluição. Foram adotados oito pontos de amostragem ao longo dos rios Atibainha, Cachoeira e Atibaia, na bacia do rio Piracicaba, São Paulo. Nestes locais foram determinadas as qualidades e toxicidades da água e do sedimento, bem como a composição do EPT em seis diferentes habitats, nas estações seca e chuvosa. Os resultados mostraram um gradiente de poluição ao longo dos rios que foi acompanhado pelo índice EPT nos níveis de gênero e família. Não foi possível selecionar grupos de táxons como indicadores de condições ambientais degradadas e preservadas, pois a maioria dos gêneros ocorrentes é tolerante à poluição. Recomenda-se o uso do índice EPT no nível de família nos programas de biomonitoramento regionais.

\begin{abstract}
Immature insects of the Orders Ephemeroptera, Plecoptera and Trichoptera (EPT) are considered sensible members of the macrobenthic community in lotic ecosystems. Accordingly, they are often used as indicators of environmental disturbances as pollution. Eight sampling sites were established along the rivers Atibainha, Cachoeira and Atibaia of Piracicaba river basin, São Paulo, Brazil, where water and sediment quality, toxicity, as well as EPT composition in six different habitats, were determined in dry and wet seasons. The results showed a pollution gradient along the water stream matched with EPT index at genus and family levels. It was not possible to select groups of taxa as indicators of degraded and preserved environmental conditions because most of genera occurring are tolerant to pollution. It is recommended the use of EPT index in family level in stream biomonitoring programs for regional purposes.
\end{abstract}




\section{INTRODUÇÃO}

As atividades humanas estão intrinsecamente associadas ao uso da água, desde o simples uso doméstico e lazer ao emprego na indústria, para as mais diversas finalidades.

Juntamente com o uso inadequado do solo, o mau aproveitamento da água é uma das principais fontes de degradação dos corpos hídricos superficiais, comprometendo a manutenção das comunidades aquáticas e a água propriamente dita, em termos de quantidade e qualidade. Em geral, as principais alterações observadas no ambiente aquático são: o assoreamento, desencadeado por processos de dinâmica de superfície no ambiente terrestre; a eutrofização artificial (ou cultural), decorrente do aporte de nutrientes e a contaminação, por compostos orgânicos (p.ex.: defensivos agrícolas) ou inorgânicos (p.ex.: metais) oriundos principalmente da indústria e agricultura, que podem atingir as águas superficiais diretamente, por meio de lançamentos ou escoamento superficial, ou indiretamente, via contribuição das águas subterrâneas previamente contaminadas.

A viabilidade da continuidade do aproveitamento dos recursos hídricos depende, cada vez mais, de medidas de planejamento e controle, de modo a disciplinar a captação, uso e disposição das águas nos corpos receptores.

Os programas de manejo e monitoramento de recursos hídricos devem incorporar, além dos componentes físicos (como clima, geologia e hidrologia do sistema) e químicos (parâmetros orgânicos, inorgânicos), os componentes biológicos como, por exemplo, o estudo das comunidades que habitam o sistema, de forma a propiciar uma visão completa do meio (JUNQUEIRA et al.,2000; MeTCALFE, 1989).

Dentre os compartimentos do ambiente aquático, é no sedimento onde ocorre o acúmulo de nutrientes e contaminantes. Este compartimento é o habitat da comunidade bentônica, a qual tem papel fundamental na transformação da matéria, no fluxo de energia e na ciclagem de nutrientes (NELSON et al., 2000; CALLISTO \& ESTEVES, 1995), por meio do revolvimento do sedimento e fragmentação da matéria orgânica. As comunidades que habitam o sedimento podem ser consideradas como as mais sensíveis a perturbações do ambiente aquático e responsáveis pelo desencadeamento de vários processos que ocorrem na coluna d'água (VARIOLI et al, 2004). 
A comunidade de macroinvertebrados bentônicos é formada, principalmente, por fases imaturas de insetos, além de moluscos, anelídeos e crustáceos que, à exceção destes últimos, apresentam, em sua maioria, hábito tipicamente séssil ou semi-séssil.

Em um ambiente não perturbado, a riqueza (S) de espécies de macroinvertebrados bentônicos é influenciada por fatores como a geologia, produtividade, heterogeneidade do ambiente, relações de competição e predação, etc. (COMPIM \& CÉRÉGHINO, 2003). No entanto as perturbações, de origem natural ou antrópica, podem culminar em alterações da qualidade ambiental, como por exemplo, o aumento da carga orgânica e de nutrientes, processos erosivos e assoreamento, contaminação da água e sedimento, etc., alterando as características naturais dos rios e conseqüentemente afetando, dentre outras, a comunidade de macroinvertebrados bentônicos (GUALDONI \& CORIGLIANO, 2002; HYNES, 1970). Assim sendo, os integrantes da comunidade bentônica podem atuar como monitores naturais do ambiente (DICKSON et al., 1971), pois tais perturbações, que podem variar em intensidade, freqüência e/ou abrangência, são interpretadaos por meio de parâmetros ecológicos como riqueza, abundância e diversidade da comunidade (PEREIRA \& DE LUCA , 2003; MCCABE \& Gotelli, 2000). Em função destas características, a comunidade bentônica tem sido amplamente utilizada em estudos de avaliação da qualidade ambiental (Buss et al., 2004; FERREIRA-PERUQUETTI \& FONSECA-GESSNER, 2003; EGLER, 2002; SWIFT, 2002; CLEMENTS, 1999; MOULTON, 1998).

Espécies que possuem tolerâncias ambientais específicas recebem a denominação de "espécies indicadoras" (NIEMI \& MCDONALD, 2004). Em síntese, a ocorrência de grupos de organismos pouco tolerantes, ou a eliminação destes, associada à abundância de organismos resistentes às condições adversas podem refletir as condições de boa e má qualidade ambiental, respectivamente (HICKEY \& CLEMENTS, 1998).

O emprego dos bioindicadores pode mudar em função do nível da abordagem pretendida. JOHNSON et al. (1993) apresentam um conceito de bioindicador no nível de organismo, onde é necessário o conhecimento dos limites específicos de tolerância para o espécime em questão. Quando a análise envolve o estudo de comunidades, as variações de riqueza e abundância refletem "integralmente os efeitos produzidos por todas as substâncias existentes na água, incluindo substâncias novas, que surgem a partir de interações entre elementos que se subtraem à análise química" (CETEC, 1998 apud JUNQUEIRA et 
al., 2000). Os indicadores podem ser considerados como características mensuráveis da estrutura (como por exemplo, o habitat ou padrão de paisagem), composição (espécies, populações, comunidades, etc.) ou funções (por exemplo, demografia, relações interespecíficas, etc.) de um sistema ecológico (BONADA et al., 2006; NIEMI \& MCDONALD, 2004). O principal papel dos indicadores biológicos é demonstrar os efeitos decorrentes de perturbações, em sua maioria de origem antrópica sobre o ambiente, não cabendo aos indicadores identificar tais perturbações. Os bioindicadores devem ainda ser capazes de distinguir a variabilidade decorrente de ações antrópicas daquelas naturalmente observadas (NIEMI \& MCDONALD, 2004). O acompanhamento da qualidade ambiental de um determinado sistema ao longo do tempo, com base em variáveis biológicas (BONADA et al, 2006) é denominado biomonitoramento.

Há mais de vinte anos os programas de biomonitoramento têm sido uma valiosa ferramenta para avaliar a qualidade ambiental de corpos d'água, em um contexto ecológico, ampliando o diagnóstico meramente físico e químico (HICKEY \& CLEMENTS, 1998).

Os invertebrados bentônicos são considerados um parâmetro adequado em biomonitoramento, devido a algumas características biológicas relacionadas abaixo (DAHL, 2004; Moulton, 1998; ReICE \& WoHLenBeRG, 1993; Balloch et al., 1976):

$\Rightarrow$ estão associados ao sedimento, região esta, como já citado, de acúmulo de nutrientes e contaminantes;

$\Rightarrow$ a baixa mobilidade dos elementos da comunidade não permite que estes se desloquem para localidades cujas condições sejam mais favoráveis, como ocorre com os peixes, por exemplo;

$\Rightarrow$ comparativamente às comunidades planctônicas, o ciclo de vida dos invertebrados bentônicos é mais longo, permitindo um maior tempo de exposição ao agente perturbador;

$\Rightarrow$ são de distribuição cosmopolita e bastante estudados, sendo que as respostas à poluição de muitas espécies já são bem conhecidas;

$\Rightarrow$ são relativamente fáceis de coletar, podendo-se utilizar equipamentos simples e de baixo custo.

Segundo MATtheWs (1982 apud RosenBerg \& RESH, 1992), define-se biomonitoramento como o uso sistemático de respostas biológicas para avaliar as mudanças no meio ambiente, usando essas informações na elaboração de um programa de controle ambiental. 
Os insetos da ordens Trichoptera, Ephemeroptera e Plecoptera medem as condições da comunidade com base em processos metabólicos, principalmente em função de sua intolerância às baixas concentrações de oxigênio dissolvido (BUTCHER et al, 2003). São comuns em drenagens de baixas e médias ordens (BISPO et al., 2001) sendo, em geral, associadas aos ambientes menos degradados. Todavia, cada ordem apresenta táxons com tolerâncias distintas às perturbações. Em função dessas características é que as ordens são potencialmente classificadas como bons indicadores da qualidade do ambiente lótico (OLIFIERS et al., 2004).

A ordem Trichoptera pode ser considerada como uma das mais diversificadas dos ambientes dulciaqüícolas, apresentado, para a América do Sul, mais de 1.100 espécies registradas (ANGRISANO \& KOROB, 2001). A maioria dos Trichoptera está restrita aos ambientes lóticos frios, porém a ordem é também bem representada em sistemas lênticos, e com temperaturas mais elevadas. Em geral, vivem em águas correntes, limpas e bem oxigenadas, sob troncos, galhos, folhas e pedras. Devido às suas exigências ambientais, são considerados bons indicadores ambientais, associado a águas limpas e oligotróficas (FROEHLICH, 1999a; GuAHYBA, 1988; PÉREZ, 1988; WigginS, 1984), porém algumas espécies podem ser tolerantes à poluição (THORNE \& WILLIAMS, 1997; BARGOS et al., 1990, PÉREZ, 1988).

Os Trichoptera pertencem, em sua maioria, aos grupos funcionais de fragmentadores e pastadores, ocorrendo também algumas espécies predadoras e poucos coletores (OLIVEIRA et al., 1999). Segundo WIGGINS e MACKAY (1978), espécies fragmentadoras são aquelas que se alimentam de tecidos de plantas vasculares vivas ou mortas e algas filamentosas. As espécies pastadoras alimentam-se de perifíton ou matéria orgânica fina que se acumula sobre a superfície de folhas ou rochas. Os coletores alimentam-se por filtração, coletam partículas em suspensão ou levemente sedimentadas. Os predadores são carnívoros, alimentam-se de outros animais vivos.

Distinguindo-se pela capacidade de construir abrigos e redes para obtenção de alimento, existem hipóteses de que estas capacidades sejam as responsáveis pela grande diversidade de Trichoptera, tornando-os aptos a explorar um número maior de microhabitats (MANDAVILLE, 2002; HUAMANTINCO \& NESSIMIAN, 1999; Wiggins \& MACKAY, 1978). Refúgios fixos no substrato, como aqueles confeccionados por representantes da família Hydropsychidae, servem 
como lastro, abrigo e para captura de alimento. (PÉREZ, 1988; WIGGINS, 1984; MACKAY \& WIGGINS, 1979).

Mundialmente, para a ordem Plecoptera estão descritas aproximadamente 2000 espécies (ROMERO, 2001). No Brasil, a Ordem é representada por apenas duas famílias: Gripopterygidae e Perlidae, ambas com ninfas de vida estritamente aquática, habitando preferencialmente águas de fluxo rápido, frias e bem oxigenadas, típicas de regiões de cabeceira de rios (WILLIAMS \& FELTMATE, 1992 apud BISPO et a.l, 2002). Vivem sob troncos, folhas e rochas (HUAMANTINCO \& Nessimian, 1999; HeliöVAara \& VÄISÄNEN, 1993; PÉreZ, 1988), ou associados à vegetação aquática (BORROR \& DE LONG, 1988). Geralmente as ninfas de Plecoptera são fragmentadoras ou predadoras.

Mesmo pouco diversa, a ordem Plecoptera é de grande importância no ambiente aquático em termos de biomassa FROEHLICH (1999) e por apresentar critérios favoráveis como indicadores de qualidade ambiental, em função de sua sensibilidade à poluição (MANDAVILLE, 2002; PÉREZ, 1988; HARPER \& STEWART, 1984).

Comparativamente a Trichoptera, a Ordem Ephemeroptera é menor, e apresenta aproximadamente 300 gêneros (aproximadamente 4.000 espécies) descritos em todo o mundo (DomínGUEZ et al., 2001).

Os insetos pertencentes à ordem Ephemeroptera apresentam adultos de vida muito curta, variando de algumas horas a aproximadamente quatro ou cinco dias (MANDAVILLE, 2002; PÉReZ, 1988; EdmundS, 1984). Assim como nas ordens acima descritas, na ordem Ephemeroptera, as formas imaturas (ninfas) possuem vida estritamente aquática, vivendo regularmente em águas limpas, correntes e com elevada concentração de oxigênio dissolvido. Apenas algumas espécies são capazes de resistir à poluição moderada (DOMíNGUEZ et al., 2001).

Os Ephemeroptera podem ser encontrados em praticamente todos os microhabtats disponíveis (enterrados em lodo ou areia, minando tecidos vegetais, no folhiço, etc.). A maioria das ninfas são coletoras ou raspadoras, alimentando-se de algas e detritos, sendo poucas espécies (DA-SILVA, 1998; EDMUNDS, 1984).

Os diversos táxons que compõem essas ordens apresentam diferentes níveis de tolerância às perturbações no ambiente aquático, sendo potencialmente adequados ao estabelecimento de espécies indicadoras de condições específicas. Assim sendo, o número dessas ordens diminuirá com o aumento da degradação do ambiente aquático. A composição das riquezas de Ephemeroptera, Plecoptera 
e Trichoptera constituem o índice denominado EPT, amplamente aplicado na avaliação da qualidade ambiental.

As vantagens da utilização de índices estão listadas em NORRIS \& GEORGES (1993), destacando-se as seguintes:

$\Rightarrow$ condensam uma série de dados ambientais, facilitando sua interpretação;

$\Rightarrow$ podem ser mais facilmente compreendidos por pessoas com menor conhecimento em ecologia e áreas afins; e

$\Rightarrow$ permitem comparação entre amostras oriundas de diferentes locais, coletadas com procedimentos e em períodos distintos.

Este trabalho é oriundo de um Projeto de Pesquisa da CETESB/SMA intitulado "Entre Serras e Águas", em colaboração com o Departamento de Ecologia do Instituto de Biociências - DE/IBUSP, integrante do Programa Pesquisas em Políticas Públicas da FAPESP (Processo FAPESP № 98/14186-7).

\subsection{ObJetIVo}

Este trabalho é oriundo de um Projeto de Pesquisa da CETESB/SMA intitulado "Entre Serras e Águas", em colaboração com o Departamento de Ecologia do Instituto de Biociências - DE/IBUSP, integrante do Programa Pesquisas em Políticas Públicas da FAPESP (Processo FAPESP № 98/14186-7). Neste trabalho, pretende-se:

1. confirmar, a partir da interpretação de dados físicos e químicos, a existência de um gradiente de poluição ao longo dos pontos selecionados para a coleta de dados;

2. avaliar a resposta das ordens Ephemeroptera, Plecoptera e Trichoptera (em nível de gênero), ao referido gradiente de poluição;

3. avaliar, para efeito de projetos de biomonitoramento, a necessidade da identificação dos organismos em nível de gênero, para obtenção de uma resposta com qualidade;

4. eleger indicadores ambientais, dentro das referidas ordens, por meio da associação da ocorrência de determinados táxons às condições ambientais constatadas. 


\section{MATERIAL E MÉTODOS}

\section{1 ÁreA de Estudo}

Os trabalhos de campo desenvolveram-se nos rios Atibainha, Cachoeira e Atibaia. Os rios Atibainha e Cachoeira são formadores do rio Atibaia, todos integrantes da bacia hidrográfica do rio Piracicaba, definida por DEL GRANDE et al. (2003) como modelo de bacia hidrográfica desenvolvida, em função da demografia e nível de industrialização.

A região está localizada na unidade morfológica denominada Planalto de Jundiaí (ROss \& MOROZ, 1997), onde predominam colinas e morros baixos com topos convexos e menor freqüência de morros altos com topos aguçados. A drenagem é do tipo dendrítica e com alta densidade em vales entalhados, estando sujeita a "ocorrência de movimentos de massas e desencadeamento de processos erosivos lineares vigorosos".

Segundo NIMER (1989), o clima na região pode ser classificado como subquente-úmido caracterizado pela menor freqüência de temperaturas elevadas no verão e predomínio de temperaturas amenas no inverno. As áreas com clima subquente apresentam no mínimo um mês com temperatura média inferior a $18^{\circ} \mathrm{C}$, e o mês mais quente aponta temperatura média superior a $22^{\circ} \mathrm{C}$. A temperatura média anual oscila entre 18 e $20^{\circ} \mathrm{C}$.

A área de cabeceira do rio Atibaia compreende 6 municípios (Joanópolis, Piracaia, Nazaré Paulista, Bom Jesus dos Perdões, Mairiporã e Atibaia) em região serrana. O rio Atibaia e seus tributários pertencente ao $4^{\circ}$ grupo de Unidades de Gerenciamento de Recursos Hídricos - UGRHIs do Estado de São Paulo, segundo estabelecido pela Lei Estadual nำ7663 de dezembro de 1991 (CETESB, 1998). As águas desta bacia destinam-se ao abastecimento público, industrial e à irrigação, recebendo efluentes domésticos, industriais pontuais e resíduos agropecuários difusos, sendo a área, predominantemente ocupada por pastagem, abriga indústrias de papel e celulose, alimentícia, sucro-alcooleira, têxtil, metalúrgicas, químicas, petroquímicas e curtumes (CETESB, 1998).

Em toda esta região, apenas $26 \%$ dos esgotos recebem tratamento e, com exceção de Bragança Paulista, contemplada com aterro sanitário, os locais de deposição de resíduos sólidos domésticos são inadequados e muitos, próximos a mananciais (SMA, 1998). 


\subsubsection{LOCAIS E PERÍODOS DE AMOSTRAGEM}

Para a obtenção dos dados, foram realizadas duas campanhas de amostragem. As coletas correspondentes à primeira campanha foram efetuadas entre os dias 21 e 29 de março de 2000. A segunda campanha foi realizada entre os dias 03 e 12 de setembro de 2002. Os meses foram escolhidos de modo a incorporar as variações sazonais como estiagem (setembro) e de maior pluviosidade (março).

Em ambas campanhas de amostragem, as coletas foram realizadas em oito localidades, apresentadas na Tabela I abaixo e representadas na Figura 1.

Os oito pontos de amostragem formam um gradiente fisiográfico, com regiões com características mais típicas de cabeceiras, representadas principalmente pelos pontos 1, 2, 4 e 5 (denominadas alto-gradiente), e de menor declividade, neste caso, os pontos 3, 6, 7 e 8 (denominados baixogradiente). Além dos aspectos fisiográficos, procurou-se, principalmente, distribuir os pontos de coleta de modo a estabelecer um gradiente de poluição, onde as regiões de alto-gradiente apresentem melhores condições à manutenção da vida aquática, se comparadas às regiões de baixo-gradiente.

A jusante dos pontos 2 e 4, nos rios Atibainha e Cachoeira, encontram-se os reservatórios de mesmo nome, destinados ao abastecimento público local e da Região Metropolitana de São Paulo.

A efetividade do gradiente de poluição deverá ser confirmada com interpretação da caracterização física e química das amostras obtidas para água e sedimento. Uma vez definido o gradiente, pretende-se observar a resposta das comunidades a esta condição. 
Tabela I - Descrição dos pontos de coleta na sub-bacia do rio Atibaia.

\begin{tabular}{|c|c|c|}
\hline PONTO & GEORREFERENCIAMENTO & DESCRIÇÃo \\
\hline 1 & $\begin{array}{l}23^{\circ} 01^{\prime} 04,4^{\prime \prime} \mathrm{S} \\
46^{\circ} 09^{\prime} 30,0^{\prime \prime} \mathrm{O}\end{array}$ & $\begin{array}{l}\text { Rio Atibainha, a montante do reservatório do mesmo } \\
\text { nome, Município de Piracaia, Bairro Atibainha Acima, } \\
\text { a montante da Fazenda Tecelagem, a jusante da } \\
\text { Salmonicultura Mantiqueira (atualmente produzindo } \\
\text { trutas). }\end{array}$ \\
\hline 2 & $\begin{array}{l}23^{\circ} 01^{\prime} 20,2^{\prime \prime} \mathrm{S} \\
46^{\circ} 10^{\prime} 40,0^{\prime \prime} \mathrm{O}\end{array}$ & $\begin{array}{l}\text { Rio Atibainha, a montante do reservatório do mesmo } \\
\text { nome, Município de Piracaia, Bairro Atibainha Acima, } \\
\text { a jusante do Sítio Pica-Pau, próximo à Fazenda } \\
\text { Nogueira Montanhês. }\end{array}$ \\
\hline 3 & $\begin{array}{l}23^{\circ} 09^{\prime} 55,8^{\prime \prime} \mathrm{S} \\
46^{\circ} 25^{\prime} 08,5^{\prime \prime} \mathrm{O}\end{array}$ & $\begin{array}{l}\text { Rio Atibainha, a jusante do reservatório do mesmo } \\
\text { nome, Município de Nazaré Paulista, Rodovia D. Pedro } \\
\text { I, entre Bom Jesus dos Perdões e Nazaré Paulista, } \\
\text { próximo à entrada do Hotel Estância Atibainha. }\end{array}$ \\
\hline 4 & $\begin{array}{l}22^{\circ} 58^{\prime} 38,5^{\prime \prime} \mathrm{S} \\
46^{\circ} 08^{\prime} 52,5^{\prime \prime} \mathrm{O}\end{array}$ & $\begin{array}{l}\text { Rio Cachoeira, a montante do reservatório do mesmo } \\
\text { nome, Município de Joanópolis, a montante da } \\
\text { Cachoeira dos Pretos, próximo à Fazenda Pedra do } \\
\text { Carmo. }\end{array}$ \\
\hline 5 & $\begin{array}{l}22^{\circ} 58^{\prime} 02,9^{\prime \prime} \mathrm{S} \\
46^{\circ} 12^{\prime} 33,4^{\prime \prime} \mathrm{O}\end{array}$ & $\begin{array}{l}\text { Rio Cachoeira, a montante do reservatório do mesmo } \\
\text { nome, Município de Joanópolis, ponte sobre o rio na } \\
\text { estrada Joanópolis - Cachoeira dos Pretos, próximo } \\
\text { ao bairro dos Pretos e a cerca de } 17 \mathrm{~km} \text { do centro da } \\
\text { cidade. }\end{array}$ \\
\hline 6 & $\begin{array}{l}23^{\circ} 06^{\prime} 00,7^{\prime \prime} \mathrm{S} \\
46^{\circ} 25^{\prime} 44,6^{\prime \prime} \mathrm{O}\end{array}$ & $\begin{array}{l}\text { Rio Cachoeira, a jusante do reservatório do mesmo } \\
\text { nome, Município de Piracaia, porto de areia próximo à } \\
\text { olaria no Bairro dos Caneados, na estrada Batatuba - } \\
\text { Caneados. }\end{array}$ \\
\hline 7 & $\begin{array}{l}23^{\circ} 06^{\prime} 08,0^{\prime \prime} \mathrm{S} \\
46^{\circ} 32^{\prime} 39,1^{\prime \prime} \mathrm{O}\end{array}$ & $\begin{array}{l}\text { Rio Atibaia, Município de Atibaia, junto à captação do } \\
\text { município de Atibaia (AT2000 da rede básica de } \\
\text { monitoramento da qualidade de água da CETESB). }\end{array}$ \\
\hline 8 & $\begin{array}{l}23^{\circ} 58^{\prime} 59,6^{\prime \prime} \mathrm{S} \\
46^{\circ} 49^{\prime} 35,0^{\prime \prime} \mathrm{O}\end{array}$ & $\begin{array}{l}\text { Rio Atibaia, a jusante do ponto } 7 \text {, junto à captação do } \\
\text { município de Itatiba. }\end{array}$ \\
\hline
\end{tabular}

Os pontos 1, 2, 4 e 5 estão situados a montante dos reservatórios Atibainha e Cachoeira, em áreas de maior altitude e declividade, em rios de mesmo nome, cuja águas estão enquadradas na classe 1 , segundo os Decretos Estaduais $n \cong$ 10.755/97 e $\mathrm{n} \cong$ 8.468/76 (CETESB/DE IB-USP, 2000). A principal ocupação antrópica do solo é a atividade rural (agricultura e pecuária), entremeada com remanescentes de vegetação nativa. Em função das características geomorfológicas, essas áreas permanecem relativamente protegidas da expansão urbana, as quais, de modo geral, correspondem a cidades pequenas, com baixa densidade populacional.

A jusante dos referidos reservatórios, as águas dos rios Atibainha e Cachoeira são enquadradas, segundo os Decretos supracitados, como classe 2. 
Os pontos de coleta 3, 6, 7 e 8 estão situados em áreas com maior adensamento populacional e cuja infraestrutura urbana é, comparativamente, mais significativa, estando sujeitos, portanto, às suas influências diretas ou indiretas.

Em função das características distintas entre as regiões de alto-gradiente (pontos 1, 2, 4 e 5) e baixo-gradiente (pontos 3, 6, 7 e 8), pressupõe-se a formação de um gradiente crescente de poluição, no sentido montante jusante.

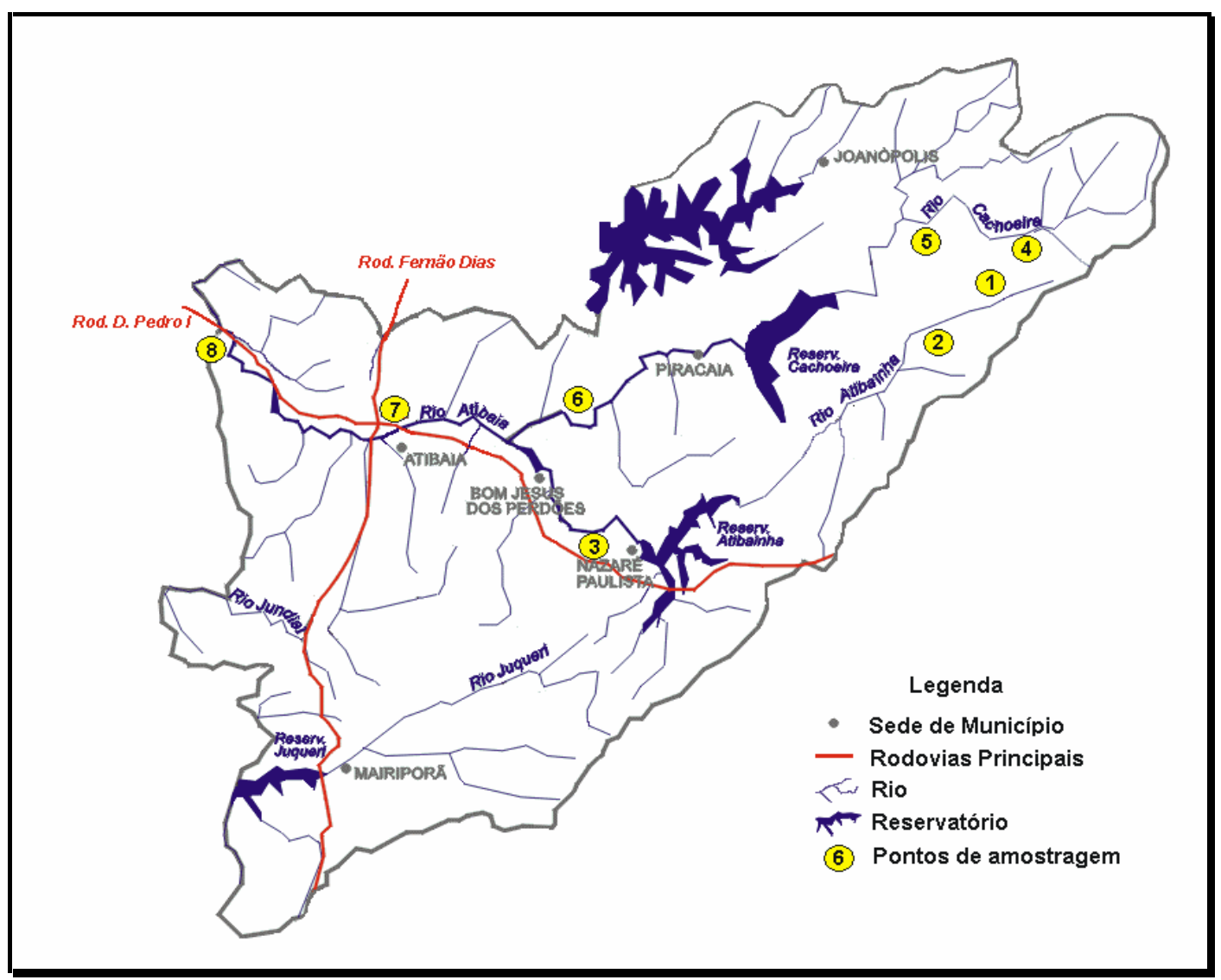

Figura 1 - Croqui da sub-bacia da região de cabeceira do rio Atibaia, SP, com a localização dos pontos de amostragem nos rios Atibainha, Cachoeira e Atibaia (fonte: CETESB/DE IB-USP, 2000).

Os dados de pluviosidade da região, para o período em que foram realizadas as atividades de campo foram obtidos por meio de consulta à página do Sistema de Informações para o Gerenciamento de Recursos Hídricos do Estado de São Paulo - SIGRH (url: 'wWw.sigrh.sp.gov.br). Foram selecionadas localidades próximas aos pontos de coleta que apresentassem dados completos de pluviosidade no período referente às campanhas de amostragem. As localidades que atenderam essas condições formam Vargem (mais próxima às cabeceiras), Bragança e Atibaia, estas últimas na região de baixo-gradiente. 
A Figura 2 representa os volumes diários de chuvas nas localidades selecionadas, nas quinzenas em que foram realizados os trabalhos de campo.

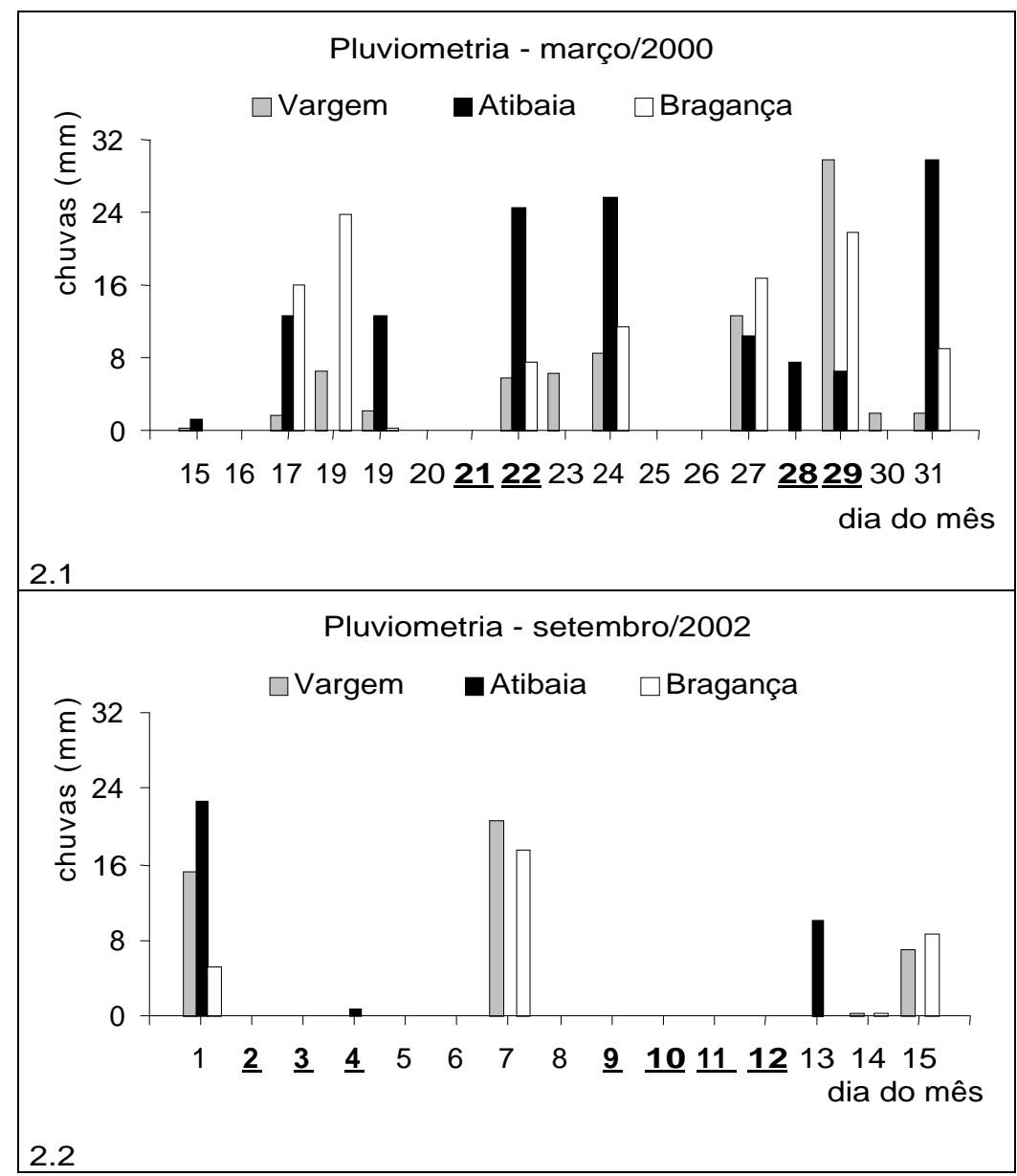

Figura 2 - Pluviosidade no período e região onde foram realizadas as coletas. (2.1) primeira campanha - 2000; (2.2) segunda campanha - 2002. As datas em destaque correspondem aos dias em que foram efetuadas coletas.

Verifica-se a partir da figura acima que as diferenças sazonais entre os períodos de amostragem confirmaram-se, apresentando a primeira campanha (março/2000) maiores freqüência e volume acumulado de chuvas na quinzena, comparativamente à segunda campanha.

Em ambas as campanhas foram coletadas, nas oito localidades, amostras de água, sedimento e da comunidade bentônica. Detalhes a respeito de parâmetros e metodologia de coleta serão abordados a seguir. 


\subsection{Coleta dAs amostras}

\subsection{1. ÁGUA}

As variáveis obtidas a partir da coleta de amostras de água encontram-se listadas na Tabela II, juntamente com o equipamento e procedimento de análise empregado.

As coletas das amostras de água seguiram os procedimentos descritos em Cetesb (1988) e ApHA (1995).

As análises químicas, microbiológicas e toxicológicas, das amostras coletadas, foram realizadas nos laboratórios da CETESB.

\subsubsection{SEDIMENTO}

No sedimento foram determinados os seguintes parâmetros: sólidos totais, fixos, voláteis e umidade, conforme procedimento descrito em APHA (1995); granulometria, segundo Norma Técnica CETESB L6.160 (CETESB, 1995). Para tal, as amostras foram obtidas em triplicata, utilizando-se um pegador de fundo do tipo Petersen modificado (área $=596 \mathrm{~cm}^{2}$ ). As amostras para determinação de metais pesados e toxicidade foram tomadas nos pontos 3,4 e 5 (somente segunda campanha), 6, 7 e 8, onde o ambiente lótico apresentou melhores condições para a formação de zonas deposicionais. A determinação de metais pesados $(\mathrm{Cd}, \mathrm{Pb}, \mathrm{Cu}, \mathrm{Zn}, \mathrm{Cr}, \mathrm{Ni}$ e $\mathrm{Hg}$ ), segue metodologia descrita em EPA 3050B. O teste de toxicidade com o uso do anfípodo aquático Hyalella azteca segue o método descrito em ASTM (1988). Todas as análises foram realizadas nos laboratórios da CETESB. 
Tabela II - Parâmetros relacionados à amostragem de água nos rios Atibainha, Cachoeira e Atibaia.

\begin{tabular}{|c|c|c|}
\hline V ARIÁVEL & EQUIPAMENTO/OBSERVAÇÃo & METODOLOGIA \\
\hline velocidade & $\begin{array}{l}\text { fluxômetro Great Atlantic modelo } \\
\text { Columbia Professional / } \\
\text { exposição do medidor à } \\
\text { correnteza por dois minutos }\end{array}$ & - \\
\hline $\begin{array}{l}\text { temperatura da água } \\
\text { (superfície e fundo) }\end{array}$ & $\begin{array}{l}\text { termistor WTW modelo PH } 197 \\
\text { método eletrométrico }\end{array}$ & - \\
\hline transparência & $\begin{array}{l}\text { disco de Secchi } \\
\varnothing=25 \mathrm{~cm}\end{array}$ & - \\
\hline $\mathrm{pH}$ & potenciômetro WTW PH 197 & APHA (1995) \\
\hline condutividade & $\begin{array}{l}\text { condutivímetro Orion modelo } \\
160\end{array}$ & - \\
\hline turbidez & $\begin{array}{l}\text { turbidímetro modelo VWR } 200 \\
\text { método nefelométrico }\end{array}$ & \\
\hline oxigênio dissolvido - OD & oxímetro WTW modelo OXI 197 & - \\
\hline sólidos totais, fios e voláteis & - & APHA (1995) \\
\hline $\begin{array}{l}\text { carbono orgânico dissolvido } \\
\text { - COD }\end{array}$ & - & APHA (1995) \\
\hline nutrientes & $\begin{array}{l}\text { ortofosfato, fósforo total, } \\
\text { nitrogênio orgânico, Kjeldahl, } \\
\text { nitrogênio-amônia, nitrato e } \\
\text { nitrito }\end{array}$ & $\begin{array}{l}\text { APHA (1995) } \\
\text { nitrato - Norma NBR } \\
12620 / 92\end{array}$ \\
\hline metais & $\begin{array}{l}\text { (cádmio-Cd, chumbo-Pb, cobre- } \\
\text { Cu, zinzco-Zn, cromo-Cr, níquel- } \\
\text { Ni e mercúrio-Hg) }\end{array}$ & $\begin{array}{l}\text { APHA }(1995) \\
\text { CETESB }(1989 a, b, c, d) \\
\text { CETESB }(1990 a, b)\end{array}$ \\
\hline coliformes fecais & tubos múltiplos com meio $\mathrm{A} 1$ & $\begin{array}{l}\text { APHA (1995) } \\
\text { CETESB (1992) }\end{array}$ \\
\hline $\begin{array}{l}\text { pigmentos vegetais } \\
\text { (clorofila- } a \text { e feofitina- } a \text { ) }\end{array}$ & coletas em duplicata & $\begin{array}{l}\text { Norma Técnica } \\
\text { CETESB L.5.306 } \\
\text { (CETESB, 1990c) }\end{array}$ \\
\hline toxicidade crônica & $\begin{array}{l}\text { organismo teste - Ceriodaphnia } \\
\text { dubia }\end{array}$ & $\begin{array}{l}\text { Norma Técnica CETESB } \\
\text { L5.022 - modificada } \\
\text { (CETESB, 1991) }\end{array}$ \\
\hline
\end{tabular}

\subsubsection{DADOS BIÓTICOS}

Para a coleta de organismos bentônicos foram previamente definidos 6 tipos diferentes de potenciais habitats: macrófitas aquáticas (somente primeira campanha), detritos encalhados, canal, corredeira, margem deposicional e margem erosional. Salienta-se que para este caso, denominou-se como "macrófitas", a vegetação marginal às drenagens naturais submersas, constituída, em sua maior parte de gramíneas. Para a obtenção das amostras 
foram utilizados, de acordo com a adequação, amostradores do tipo Hess (com rede de $0,5 \mathrm{~mm}$ de abertura e área de $678,9 \mathrm{~cm}^{2}$ ), rede manual (com malha de $0,5 \mathrm{~mm}$ de abertura) e pegadores do tipo Petersen tradicional e modificado (com áreas de 325 e $596 \mathrm{~cm}^{2}$ ), além de amostragem manual por catação. No uso da rede manual, foi padronizado o esforço amostral através da fixação do tempo de captura, estipulado em 2 minutos. As amostragens com Hess e pegador Petersen foram sempre obtidas em triplicata, enquanto que as amostras com emprego de rede manual foram realizadas em triplicatas ou únicas, mediante as possibilidades no momento. Assim sendo, em função dos diversos métodos de coleta empregados, foram obtidas amostras quantitativas (com Hess e Petersen), semi-quantitativas (com rede manual) e qualitativas (catação). O material coletado foi pré-fixado com solução de formalina neutralizado em volume suficiente para se atingir uma concentração final de $4 \%$ e armazenado em sacos plásticos reforçados para transporte. No laboratório, as amostras foram lavadas através de peneira com abertura de malha equivalente a $0,5 \mathrm{~mm}$. O material retido foi preservado em álcool $70^{\circ} \mathrm{GL}$ e corado com Rosa de Bengala. Amostras ricas em material inorgânico grosseiro (areia, cascalho) foram previamente submetidas à flotação com solução saturada de $\mathrm{NaCl}$ (BRANDIMARTE \& ANAYA, 1995).

Os organismos foram identificados até o nível taxonômico de gênero (ou menor nível taxonômico possível, em função de seu estado de conservação e/ou de maturidade) sob estereomicroscópio, empregando-se as chaves de SALLES et al. (2004); SALLES \& FRANCISCHETTI (2004); BAUMGARDNER et al. (2003); MOLINERI (2003, 1999); FERNÁNDEZ \& DOMÍNGUEZ (2001); WIERSEMA \& MCCAFFERTY (2000); FLINT et al. (1999); CHACÓN \& SEGNINI (1996); LUGO-ORTIZ \& MCCAFFERTY (1996); MERRIT \& CUMmins (1996); THORP \& COVICH (1991); PENNAK (1989) e PÉREZ (1988). As amostras quantitativas da macrofauna bentônica tiveram seus números convertidos para ind $/ \mathrm{m}^{2}$. Os exemplares cuja identificação foi duvidosa foram encaminhados à especialistas para a confirmação. Os gêneros de Trichoptera foram confirmados pelo Dr. Leandro Gonçalves Oliveira, do Laboratório de Limnologia - Instituto de Ciências Biológicas da Universidade Federal de Goiás. A confirmação de alguns gêneros de Ephemeroptera foi feita pelo Dr. Carlos Molineri, da Facultad de Ciencias Naturales - Universidad Nacional de Tucumán, Argentina. 


\subsection{ANÁLISE DOS DADOS}

\subsubsection{Físicos e químicos}

Primeiramente os dados físicos e químicos foram diretamente empregados na elaboração de gráficos de barras, por pontos de coleta, para as duas campanhas.

Os dados cuja representação gráfica foi pouco ilustrativa, como por exemplo, os metais na água, cujas concentrações foram, na maioria dos pontos de coleta, abaixo do limite de detecção, foram apresentados na forma de Tabela.

As variáveis da água, em sua maioria, acrescida de algumas referentes ao sedimento foram analisadas por meio de Análise de Componente Principal, por campanha de coleta, após tratamento por padronização das mesmas.

As mesmas variáveis foram submetidas a uma análise de agrupamento, cujo coeficiente foi a Distância Euclidiana Simples, com agrupamento dos pontos pelo Método de Ward. Todas as análises de agrupamento foram efetuadas por meio do software FITOPAC 1.0 (SHEPHERD, 1995).

\subsubsection{Bióticos}

Os dados referentes ao meio biótico, neste caso, registros quanti e qualitativos de gêneros das ordens Ephemeroptera, Plecoptera e Trichoptera, foram empregados na forma de dois índices (BARBOUR et al., 1999; RESH \& JACKSON, 1993) a saber:

$\Rightarrow$ Riqueza EPT: corresponde à soma dos táxons pertencentes às ordens Ephemeroptera, Plecoptera e Trichoptera;

$\Rightarrow$ Relação Hydropsychidae/Trichoptera: abundância relativa de uma família de Trichoptera mais tolerante à poluição em relação à totalidade de famílias da ordem.

A riqueza EPT foi calculada adotando-se os níveis taxonômicos de gênero e família. Para verificar a equivalência dos resultados obtidos, os valores de EPT foram submetidos a um teste de correlação de Spearman.

Os dados quantitativos e qualitativos foram analisados separadamente, no entanto ambos foram submetidos à análise por agrupamento, empregando-se coeficientes de similaridade. Previamente à análise, os dados quantitativos sofreram transformação logarítmica $\left(\log _{10} X+1\right)$. 
A análise por agrupamentos foi utilizada ainda, para execução de uma Análise Nodal (WIEDEnBRUG et al, 1997; DiAZ \& ERSÉUS, 1994) para evidenciar os gêneros cuja ocorrência foi representativa nos pontos de coleta, em ambas as campanhas de amostragem. Para este procedimento foram utilizados apenas os dados quantitativos, em função da maior regularidade em termos de esforço amostral. Em linhas gerais, o procedimento consiste em agrupar os dados referentes às duas campanhas e submetê-los à análise por agrupamento, agrupando-os por meio dos pontos de coleta em um primeiro momento e em seguida, por meio dos gêneros. Os grupos formados são então ordenados na planilha de origem, evidenciando-se a relação entre gêneros e pontos de coleta. Os gêneros mais representativos em um determinado ponto de coleta serão, então, confrontados com a caracterização física e química daquela localidade. Em qualquer uma das análises efetuadas, os valores "faltantes" nas planilhas, foram substituídos pelo valor médio da variável. A seleção dos gêneros a serem considerados será feita por meio da aplicação do Índice de Valor de Importância - IVI, com base em valores de abundância e freqüência relativas (MEGURO, 2000).

\section{RESULTADOS E DISCUSSÃO}

\subsection{ARIÁVEIS FÍSICAS E QUÍMICAS}

Os resultados das variáveis físicas e químicas obtidos para o ar e água nos pontos de coleta 1 a 8 estão representados graficamente na Figura 3 (3.1 a 3.21). As formas como os resultados estão apresentados permitem a comparação entre campanhas, ou seja, a potencial influência da sazonalidade sobre determinados parâmetros, bem como a visualização do gradiente de poluição esperado, uma vez que todas as localidades amostradas estão representadas em um único gráfico.

Os principais fatores determinantes da caracterização das águas superficiais que drenam uma bacia hidrográfica são a litologia, as interações solo-água e padrões de uso e ocupação do solo (SILVA \& SACOMANI, 2001).

Os dados de velocidade da corrente estão representados na Figura 3.1. De modo geral, os pontos situados em maiores altitudes (1, 2, 4 e 5) apresentaram valores de velocidade maiores que as localidades situadas a jusante. Naturalmente os valores podem ter sofrido influência da ocorrência de chuvas, 
principalmente na primeira campanha. Além deste fator, os pontos 3 e 6 , situados a jusante dos reservatórios Atibainha e Cachoeira, respectivamente, são influenciados pelo regime operacionais das referidas unidades, destinadas ao abastecimento público local e da Região Metropolitana de São Paulo.

A Figura 3.2 apresenta os dados referentes à temperatura do ar. Durante a primeira campanha, a menor temperatura foi observada no ponto $6\left(21,5^{\circ} \mathrm{C}\right)$, e a maior, $23^{\circ} \mathrm{C}$, observada nos pontos $2,3,5$ e 8 . Na segunda campanha observou-se uma maior amplitude de temperatura. A menor temperatura foi observada no ponto $1\left(19,5^{\circ} \mathrm{C}\right)$ e a maior foi registrada nos pontos 5 e $8\left(26^{\circ} \mathrm{C}\right)$. Fatores como sazonalidade, horário da coleta e grau de sombreamento (cobertura vegetal marginal) têm forte influência sobre os resultados de temperatura do ar.

Os valores de temperatura da água de superfície (fig. 3.3) e fundo (fig. 3.4) foram muito próximos ou idênticos em ambas as campanhas, em todos os pontos de coleta. Isto se deve ao grau de turbulência, aliado à pequena profundidade dos corpos d'água que, inevitavelmente, provocam a homogeneização da coluna d'água. Como esperado, para os pontos de altogradiente $(1,2,4$ e 5$)$ as temperaturas registradas foram inferiores àquelas obtidas nos pontos mais a jusante.

Assim como para a temperatura e pelas mesmas razões, os valores de OD na superfície (fig. 3.5) e no fundo (fig. 3.6) apresentaram valores muito semelhantes. A maior concentração de oxigênio dissolvido foi 9,8 mg/L, obtida no ponto 4 (superfície e fundo) durante a segunda campanha de amostragem e o menor valor $(5,3 \mathrm{mg} / \mathrm{L})$, foi obtido no ponto 3 , durante a primeira campanha de amostragem.

A concentração de oxigênio dissolvido no meio líquido é influenciada por interações complexas de inúmeros fatores (SILVA \& SACOMANI, 2001), dentre os quais: a morfologia do canal, que pode ser favorável à injeção de ar na coluna d'água, a demanda metabólica dos seres vivos aeróbios e a temperatura. Com base neste último fator e observando-se em conjunto as Figuras 3.3 e 3.5, verifica-se que as maiores concentrações de OD foram obtidas nas datas e localidades onde a temperatura da água era mais baixa, e os menores valores observados nos momentos onde a temperatura da água esteve mais elevada (primeira campanha, pontos 3, 6, 7 e 8). Ressalte-se que nestas localidades, uma maior demanda por oxigênio, para a metabolização da matéria orgânica pode ter influência significativa sobre a concentração de oxigênio dissolvido. 


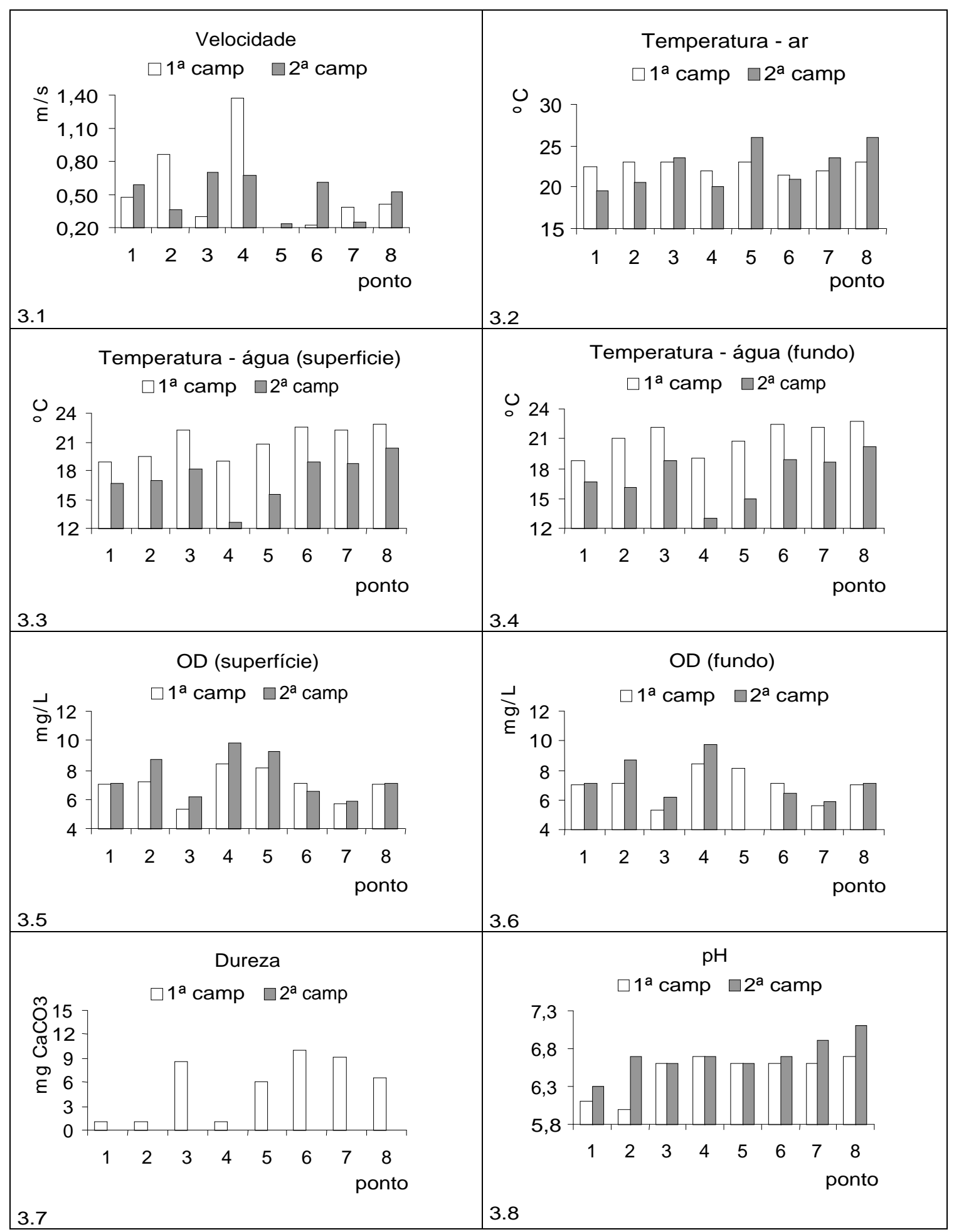

Figura 3 - Resultados das análises físicas e químicas das amostras de água na primeira e segunda campanhas. 


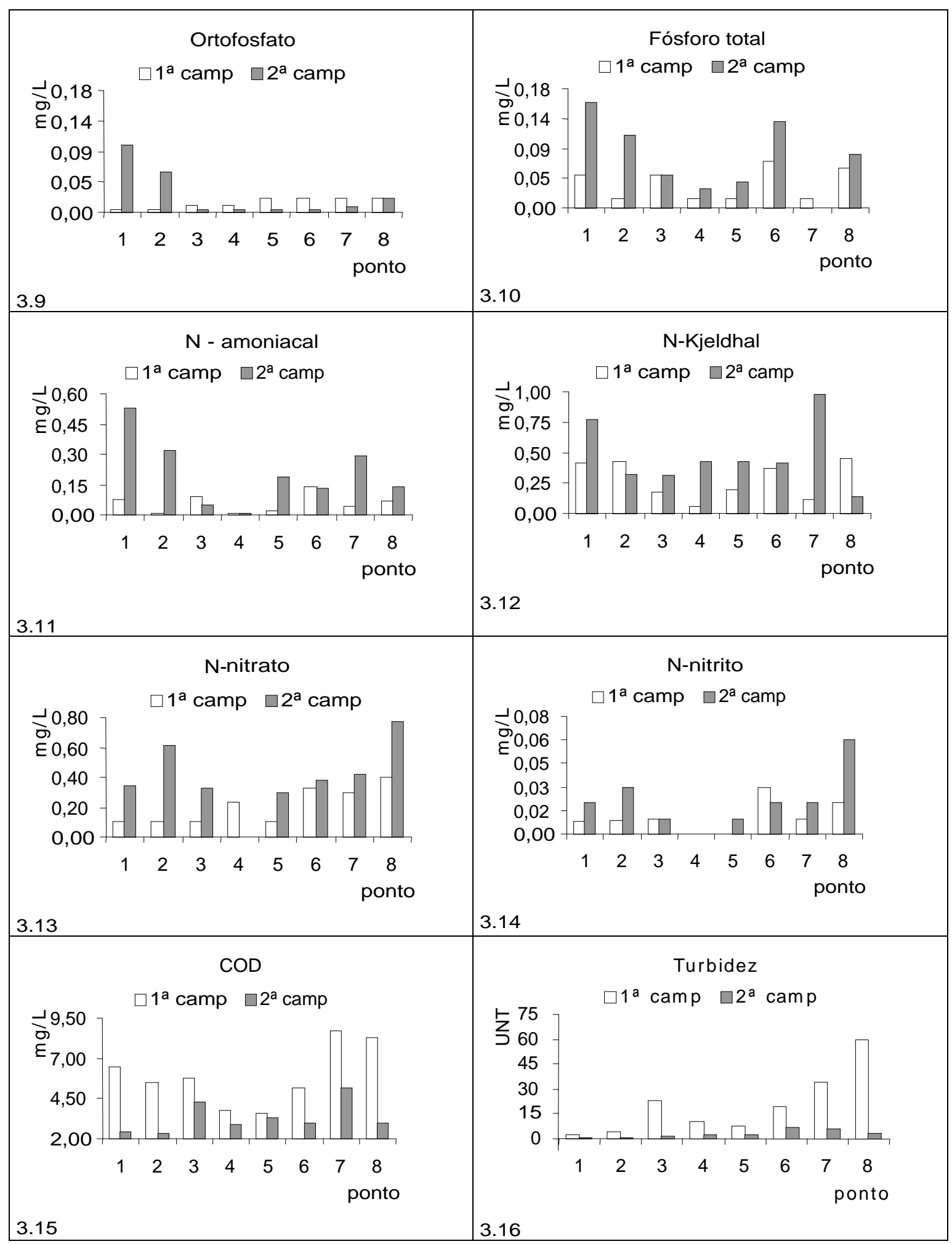

Figura 3 (cont.) - Resultados das análises físicas e químicas das amostras de água na primeira e segunda campanhas. 


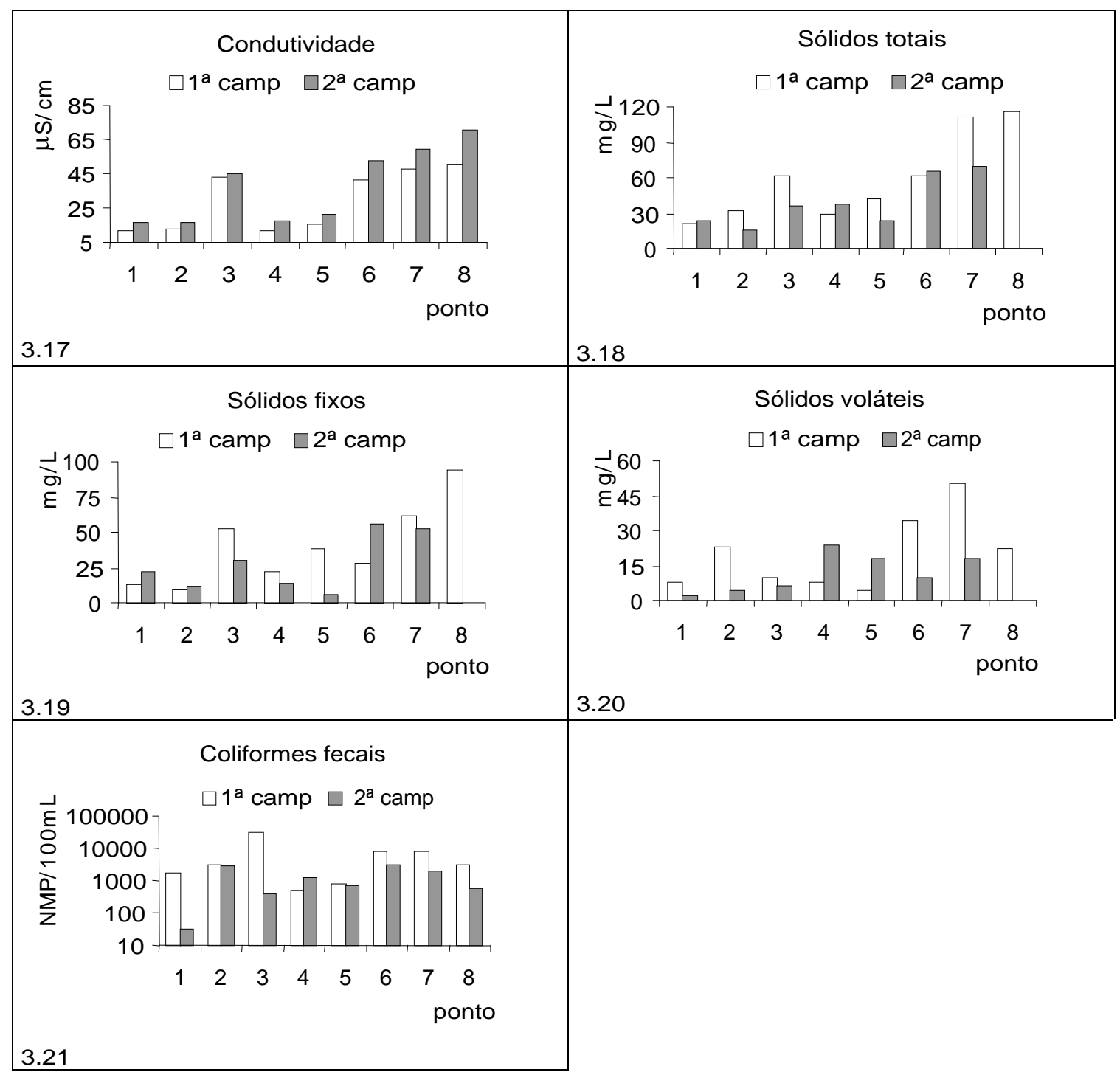

Figura 3 (cont.) - Resultados das análises físicas e químicas das amostras de água na primeira e segunda campanhas.

DANIEL et al. (2002), em levantamento realizado em pequenas drenagens naturais da bacia do rio Piracicaba, encontraram dois grupos de sub-bacias com concentrações razoavelmente distintas de OD. No primeiro grupo, a concentração de oxigênio dissolvido variou entre 5,6 e 9,1 m g/L. Esses valores foram obtidos em localidades com baixo grau de urbanização ou que possuíam tratamento de efluentes. O segundo grupo apresentou valores de OD entre 1,8 e 2,9 mg/L, encontrados em localidades com condições opostas ao primeiro grupo, ou seja, onde o sistema de tratamento de efluentes era muito deficitário ou inexistente ou em áreas de alta taxa de urbanização.

Considerando-se as duas campanhas de amostragem do presente 
trabalho, os valores de OD variaram entre 5,3 e 9,8 mg/L, razoavelmente superiores àqueles obtidos para as áreas altamente urbanizadas na mesma bacia hidrográfica. De todo modo, os valores mais baixos foram obtidos na região de baixo-gradiente, provavelmente em função do lançamento de efluentes domésticos e industriais. DANIEL et al. (2002) detectaram que os efluentes impactam mais as pequenas drenagens, comparativamente aos principais rios da bacia, o que pode explicar concentrações relativamente altas de OD, mesmo nas localidades de baixo-gradiente.

O menor valor de $\mathrm{pH}$ registrado foi 6,0 , no ponto 2 - primeira campanha (fig. 3.8) e o maior $(7,1)$ no ponto 8 , segunda campanha. Nas demais localidades o pH, durante as coletas, manteve-se entre 6,6 e 6,9. WILLIAMS et al. (2001) encontraram, em trabalho realizado na bacia do rio Piracicaba, valor médio de $\mathrm{pH}$ igual a 7,0, com variação entre 6,2 e 8,1, nos diversos locais amostrados.

Os valores de $\mathrm{pH}$, de modo geral estão associados à dureza (fig.3.7), que por sua vez, reflete a concentração de íons de cálcio e magnésio. Os dados de dureza foram obtidos apenas na primeira campanha, com valores variando entre 1 e aproximadamente $10 \mathrm{mg} / \mathrm{L}$ de $\mathrm{CaCO}_{3}$. O valor médio de dureza para o estado de São Paulo, obtido em levantamento realizado por oito anos consecutivos em 112 localidades foi de $31 \mathrm{mg} / \mathrm{L}$ de $\mathrm{CaCO}_{3}$ (ARAGÃo et al., 2003), valor este muito superior ao obtido nas amostragens efetuadas. De modo geral, pode-se afirmar que a dureza nas águas dos rios da sub-bacia do Atibaia amostrados, no período correspondente às campanhas, é baixa, pois valores até $75 \mathrm{mg} / \mathrm{L}$ de $\mathrm{CaCO}_{3}$ conferem à água a classificação de "água mole" (SPRAGUE, 1985 apud ARAGÃo et al., 2003).

Em ambientes com perturbações de origem antrópica, o lançamento de efluentes nos corpos d'água é o principal fator que influencia alteração do $\mathrm{pH}$ nos mesmos.

Segundo PAYNE (1986), de modo geral, em rios tropicais, a variação de $\mathrm{pH}$ localiza-se entre 4,3 e 7,5. Deste modo, em termos de $\mathrm{pH}$, os rios amostrados enquadram-se em uma condição típica de regiões tropicais.

Os parâmetros que refletem a concentração de nutrientes na água apresentaram valores discrepantes daqueles esperados para a configuração de um gradiente de poluição. Em síntese, esperava-se que a concentração de nutrientes fosse maior na região de baixo-gradiente, no entanto observou-se elevadas concentrações de fósforo-total, ortofosfato, nitrogênio amoniacal, nitrogênio Kjeldhal nos pontos 1 e 2 (figs. 3.9 a 3.12). A fonte de nitrogênio e 
fósforo nessas localidades é, provavelmente, o criadouro de trutas situado a montante do ponto 1, cujo efluente é rico em nutrientes, devido aos alimentos adicionados à água e aos excretas dos peixes, na forma de amônia. Valores inferiores observados para os mesmos nutrientes naquelas localidades podem ser decorrentes de mudança operacional do trutário ou de efeito de diluição provocado por chuvas.

As principais mudanças em um corpo d'água decorrentes do lançamento de efluentes deste tipo de empreendimento podem ser: a) lançamento de partículas finas e homogêneas a jusante, aumentando a concentração de sólidos em suspensão; b) aumento da carga de matéria orgânica dissolvida; c) aumento das concentrações de amônia, nitrato e fosfato; aumento da DBO e conseqüente redução de OD; d) potencial efeito tóxico da amônia a jusante (PILLAY, 1992 apud LOCH et al., 1996).

Como conseqüência da elevada concentração de amônia no ponto 1 , observa-se um pico de nitrato e nitrito no ponto 2 (segunda campanha - figs. 3.13 e 3.14), devido ao processo de nitrificação, num período de vazão menor.

Deve-se considerar ainda que os pontos 3 e 6 estão situados a jusante de reservatórios e que, em função das condições limnológicas inerentes (ambiente lêntico que propicia o desenvolvimento e manutenção de comunidade fitoplanctônica), ficam retidos parte dos nutrientes e frações de sólidos carregados pelos rios. Assim sendo, supõe-se que, na hipótese da inexistência dessas estruturas, os valores dessas variáveis (e outras associadas, como turbidez) seriam certamente distintos dos obtidos (provavelmente superiores).

Os resultados dos referidos parâmetros, para os demais pontos de coleta foram mais condizentes com um gradiente de poluição, conforme esperado.

Segundo MARTINELLI et al. (1999), as principais fontes de nutrientes nos rios são os efluentes domésticos e industriais, tratados ou in natura, dispostos nos corpos d'água e a agricultura, como conseqüência da aplicação de fertilizantes nas lavouras. Neste último caso, os compostos de nitrogênio e fósforo podem ser carreados juntamente com o solo por meio de processos de dinâmica de superfície (erosão) ou subsuperfície, onde o transporte é essencialmente de suas frações solúveis (SIMÕES, 2003). A taxa de carreamento pode variar em função da geomorfologia, pedologia, suscetibilidade à erosão, existência ou não de mata ciliar, pluviosidade, etc.

O fósforo é associado ao processo de eutrofização, como elemento limitante ao desencadeamento de florações de algas ou macrófitas em um corpo 
d'água, e o ortofosfato é a forma de fósforo prontamente absorvido pelos vegetais (ESTEVES, 1988). As concentrações mais elevadas das formas de fósforo no ambiente aquático são indicativas de interferência antropogênica (AGOSTINHO et al., 1995).

Assim como o obtido por SMITH \& PETRERE JR. (2000) na bacia do rio Sorocaba, as variáveis associadas aos nutrientes foram ligeiramente influenciadas pela sazonalidade, com concentrações mais elevadas no período de estiagem, decorrente da menor diluição provocada pelas águas pluviais.

O parâmetro COD (fig. 3.15), à exceção da primeira campanha do ponto 1, reflete o gradiente de poluição esperado entre os pontos 1 e 6, nos rios Atibainha e Cachoeira. Em águas naturais, aproximadamente $60 \%$ do COD é proveniente de substâncias húmicas dissolvidas (THURMAN, 1985 apud CUNHA-SANTINO \& BIANCHINI-JÚNIOR, 2004). No entanto, em ambientes em processo de degradação, DANIEL et al. (2002) associam o aumento da concentração de COD ao lançamento de efluentes, encontrando ainda correlação positiva entre esta variável e a condutividade.

As variáveis condutividade, turbidez e série de sólidos (figs. 3.16 a 3.20) apresentaram aumento de seus valores na medida em que os rios atingem cotas mais baixas, com menor declividade e, conseqüentemente, estão mais suscetíveis a lançamentos de efluentes, com o aumento da taxa de urbanização.

O valor médio de turbidez entre as duas campanhas foi 11,5 U.N.T. O mínimo foi 0,6 U.N.T., obtido no ponto 1, segunda campanha, e o máximo 60 U.N.T., correspondente ao ponto 8, primeira campanha. Por meio da Figura 3.16 observa-se que, nitidamente, os valores de turbidez na primeira campanha são superiores aos da segunda, influenciados pelas chuvas.

Os valores de condutividade (fig. 3.17) variaram entre $11,7 \mu \mathrm{S} / \mathrm{cm}$ (ponto 1, primeira campanha) e $70,6 \mu \mathrm{S} / \mathrm{cm}$ (ponto 8, segunda campanha). Valores semelhantes a estes foram obtidos por DANIEL et al. (2002) na bacia do rio Piracicaba, em localidades classificadas por aqueles autores como mais prístinas.

A turbidez e a condutividade apresentam relação direta com a concentração de sólidos presentes na água justificando-se, portanto, a semelhança de comportamentos destes parâmetros nas amostras obtidas. Os valores de condutividade e sólidos totais apresentaram correlação significativa (correlação de Spearman) na primeira e segunda campanhas ( $\rho=0,99$ e $\rho=0,92$, respectivamente; $p=0,0025)$. Esses resultados corroboram os obtidos no trabalho supracitado. 
Observa-se que, de modo geral, os valores de sólidos, assim como turbidez, foram mais altos durante a primeira campanha, por influência da maior freqüência e volume de chuvas naquele período.

Os valores obtidos para coliformes fecais (fig. 3.21) não representa qualquer gradiente, pois observou-se elevada concentração destes no ponto 2 em ambas as campanhas e valores menores nos pontos de baixo-gradiente. Essa variabilidade dos dados pode estar sofrendo influência de descargas pontuais muito próximas ao local de coleta, como no ponto 2 ou do período de estiagem onde, em geral foram menores as concentrações de coliformes.

Os bioensaios desenvolvidos com o cladócero Ceriodaphnia dubia indicaram toxicidade crônica nas coletas efetuadas na primeira campanha, nos pontos de cabeceira (1, 2, 4 e 5 - Tabela IV). Na segunda campanha não foi detectada toxicidade em nenhuma das amostras obtidas. Segundo a CETESB/DE IB-USP (2000), o efeito tóxico observado pode estar associado à ocorrência de alguns metais, em concentração mais elevada, citando o cádmio (pontos 3, 4, 6, 7 e 8), o zinco (pontos 1, 2 e 5), o níquel (pontos 2 e 4) e o cobre (pontos 2 e 5). Ressalte-se que as concentrações obtidas para os metais correspondem a seus valores totais e não somente à fração biodisponível. Segundo o mesmo documento, o efeito tóxico pode ter sido uma ocorrência pontual (cuja comprovação depende de amostragem em série temporal) potencializada pela baixa concentração de sólidos, associada a baixa dureza e pH que potencializam o efeito tóxico dos metais, pois sob essas condições, a fração biodisponível tende a ser maior.

A mais freqüente crítica sobre os ensaios de toxicidade é que as respostas da espécie utilizada não necessariamente representam as respostas da população natural (von der OHE \& LIESS, 2004; HICKEY \& CLEMENTS, 1998), portanto a toxicidade detectada em uma determinada localidade pode não apresentar reflexos sobre a composição ou densidade absoluta da comunidade instalada.

Os metais pesados são em geral transportados com o sedimento, e em ambiente lótico, os sólidos suspensos têm importante papel no transporte de metais, em função, principalmente, de sua elevada área de superfície, que também é rica em óxidos (WARREN \& ZIMMERMAN, 1993 apud SALOMÃo et al., 2001).

O destino dos metais em suspensão é o sedimento, por meio do processo de adsorsão, sedimentação e precipitação (CHAPMAN et al., 2003), e os lagos e reservatórios são, em decorrência de suas características, depósitos dos metais 
até então na coluna d'água dos rios (YAMASHIKI et al., 2006). Assim sendo, os metais observados na água dos rios Atibainha e Cachoeira devem estar sendo depositados nos reservatórios do mesmo nome.

Como aproximadamente $80 \%$ dos resultados obtidos para os metais correspondem a valores inferiores ao limite de detecção do método, impossibilitando, portanto, a avaliação de sua potencial interferência no meio, bem como sua contribuição para a configuração de um gradiente de poluição, buscar-se-á, por meio dos demais parâmetros indicativos de poluição ou relacionados a aspectos fisiográficos (por exemplo temperatura e velocidade), a definição do referido gradiente.

A classificação do sedimento entre os pontos de coleta, e nos diferentes ambientes, refletiu o que se espera ao longo de um gradiente de altitude. Nos pontos 1 a 5 , mesmo na margem deposicional, o sedimento permaneceu essencialmente arenoso. No ponto 6, comparativamente, a contribuição de frações mais finas como argila e silte na composição do sedimento aumentou, e nos pontos 7 e 8 (á exceção da segunda campanha neste último) o sedimento coletado foi classificado como argiloso, ou areno argiloso (tabela V), ou seja, como uma considerável proporção de fração fina.

De modo geral, o sedimento coletado na margem erosional, assim como no canal, apresentou fração arenosa predominante, classificado como arenoso, areia síltica, areia argilosa ou areia síltica argilosa. Isto se deve, sem dúvida à maior velocidade da correnteza nessas regiões que impossibilitam a sedimentação de material mais fino.

$\mathrm{Na}$ Figura 4, estão representadas as frações de sólidos fixos e voláteis obtidas no sedimento da margem deposicional, na primeira (fig. 4.1; tabela V) e segunda (fig. 4.2) campanhas. A fração de sólidos voláteis é indicativa da concentração de matéria orgânica no sedimento. Sua maior contribuição para a composição do sedimento, como observado nos pontos 3 e 6 - a jusante dos reservatórios Atibainha e Cachoeira, respectivamente - reflete a influência dos reservatórios na tranferência de matéria orgânica rio abaixo, em conjunto com o lançamento de efluentes de cidades próximas.

Segundo UNGEMACH (1960 apud ESTEVES, 1988), pode-se considerar o sedimento como orgânico quando este apresentar fração orgânica superior a $10 \%$ em peso seco. Segundo este critério, somente caracterizam-se como sedimento orgânico aqueles coletados no ponto 7 , primeira campanha $(12,5 \%)$ e nos pontos $3(11,1 \%), 4(11,7 \%)$ e $7(10,2 \%)$, segunda campanha. Na margem 
erosional e canal não foram observadas frações de sólidos voláteis superior a $10 \%$.

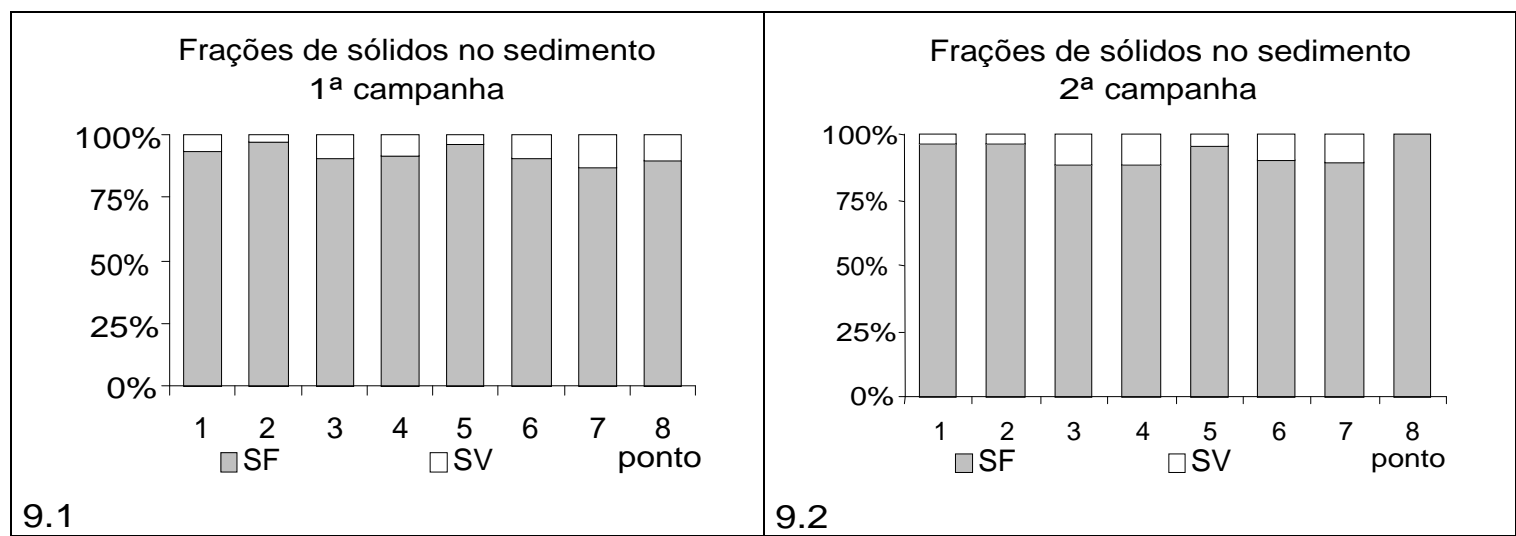

Figura 4 - Frações de sólidos fixos - SF e sólidos voláteis - SV no sedimento, margem deposicional, correspondentes à: (4.1) primeira campanha; (4.2) segunda campanha.

A determinação de metais no sedimento está condicionada a coleta deste na margem deposicional do rio e a qualidade do resultado associada à composição granulométrica da amostra. Resultados de melhor qualidade são obtidos em sedimentos de granulometria mais fina, preferencialmente sílticos ou argilosos, devido a sua maior capacidade de adsorção dos íons metálicos, em função da maior área de superfície que proporcionam.

Nos pontos 1 e 2, em função das características locais (canal muito estreito e ausência de margem deposicional com sedimento adequado), não foi coletado sedimento para este tipo de análise. Nos pontos 4 e 5 , as coletas foram efetuadas apenas na segunda campanha $e$ os demais pontos foram contemplados com coletas nas duas campanhas.

As fontes de metais nas drenagens naturais estão associadas principalmente aos lançamentos de efluentes industriais, mas também podem estar associadas a fertilizantes e defensivos agrícolas, os quais atingem o corpo d'água na forma de carga difusa. A litologia também pode ter influência sobre a concentração de metais nos corpos d'água, principalmente em termos de ferro, alumínio e manganês (para o estado de São Paulo).

Com base na Tabela VI, observamos que, de modo geral, as maiores concentrações de metais foram obtidas nos pontos de baixo-gradiente, em particular nos pontos 7 e 8 . Essas localidades, além de estarem mais próximas à grandes cidades, portanto sujeitas ao recebimento de carga maior de efluentes, são aquelas cujo sedimento apresenta condições mais propícias à adsorsão de 
sedimento, como já explicitado. A influência da granulometria na resposta a concentrações de metais no sedimento fica clara ao observar-se os dados correspondentes ao ponto 8 , os quais na primeira campanha são superiores ao segundo período de amostragem, quando o sedimento foi classificado como arenoso. Segundo CETESB/DE IB-USP (2000), a areia pode agir como um "agente de diluição" dos metais que se encontram preferencialmente associados à frações mais finas.

A Tabela III apresenta critérios de classificação do sedimento quanto ao grau de poluição, segundo a agência ambiental norte-americana (Environmental Protection Agency - EPA) e valores indicativos de efeito limiar e severo aos organismos aquáticos, compilados por SMITH et al. (1996), considerando-se para tal, os valores mais conservadores apresentados.

Tabela III - Classificação do grau de poluição do sedimento em função da concentração de metais pesados (em $\mathrm{mg} / \mathrm{kg}$ ).

\begin{tabular}{cccc|cc}
\hline \multicolumn{4}{c|}{${(\mathrm{EPA}, 1997)^{1}}^{1}$} & \multicolumn{2}{c}{$\left(\right.$ SMITH et al., 1996) ${ }^{2}$} \\
\hline Elemento & não poluído & $\begin{array}{c}\text { moderadamente } \\
\text { poluído }\end{array}$ & $\begin{array}{c}\text { altamente } \\
\text { poluído }\end{array}$ & efeito limiar & efeito severo \\
\hline $\mathrm{Hg}$ & $<0,1$ & - & $>0,1$ & 0,15 & 0,486 \\
$\mathrm{~Pb}$ & $<90$ & $90-200$ & $>200$ & 31 & 82 \\
$\mathrm{Zn}$ & $<90$ & $90-200$ & $>200$ & 98 & 270 \\
$\mathrm{Cu}$ & - & - & - & 16 & 86 \\
$\mathrm{Cr}$ & $<25$ & $25-75$ & $>75$ & 26 & 90 \\
$\mathrm{As}$ & $<3$ & $3-8$ & $>8$ & 5,9 & 17 \\
$\mathrm{Ni}$ & - & - & - & 16 & 33 \\
$\mathrm{Cd}$ & & & $>6$ & 0,58 & 3 \\
\hline
\end{tabular}

Fonte: 1. FAVARO et al. (2004)

2. SMITH et al. (1996)

Confrontando-se os resultados das análises com os valores de referência, verificamos que foram ultrapassados os valores de efeito limiar para os seguintes metais: $\mathrm{Cr}$ (pontos 3, 6, 7 e 8), $\mathrm{Cu}$ (ponto 7) e $\mathrm{Pb}$ (ponto 8). Não foram considerados os resultados cujo limite de detecção foi superior ao valor de referência.

Segundo a mesma tabela supracitada, os pontos 6,7 e 8 qualificam-se como moderadamente poluídos, simplesmente em função da concentração de cromo.

O efeito deletério de um metal sobre organismos aquáticos está condicionado a uma série de fatores, dentre os quais sua biodisponibilidade (CHAPMAN et al., 2003; BAUdo, 2001; ARAUJO, 1998), não cabendo, portanto, uma conclusão direta de causa/efeito. As conseqüências da interação destes diversos 
fatores podem ser evidenciadas por meio de ensaios de toxicidade. Na Tabela VI estão expressos os resultados de toxicidade ao anfípodo Hyalella sp. Observouse toxicidade aguda apenas na primeira campanha de amostragem, nos pontos 3, 6, 7 e 8. Define-se toxicidade aguda como uma "resposta severa e rápida dos organismos aquáticos a um estímulo, que se manifesta, em geral, num intervalo de 0 a 96 horas" (CETESB, 1992a), na forma de imobilidade, por exemplo, mas geralmente culmina com a morte dos organismos-teste.

ARAUJO (1998), em ensaio realizado com sedimento coletado no rio Atibaia (pontos situados a jusante da área de estudo em tela), observou toxicidade aguda a Hyalella meinerti, sem verificar, no entanto, elevada contaminação por metais, como no presente caso.

TOMAZELLI e MARTINELLI (2003), em um trabalho que contempla a o levantamento de dados sobre metais $(\mathrm{Cd}, \mathrm{Pb}$ e $\mathrm{Hg}$ ) em seis bacias hidrográficas do estado de São Paulo (Piracicaba, Aguapeí, Peixe, Mogi-Guaçu, Alto Paranapanema e São José dos Dourados), verificam que, dentre as localidades amostradas, a bacia do rio Piracicaba está entre as mais atingidas pela poluição. Os valores obtidos para $\mathrm{Pb}$ foram próximos àqueles obtidos no ponto 8 .

Os resultados das variáveis físicas e químicas de ambas as campanhas, para todos dos pontos de coleta foram submetidos a uma análise de agrupamento, por meio do índice Distância Euclidiana Simples (Método de Ward), cuja representação gráfica encontra-se nas Figuras 5 e 6 , correspondentes à primeira e segunda campanhas, respectivamente.

Para a referida análise, foram considerados os seguintes parâmetros:

$\Rightarrow$ água: velocidade da correnteza, temperatura da água, OD, condutividade, $\mathrm{pH}$, turbidez, ortofosfato, fósforo total, nitrogênio amoniacal, nitrogênio kjeldhal, nitrogênio orgânico, nitrato, nitrito, COD, coliformes fecais, sólidos totais, fixos e voláteis, clorofila- a e feofitina- $a$;

$\Rightarrow$ sedimento: diâmetro médio do grão, sólidos totais, sólidos voláteis e os metais cromo, zinco e cobre.

Observa-se na Figura 5, correspondente à primeira campanha, a formação de dois conjuntos de grupos distintos. O primeiro grupo é formado pelos pontos de alto-gradiente $(1,2,4$ e 5$)$ e o outro constituído pelos demais pontos, os quais compõem o baixo-gradiente $(3,6,7$ e 8$)$. Verifica-se que no altogradiente, a maior proximidade está entre os pontos pertencentes à mesma subbacia, enquanto que no baixo-gradiente, a maior proximidade está entre pontos de sub-bacias distintas. 
Segundo VALENTIN (2000), o melhor método de agrupamento é aquele que fornece um dendrograma com a imagem menos distorcida da realidade. $O$ mesmo autor refere-se ainda ao Método de Ward como o mais eficiente, mesmo que não apresentando os melhores valores de correlações cofenéticas.

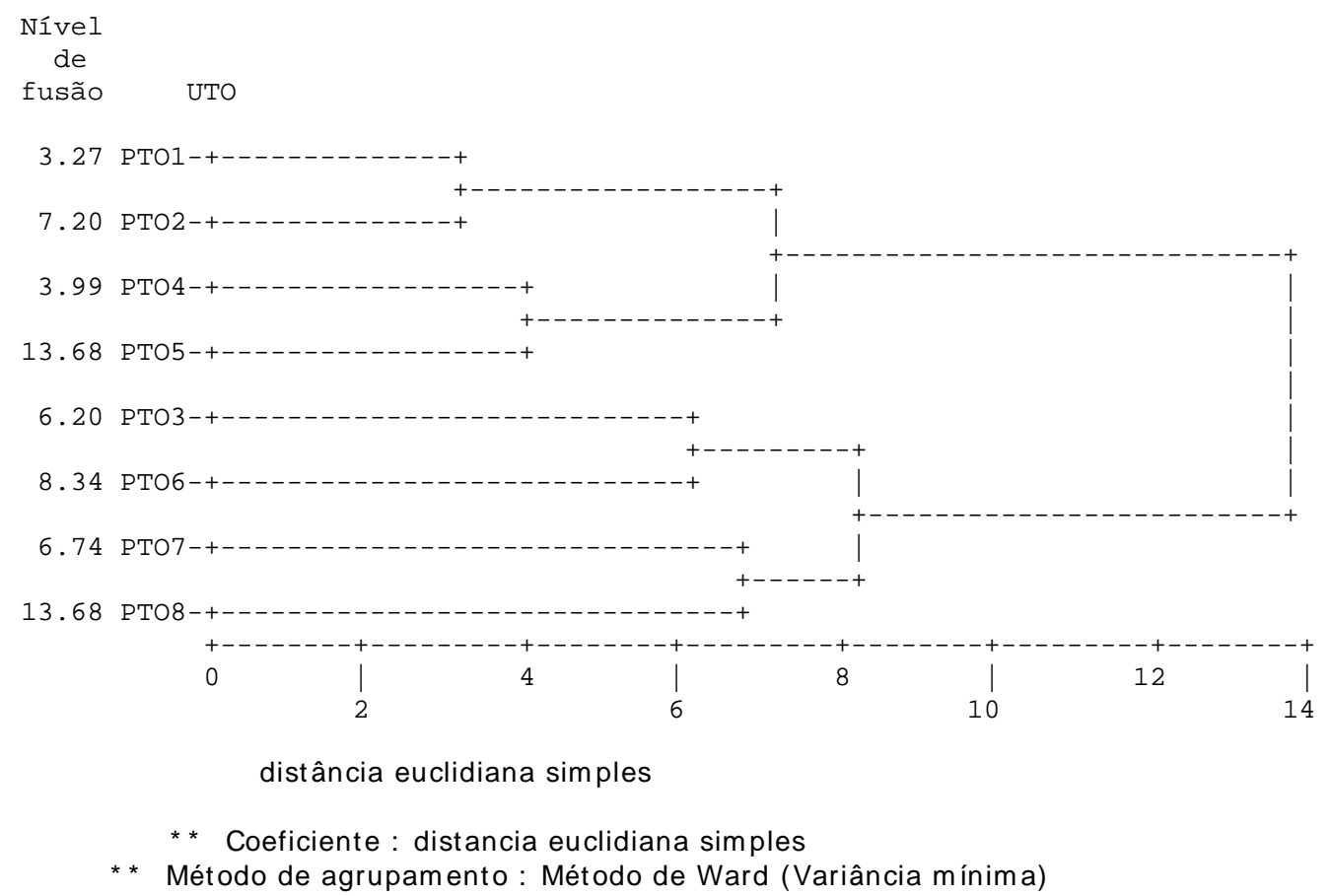

Figura 5 - Representação gráfica da análise de agrupamento dos pontos de coleta a partir dos resultados físicos e químicos para a água e sedimento - primeira campanha. Correlação cofenética $=0,7762$. 


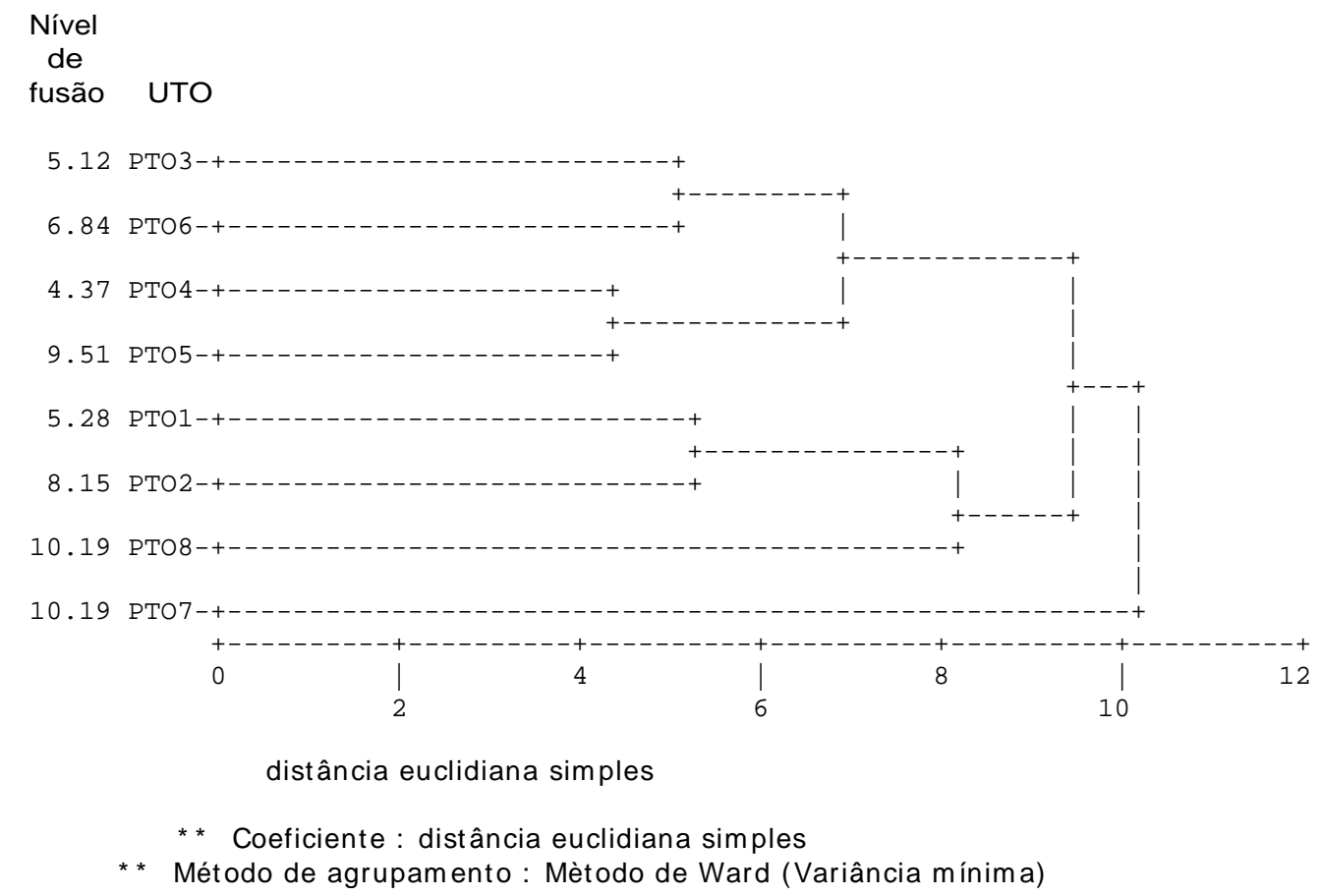

Figura 6 - Representação gráfica da análise de agrupamento dos pontos de coleta a partir dos resultados físicos e químicos para a água e sedimento - segunda campanha. Correlação cofenética $=0,7303$.

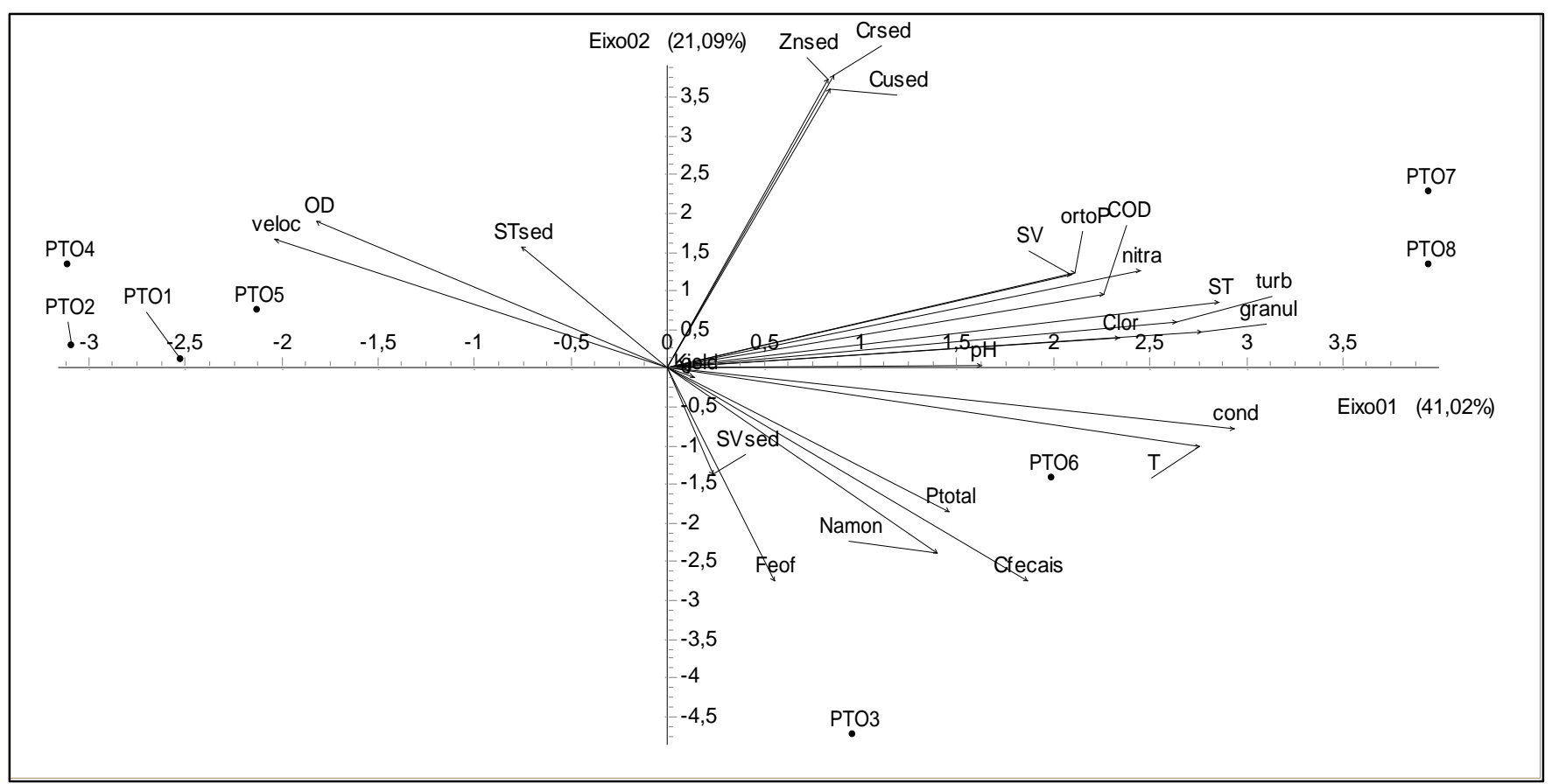

Figura 7 - Análise de Componentes Principais para as variáveis e pontos de coleta na primeira campanha de amostragem. 
Os mesmos dados utilizados na análise por agrupamento formam submetidos a uma Análise de Componente Principal - ACP.

Na primeira campanha (fig. 7) verifica-se a separação dos pontos de alto e baixo-gradientes, corroborando o resultado obtido na análise por agrupamento. Os eixos 1 e 2 respondem por aproximadamente $62 \%$ da variabilidade dos dados considerados na análise. A partir do gráfico, verifica-se que a distribuição dos pontos em alto e baixo-gradientes deve-se, principalmente, a parâmetros como condutividade (cond), COD, sólidos totais (ST), turbidez (turb) e diâmetro médio do grão (granul), por apresentarem maior correlação com o eixo 1 . No eixo 2, os metais determinados para o sedimento separam os pontos 3 das demais localidades. Nesses pontos foram obtidos os menores valores para os metais considerados. $\mathrm{O}$ eixo 3 (não representado graficamente) explica aproximadamente $15 \%$ da variabilidade dos resultados. Nessa componente, as variáveis de sedimento SV e ST, juntamente com nitrogênio kjeldhal apresentaram maior correlação com o referido eixo.

Diferentemente do ocorrido para a primeira campanha, a análise de agrupamento para os pontos de coleta na segunda campanha não produziu uma divisão precisa entre alto e baixo gradientes. Observa-se na Figura 6, um grupo formado pelos pontos 1,2 , e 8 , um segundo grupo, composto pelos pontos 6 e 3 e 4 e 5. O terceiro grupo formado corresponde ao ponto 7 que, neste caso, aparece isolado.

A interpretação do agrupamento dos pontos de coleta, na forma como se apresentam na segunda campanha pode calcar-se nos resultados obtidos por meio da Análise de Componente Principal - ACP, apresentada na Figura 8.

Assim como ocorreu para a primeira campanha, a ACP referente aos dados da segunda campanha representou, por meio do eixo 1, a mesma distribuição das localidades, inclusive com o isolamento do ponto 7. Os eixos 1 e 2 explicam aproximadamente $55 \%$ da variabilidade dos resultados.

Os vetores das variáveis sólidos totais (ST) e COD, estes para a água, além da concentração dos metais cobre (Cused), zinco (Znsed) e cromo (Crsed) no sedimento, indicam que estes são os parâmetros principais na definição do agrupamento dos pontos.

No eixo 2, a maior contribuição provém das variáveis associadas aos pigmentos (clrofila-a e feofitina) e nitrato. Observa-se a separação dos pontos 2 , 6,7 e 8 dos demais. Nessas localidades foram observados elevados valores de clorofila- $a$, sendo a maior distinção dos pontos 2 e 8 devido às maiores 
concentrações de nitrato que por sua vez favorece o desenvolvimento de algas, elevando-se, portanto, a concentração de clorofila-a. A feofitina correlaciona-se negativamente com a clorofila- $a$, visto que é produto da degradação desta.

A interpretação dos eixos 3 e 4 (não representados graficamente) revela a forte correlação da variável nitrogênio amoniacal com o eixo 3 . Nessa componente, os pontos 1 e 2 e 7 estão separados dos demais, em função da elevada concentração apresentada por este íon.

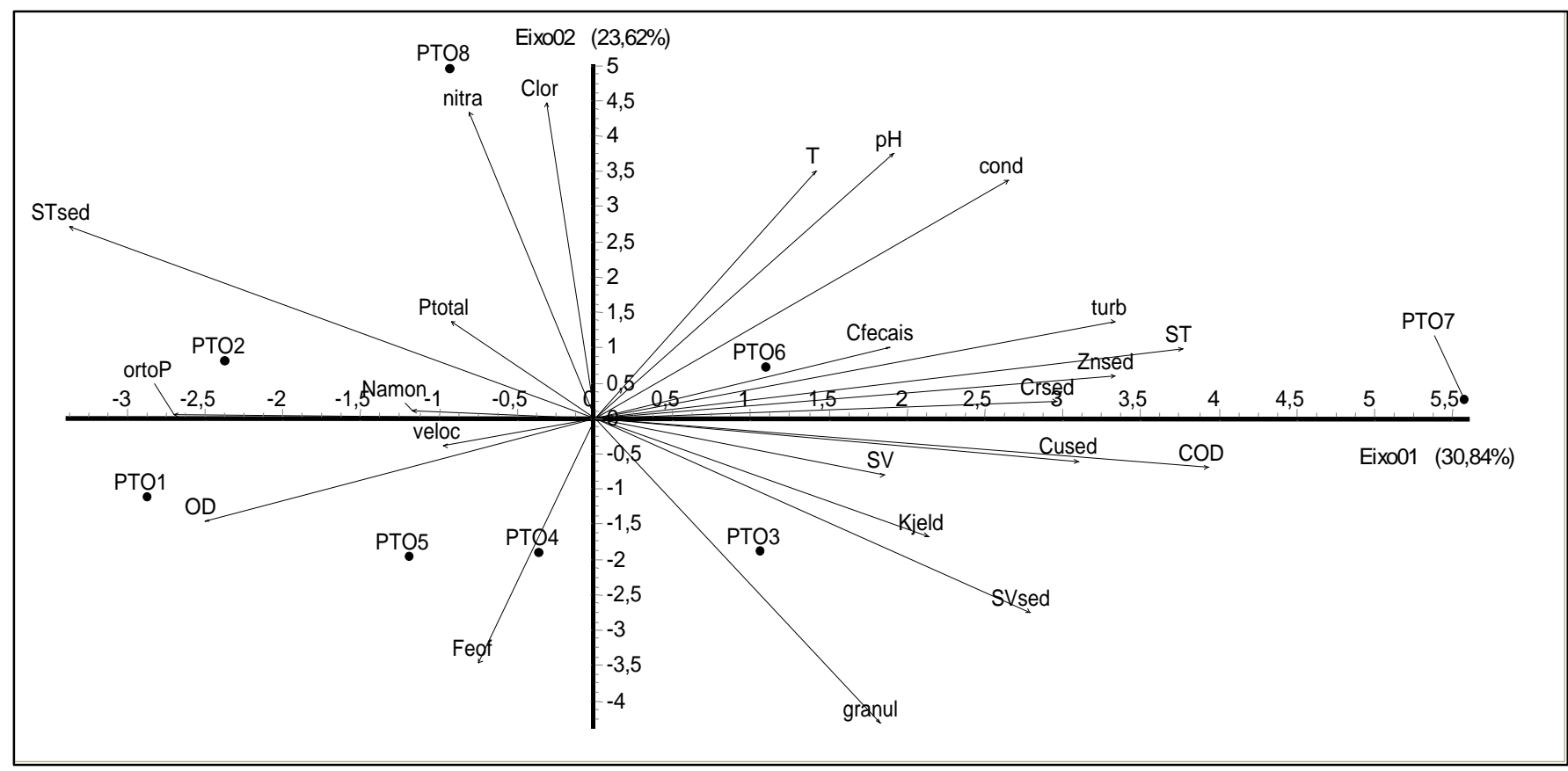

Figura 8 - Análise de Componentes Principais para as variáveis e pontos de coleta na segunda campanha de amostragem.

Com base no apresentado em relação aos parâmetros físicos e químicos da água e do sedimento, pode-se afirmar que existe um gradiente ambiental, influenciado por aspectos fisiográficos e de poluição. Cumpre lembrar que, mesmo poluída, a região amostrada apresenta condições ambientais melhores do que aquelas obtidas na mesma bacia hidrográfica, mais a jusante, conforme relatado por DANIEL et al. (2002).

Uma terceira análise de agrupamento foi feita considerando-se ambas as campanhas de amostragem, cujo resultado pode ser visto na Figura 9. Formaram-se três grupos distintos. O primeiro grupo é composto pelos pontos de alto-gradiente mais os pontos 3 e 6 . Os demais grupos são compostos pelos pontos 7 e 8 . Observa-se também que as menores distâncias ocorrem entre 
pontos de uma mesma campanha. Constata-se, portanto, com base nas observações, que a sazonalidade não interfere significativamente na formação do gradiente ambiental, todavia uma campanha é particularmente distinta da outra, condição refletida pelo agrupamento entre pontos correspondentes ao mesmo período de amostragem.

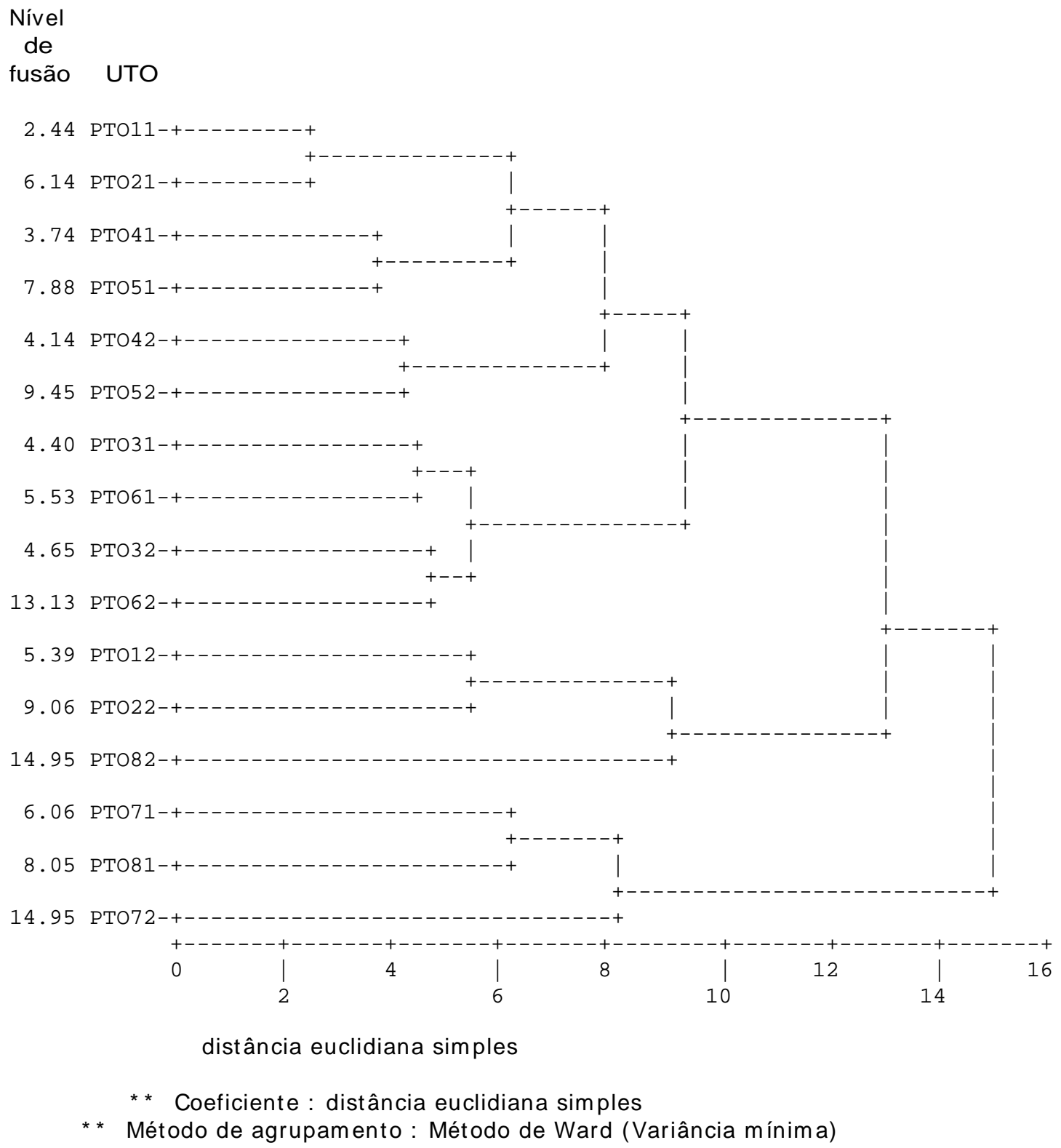

Figura 9 - Representação gráfica da análise de agrupamento dos pontos de coleta a partir dos resultados físicos e químicos para a água e sedimento campanhas I e II. Correlação cofenética $=0,7613$. Legenda: PTOXY, $\mathbf{X}=\mathrm{n}^{\circ}$ do ponto; $\mathbf{Y}=$ campanha de amostragem. 
Tabela IV - Concentrações de metais e toxicidade* na água obtidas nas duas campanhas de amostragem (em mg/L).

\begin{tabular}{|c|c|c|c|c|c|c|c|c|c|c|c|c|c|c|c|c|}
\hline \multirow[b]{3}{*}{ CAMPANHA } & \multicolumn{16}{|c|}{ PONTOS DE COLETA } \\
\hline & \multicolumn{2}{|c|}{1} & \multicolumn{2}{|c|}{2} & \multicolumn{2}{|c|}{3} & \multicolumn{2}{|c|}{4} & \multicolumn{2}{|c|}{5} & \multicolumn{2}{|c|}{6} & \multicolumn{2}{|c|}{7} & \multicolumn{2}{|c|}{8} \\
\hline & $\mathbf{I}$ & $\mathbf{I I}$ & I & $\mathbf{I I}$ & I & $\mathbf{I 1}$ & $\mathbf{I}$ & $\mathbf{I}$ & $\mathbf{I}$ & $\mathbf{I}$ & $\mathbf{I}$ & $\mathbf{I I}$ & $\mathbf{I}$ & $\mathbf{I}$ & $\mathbf{I}$ & $\mathbf{I}$ \\
\hline Cádmio & $<0,005$ & $<0,001$ & $<0,005$ & $<0,001$ & 0,002 & $<0,001$ & 0,005 & $<0,001$ & $<0,005$ & $<0,001$ & 0,003 & $<0,001$ & 0,003 & - & 0,006 & $<0,001$ \\
\hline Cromo & $<0,01$ & $<0,05$ & $<0,01$ & $<0,05$ & $<0,04$ & $<0,05$ & $<0,01$ & $<0,05$ & $<0,01$ & $<0,05$ & $<0,05$ & $<0,05$ & $<0,05$ & - & $<0,05$ & $<0,05$ \\
\hline Cobre & $<0,01$ & $<0,01$ & 0,03 & $<0,01$ & $<0,004$ & $<0,01$ & $<0,01$ & $<0,01$ & 0,11 & $<0,01$ & $<0,004$ & $<0,01$ & $<0,004$ & - & 0,01 & $<0,01$ \\
\hline Níquel & $<0,02$ & $<0,01$ & 0,070 & $<0,01$ & 0,020 & $<0,01$ & 0,200 & $<0,01$ & $<0,02$ & $<0,01$ & $<0,01$ & $<0,01$ & 0,01 & $<0,01$ & 0,02 & $<0,01$ \\
\hline Chumbo & $<0,05$ & $<0,10$ & $<0,05$ & $<0,10$ & $<0,02$ & $<0,10$ & $<0,05$ & $<0,10$ & $<0,05$ & $<0,10$ & $<0,02$ & $<0,10$ & $<0,02$ & - & $<0,02$ & $<0,10$ \\
\hline Zinco & 0,310 & 0,01 & 0,280 & 0,020 & $<0,01$ & 0,010 & 0,130 & $<0,01$ & 0,570 & 0,010 & $<0,01$ & 0,010 & $<0,01$ & $<0,01$ & 0,020 & 0,010 \\
\hline Mercúrio & $<0,0003$ & $<0,0001$ & $<0,0003$ & $<0,0001$ & $<0,0003$ & 0,0001 & $<0,0003$ & 0,0006 & $<0,0003$ & $<0,0001$ & $<0,0003$ & $<0,0001$ & $<0,0003$ & $<0,0001$ & $<0,0003$ & $<0,0001$ \\
\hline Toxicidade & $\mathrm{CR}$ & N.T. & $\mathrm{CR}$ & N.T. & N.T. & N.T. & $\mathrm{CR}$ & N.T. & $\mathrm{CR}$ & N.T. & N.T. & N.T. & N.T. & N.T. & N.T. & N.T. \\
\hline
\end{tabular}

Fonte: CETESB/DE IB-USP (2000) e CETESB (no prelo)

Legenda: * ensaio de toxicidade crônica com o cladócero Ceriodaphnia dubia;

- análise não efetuada:

N.T. não tóxico;

$\mathrm{CR}$ toxicidade crônica. 
Tabela V - Classificação e determinação das frações de sólidos no sedimento.

\begin{tabular}{|c|c|c|c|c|c|c|c|c|c|c|c|c|c|c|c|c|}
\hline \multirow[b]{3}{*}{ campanha } & \multicolumn{16}{|c|}{ Pontos de coleta } \\
\hline & \multicolumn{2}{|c|}{1} & \multicolumn{2}{|c|}{2} & \multicolumn{2}{|c|}{3} & \multicolumn{2}{|c|}{4} & \multicolumn{2}{|c|}{5} & \multicolumn{2}{|c|}{6} & \multicolumn{2}{|c|}{7} & \multicolumn{2}{|c|}{8} \\
\hline & $\mathbf{I}$ & $\mathbf{I I}$ & I & $\mathbf{I 1}$ & 1 & $\mathbf{I 1}$ & I & $\mathbf{I I}$ & $\mathbf{I}$ & $\mathbf{I I}$ & 1 & $\mathbf{I 1}$ & I & $\mathbf{I I}$ & I & $\mathbf{I I}$ \\
\hline & \multicolumn{16}{|c|}{ MARGEM DEPOSICIONAL } \\
\hline classificação & AS & $A$ & A & A & AArg & AS & $A$ & $A$ & A & AS & ASArg & A & ArgS & AArg & ArgS & A \\
\hline ST (\%) & 55,2 & 66,3 & 70,2 & 68,1 & 46,5 & 32,2 & 56,9 & 44,9 & 67,5 & 55,4 & 46,7 & 45,5 & 39,6 & 34,3 & 48,6 & 74,0 \\
\hline SV (\%) & 6,6 & 3,1 & 3,2 & 3,7 & 8,9 & 11,1 & 8,7 & 11,7 & 3,4 & 4,2 & 9,2 & 9,8 & 12,5 & 10,2 & 9,9 & 0,4 \\
\hline \multirow[t]{2}{*}{ umidade (\%) } & 44,8 & 33,7 & 29,8 & 31,9 & 53,5 & 67,8 & 43,1 & 55,1 & 32,5 & 44,6 & 53,3 & 54,5 & 60,4 & 65,7 & 51,4 & 26,0 \\
\hline & \multicolumn{16}{|c|}{ MARGEM EROSIONAL } \\
\hline classificação & - & $A$ & - & $A$ & - & AS & - & $A$ & - & AS & - & SA & - & ASArg & - & AArg \\
\hline ST (\%) & - & 77,0 & - & 70,4 & - & 64,4 & - & 66,0 & - & 52,2 & - & 55,9 & - & 67,2 & - & 57,8 \\
\hline SV (\%) & - & 6,6 & - & 4,3 & - & 3,8 & - & 3,3 & - & 8,5 & - & 6,4 & - & 5,9 & - & 8,6 \\
\hline \multirow[t]{2}{*}{ umidade (\%) } & - & 23,0 & - & 29,6 & - & 35,6 & - & 34,0 & - & 47,8 & - & 44,1 & - & 32,8 & - & 42,2 \\
\hline & \multicolumn{16}{|c|}{ CANAL } \\
\hline classificação & - & A & - & A & - & A & - & A & - & laje & - & A & - & AArg & - & AS \\
\hline ST (\%) & - & 72,2 & - & 75,9 & - & 37,1 & - & 64,6 & - & laje & - & 73,8 & - & 75,2 & - & 52,1 \\
\hline SF(\%) & - & 94,1 & - & 98,0 & - & 93,0 & - & 94,6 & - & laje & - & 98,3 & - & 97,7 & - & 93,9 \\
\hline SV (\%) & - & 5,9 & - & 2,0 & - & 7,0 & - & 5,4 & - & laje & - & 1,7 & - & 2,3 & - & 6,1 \\
\hline umidade (\%) & - & 27,8 & - & 24,1 & - & 62,9 & - & 35,4 & - & laje & - & 26,2 & - & 24,8 & - & 47,9 \\
\hline
\end{tabular}

Fonte: CETESB/DE IB-USP(2000) e CETESB (no prelo)

Legenda: $\underline{A}=$ arenoso; $\underline{A A r g}=$ Areia argilosa; $\underline{A S}=$ areia síltica; $\underline{A S A r g}=$ areia síltico-argilosa; $\underline{A r g S}=\operatorname{argila}$ síltica; $\underline{A A r g}=\operatorname{areia}$ argilosa; $\underline{\mathrm{SA}}=\mathbf{s i l t e}$ arenoso; $\mathrm{ST}=$ sólidos totais; $\mathrm{SF}=$ sólidos fixos; $\mathrm{SV}$ = sólidos voláteis) 
Tabela VI - Concentrações* de metais e toxicidade** no sedimento (margem deposicional) obtidas nas duas campanhas de amostragem (em $\mathrm{mg} / \mathrm{kg})$.

\begin{tabular}{|c|c|c|c|c|c|c|c|c|c|c|c|c|c|c|c|c|}
\hline \multirow[b]{3}{*}{ campanha } & \multicolumn{16}{|c|}{ PONTOS DE COLETA } \\
\hline & \multicolumn{2}{|c|}{1} & \multicolumn{2}{|c|}{2} & \multicolumn{2}{|c|}{3} & \multicolumn{2}{|c|}{4} & \multicolumn{2}{|c|}{5} & \multicolumn{2}{|c|}{6} & \multicolumn{2}{|c|}{7} & \multicolumn{2}{|c|}{8} \\
\hline & $\mathbf{I}$ & II & I & 11 & I & $\mathbf{I I}$ & I & $\mathbf{I I}$ & I & $\mathbf{I I}$ & I & $\mathbf{I I}$ & I & $\mathbf{I I}$ & I & $\mathbf{I I}$ \\
\hline Cádmio & - & - & - & - & $<1,5$ & $<0,35$ & - & $<0,70$ & - & $<0,35$ & $<1,5$ & $<0,70$ & $<1,5$ & $<0,35$ & $<1,5$ & $<0,35$ \\
\hline Cromo & - & - & - & - & 14,63 & 30,5 & - & $<30,0$ & - & 20,8 & 26,1 & $<30,00$ & 40,37 & 51,20 & 30,53 & 23,4 \\
\hline Cobre & - & - & - & - & 4,93 & 10,80 & - & 11,5 & - & 8,09 & 9,80 & 8,00 & 22,83 & 19,30 & 13,93 & 8,51 \\
\hline Níquel & - & - & - & - & $<1,5$ & $<7,00$ & - & $<7,00$ & - & $<7,00$ & $<1,5$ & $<7,00$ & $<1,5$ & 12,30 & $<1,5$ & $<7,00$ \\
\hline Chumbo & - & - & - & - & 10,77 & $<25,0$ & - & $<50,0$ & - & $<25,0$ & 15,23 & $<50,0$ & 19,90 & 25,2 & 18,97 & 33,6 \\
\hline Zinco & - & - & - & - & 27,00 & 36,7 & - & 34,0 & - & 22,3 & 55,20 & 36,6 & 79,87 & 79,9 & 59,37 & 34,5 \\
\hline Mercúrio & - & - & - & - & 0,046 & $<0,10$ & - & $<0,10$ & - & $<0,10$ & 0,061 & $<0,10$ & 0,062 & $<0,10$ & 0,053 & $<0,10$ \\
\hline Toxicidade & - & - & - & - & $A-A-A$ & NT & - & NT & - & NT & NT-A-A & NT & NT-A-A & NT & A-NT-A & NT \\
\hline
\end{tabular}

Fonte: CETESB/ DE IB- USP (2000) e CETESB (no prelo)

Legenda:* correspondente à média de análise em triplicata;

** ensaio de toxicidade usando o anfípodo aquático Hyalella sp.;

- análise não efetuada;

tóxico

A toxicidade aguda;

X-X-X Resultado de análise em triplicata. 


\subsection{DADOS BIÓTICOS}

Como previamente citado, a amostragem da comunidade bentônica foi feita com base em procedimentos que produzem resultados quantitativos (amostradores do tipo Hess e Petersen) ou qualitativos (rede e coleta de detritos). Com isso, os dados foram analisados quanti e qualitativamente, sendo que esta última análise considerou também os dados quantitativos.

As riquezas de EPT obtidas em ambas as campanhas estão representadas graficamente em barras acumuladas (fig. 10) de modo a exibir os valores totais e por ordem, distintamente.

Para a composição dos gráficos de riqueza somente foram considerados os registros definidos como "não identificados" quando estes correspondiam à única ocorrência dentro de uma família. Com este procedimento evitou-se superestimar as riquezas, considerando-se o mesmo gênero duas vezes.

Os organismos cuja identificação não foi possível correspondem a exemplares muito pequenos (primeiros ínstares) ou em estado precário de conservação, condições estas que impossibilitam a identificação dos mesmos com base nos caracteres apresentados no material de apoio.

A primeira campanha de amostragem, correspondente ao período com maior pluviosidade, exibiu as maiores riquezas de EPT (figs. 10.1 e 10.2), contrariando o que, de modo geral é esperado: a maior diversidade de invertebrados bentônicos é obtida na estação seca, pois as enxurradas tendem a desestabilizar o substrato e conseqüentemente reduzir a riqueza e abundância de organismos (FATMA/GTZ, 1999 apud JUNQUEIRA et al., 2000; BENSON \& PEARSON,1987). Todavia, neste caso em particular, a maior riqueza obtida na primeira campanha pode estar associada à maior diversidade de habitats amostrados naquele período. Observando-se a totalidade dos resultados (qualitativos e quantitativos, organizadas por ponto, com as médias obtidas para cada habitat amostrado), apresentadas no Anexo, verifica-se que, em muitas das localidades amostradas, as coletas efetuadas com rede em macrófitas (efetuadas exclusivamente na primeira campanha) contribuíram significativamente para a composição da riqueza obtida. O exemplo crítico que pode ser citado é o ponto 5 , onde foram efetuadas coletas apenas nos habitats "margem deposicional" e "macrófitas", sendo que este último foi responsável pela totalidade da riqueza obtida naquela localidade. 


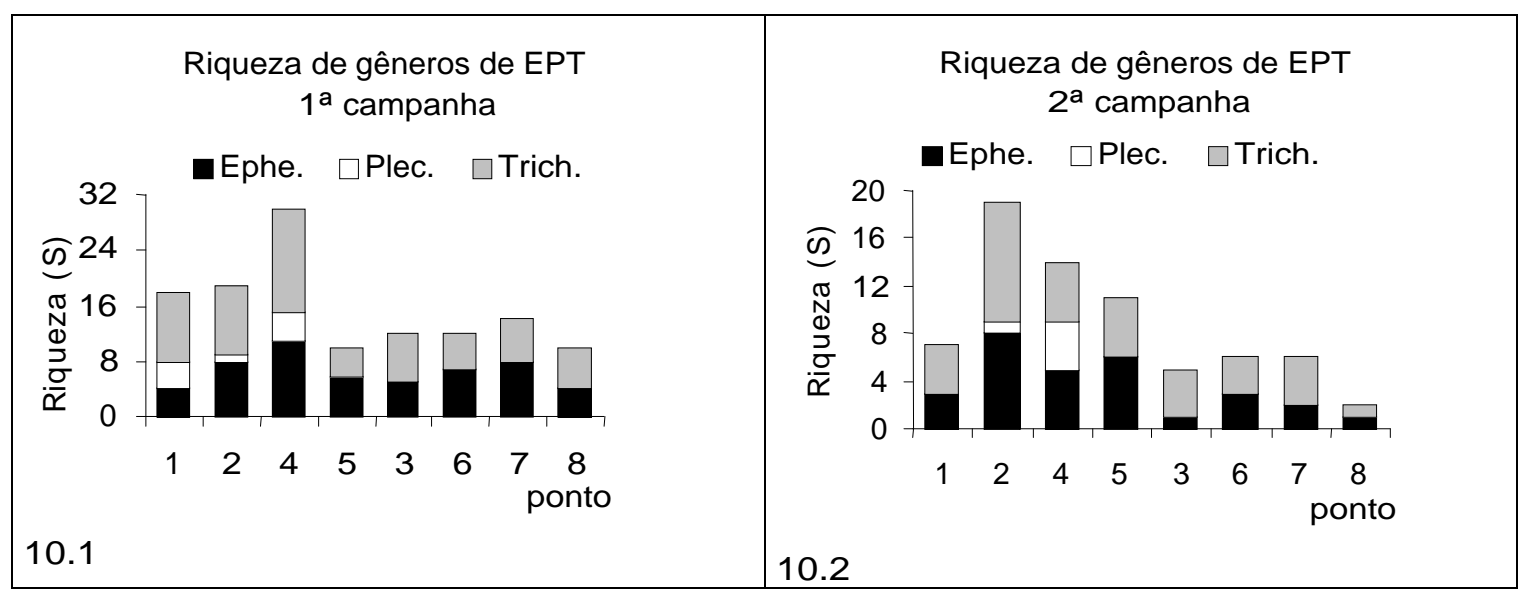

Figura 10- Riquezas das Ordens Ephemeroptera, Plecoptera e Trichoptera - EPT, em nível de gênero, obtidas na primeira (10.1) e segunda (10.2) campanhas. A seqüência de pontos foi propositadamente alterada, para facilitar a visualização.

Na primeira campanha (fig. 10.1), a maior riqueza $(S=30)$ foi registrada no ponto 4. Neste ponto ocorreram também, isoladamente, as maiores riquezas de Ephemeroptera $(S=11)$, Plecoptera $(S=4)$ e Trichoptera $(S=15)$. A exceção do ponto 5, onde foram registrados apenas 10 táxons, as demais regiões de cabeceira concentraram os maiores valores de riqueza, sendo $S=19$ para o ponto 2 e $S=18$ para o ponto 1 . A baixa riqueza obtida no ponto 5 , como já citado, deve-se ao menor esforço amostral efetuado naquele local, onde amostrou-se apenas dois habitats (margem deposicional e macrófitas). Os demais habitats que poderiam ser explorados, como "margem erosional" e "canal" correspondiam à rocha (laje), e naquele momento, a profundidade da coluna d'água e a velocidade da corrente não permitiram o emprego do amostrador do tipo Hess.

Dentre os pontos de baixo gradiente, a maior riqueza foi registrada no ponto $7(S=14)$, e a menor no ponto $8(S=10)$.

Tomando-se por base os dados quantitativos apenas, verificam-se menores valores $S$ e valores distintos das riquezas entre os pontos de coleta (fig. 13), comparativamente aos dados qualitativos. De modo geral (à exceção do ponto 5) também verifica-se maiores valores de $S$ no alto-gradiente, contudo a maior riqueza observada no ponto 4 , a partir de dados qualitativos na primeira campanha não se repete nos dados quantitativos.

A coleta de dados quantitativos está sujeita à existência de condições específicas para coletas, como tipo de substrato (para emprego de pegadores de fundo) ou velocidade de corrente, que são limitantes ao uso de amostradores como Surber ou Hess (BRANDIMARTE et al., 2004). Esta limitação certamente 
interfere na composição da riqueza na localidade, como pode ser observado nos dados apresentados.

A análise por agrupamento a partir dos dados qualitativos está apresentada na Figura 11. Verifica-se a divisão dos pontos em dois grupos. Um grupo é formado pelos pontos 3, $6,7,8$ e 5 , sendo que os pontos 6 e 7 apresentam a maior similaridade entre si. Nesses pontos, a riqueza de Ephemeroptera para a composição da comunidade foi superior a de Trichoptera (fig. 10.1), diferenciando-os das demais localidades amostradas no baixo gradiente. O fato do ponto 5 estar mais associado a esse grupo decorre da baixa riqueza obtida naquele local, por motivos previamente apontados.

No outro grupo, composto pelos pontos 1, 2 e 4, a maior similaridade foi observada entre os dois últimos, os quais apresentam as maiores riquezas observadas.

De certa forma, o agrupamento dos pontos a partir dos dados qualitativos para a primeira campanha diferenciou as localidades de alto e baixo-gradientes a partir de suas riquezas, com prejuízos apenas para o ponto 5 , em função do menor esforço amostral naquela localidade.

O mesmo tipo de análise foi feito com os dados quantitativos, empregando-se o coeficiente de similaridade de Bray-Curtis. O dendrograma obtido (fig. 12) é diferente daquele observado para os dados qualitativos. Observa-se a formação de três grupos. Um grupo é formado pelos pontos de baixo gradiente $(3,6,7$ e 8$)$ mais o ponto 4 , onde a baixa riqueza obtida neste último é, provavelmente, a principal responsável por sua inserção no grupo. Na primeira campanha, a coleta naquela localidade foi essencialmente qualitativa, coletando-se com pegador de fundo apenas na margem deposicional. A maior riqueza observada neste ponto foi obtida na corredeira, com coleta efetuada com rede manual (ver planilha completa no Anexo). A maior similaridade foi observada entre os pontos 7 e 8. Com base no Quadro 1 e na Figura 17.1, verifica-se que a composição da comunidade nos dois pontos é bastante semelhante, com vários gêneros em comum e densidade relativa de Ephemeroptera e Plecoptera também bastante semelhante entre os pontos, em que pese as diferenças de densidade absoluta, principalmente na margem deposicional.

O segundo grupo formado é composto pelos pontos 1 e 2 , contudo seu baixo nível de fusão reflete pouca similaridade entre os mesmos. 


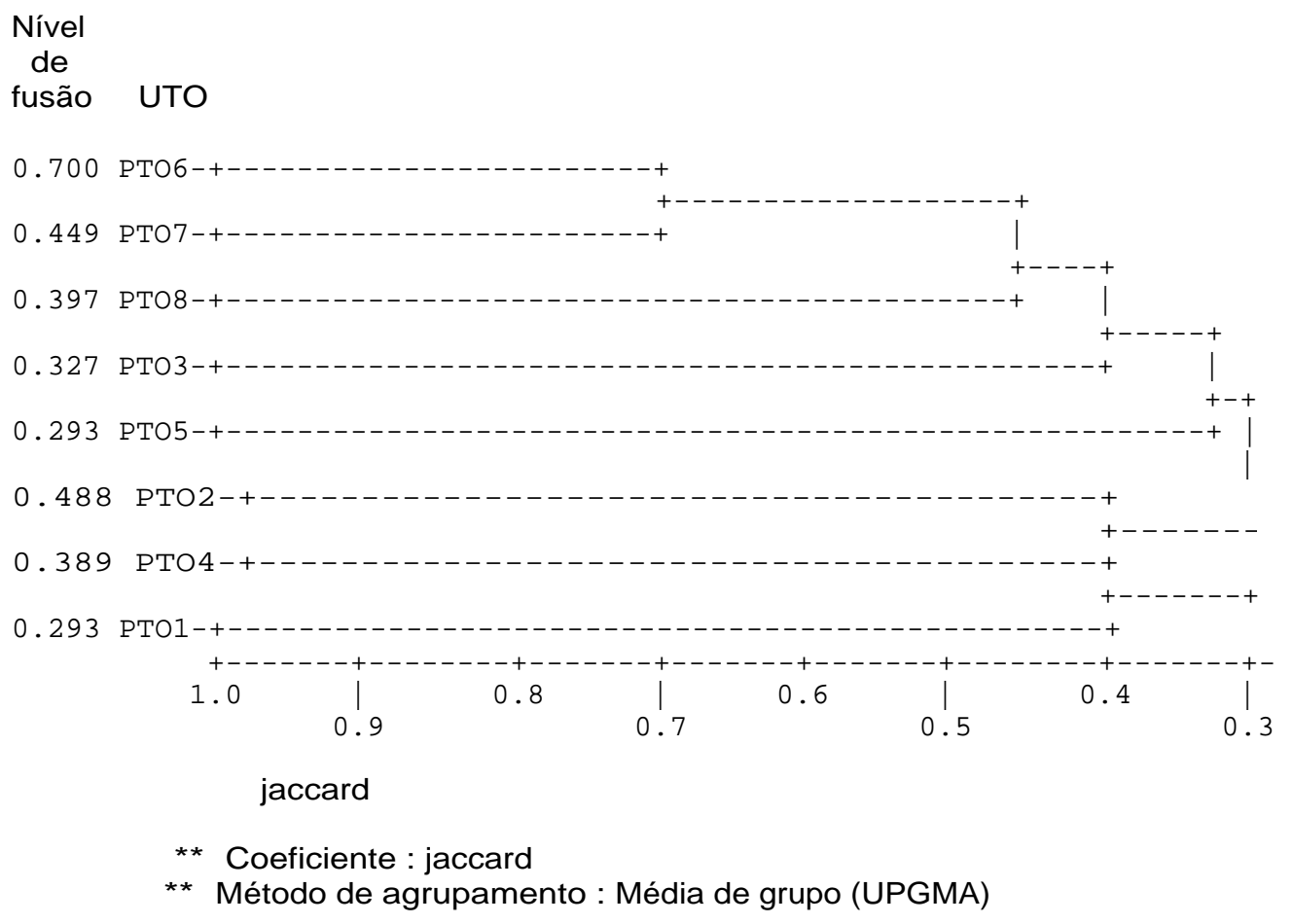

Figura 11- Análise de agrupamento dos pontos de amostragem a partir da composição da comunidade de Ephemeroptera, Plecoptera e Trichoptera (dados qualitativos, por ponto de coleta) obtida na primeira campanha de amostragem. (correlação cofenética $=0,8035$ ).

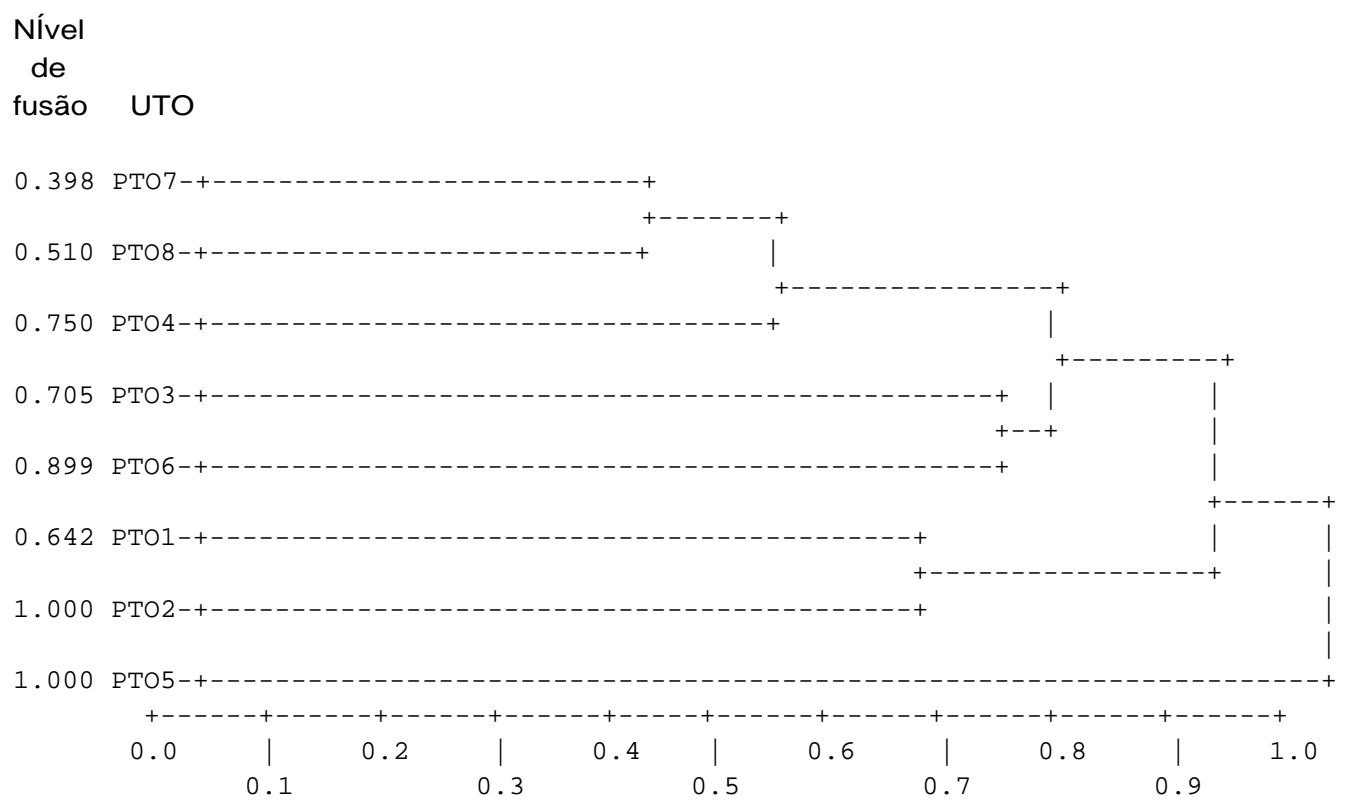

bray curtis

** Coeficiente : Bray Curtis

** Método de agrupamento : Média de grupo (UPGMA)

Figura 12 - Análise de agrupamento dos pontos de amostragem a partir de dados quantitativos de EPT obtidos na primeira campanha de amostragem (correlação cofenética $=0,9281$ ). 
O terceiro grupo corresponde ao ponto 5, o qual está isolado, em função de sua riqueza (e conseqüentemente densidade absoluta) ser zero.

$\mathrm{Na}$ segunda campanha (fig. 10.2), a maior riqueza foi obtida no ponto 2 $(S=19)$, seguido do ponto $4(S=14)$. A menor riqueza no alto-gradiente foi registrada no ponto $1(\mathrm{~S}=7)$.

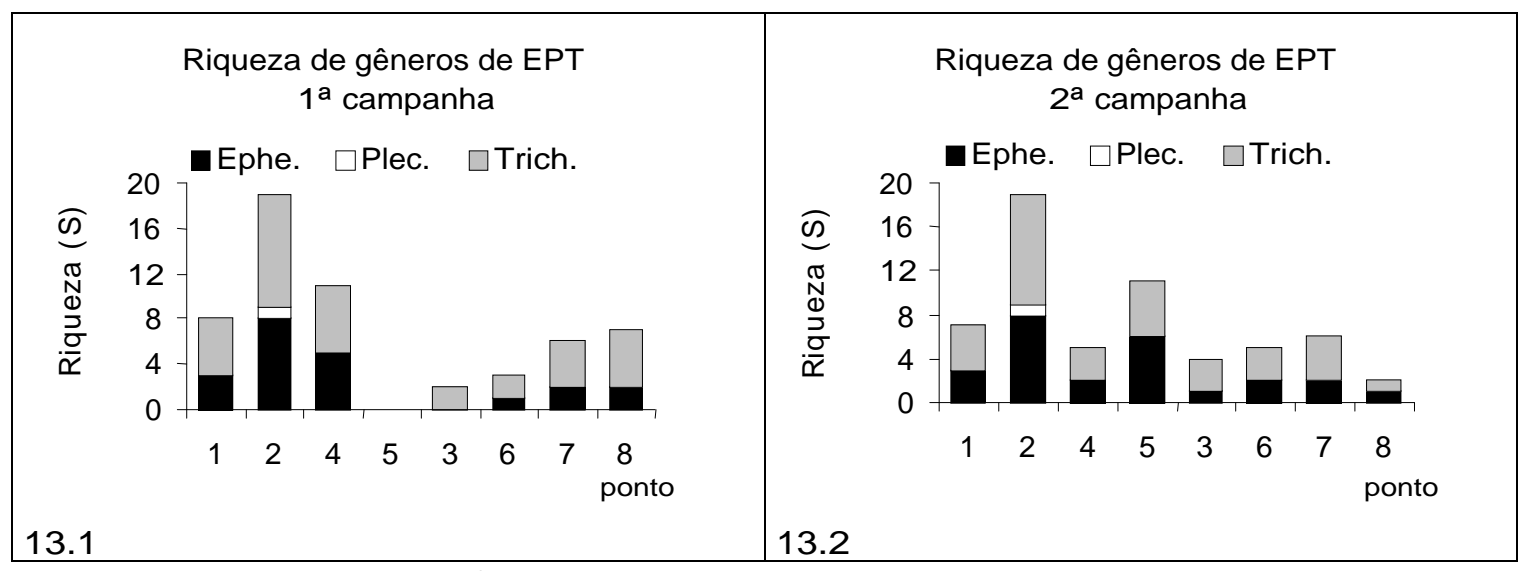

Figura 13- Riquezas das Ordens Ephemeroptera, Plecoptera e Trichoptera - EPT, em nível de gênero, obtidas na primeira (13.1) e segunda (13.2) campanhas, com base em apenas dados quantitativos. A seqüência de pontos foi propositadamente alterada, para facilitar a visualização.

A baixa riqueza obtida no ponto 1 deve-se às condições ambientais locais. Neste ponto onde a degradação da qualidade da água ficou evidente em termos químicos, mesmo que não verificado efeito tóxico na água em ensaio específico, com valores mais elevados das formas de fósforo e nitrogênio amoniacal. A redução de riqueza de EPT também foi observada por LOCH et al. (1996), também a jusante de um criadouro de trutas, associando à baixa qualidade da água, decorrente dos efluentes do empreendimento.

O baixo-gradiente apresentou, comparativamente à primeira campanha, riquezas bastante inferiores. O menor valor foi obtido no ponto $8(S=2)$ e os maiores nos pontos 6 e 7 (ambos com $S=6$ ).

Os valores de EPT baseados apenas em dados quantitativos, na segunda campanha apresentam configuração mais aproximada àquela obtida a partir de dados qualitativos no mesmo período (fig. 13.2 e 10.2, respectivamente). As coletas envolveram, principalmente, os amostradores do tipo Petersen e Hess, considerando-se para a escolha entre eles a profundidade e o tipo de sedimento. O único ponto onde efetuou-se coleta com rede (qualitativa) foi o ponto 4 , justamente aquele que apresenta maiores diferenças de riquezas entre os dados qualitativos e quantitativos. 
Com isso, pode-se dizer que, em função da restrição de habitats para a coleta de dados quantitativos, a avaliação da qualidade ambiental a partir das ordens Ephemeroptera, Plecoptera e Trichoptera produz melhores resultados com base em dados qualitativos onde, em cada localidade, sejam explorados os diversos habitats, para composição de uma maior riqueza.

O agrupamento dos pontos, a partir dos dados bióticos qualitativos obtidos na segunda campanha de amostragem está representado na Figura 14. A redução da qualidade da água no ponto 1 interferiu na riqueza daquela localidade e, conseqüentemente, no agrupamento dos pontos.

No gráfico, verifica-se a formação de três grupos. O primeiro grupo é formado pelos pontos 2, 5, 4, 6 e 1. A maior similaridade é observada entre os pontos 2, 4 e 5, que compõem o alto-gradiente. Como o ponto 1 apresentou riqueza bastante inferior que as demais localidades do alto-gradiente, obteve menor similaridade com os mesmos. O ponto 6, apesar de apresentar a mesma riqueza que o ponto 7 apresenta, nesta segunda campanha, mais gêneros em comum com os pontos 4 e 5 (Quadro 2).

No baixo-gradiente, a maior similaridade ocorre entre os pontos 3 e 7 , os quais correspondem ao segundo grupo formado.

O terceiro grupo é formado apenas pelo ponto 8 , o qual por sua riqueza extremamente baixa $(S=2)$, não apresenta similaridade significativa com os demais pontos.

$\mathrm{Na}$ segunda campanha o gráfico de agrupamento obtido para as densidades absolutas de EPT (fig. 15) guarda semelhança com o agrupamento apresentado na Figura 14, todavia quatro grupos são formados.

Assim como ocorre para os dados qualitativos, observa-se maiores similaridades entre os pontos 3 e 7 e pontos 2, 4, 5 e 6 .

Neste caso o ponto 1 encontra-se isolados dos demais pontos de altogradiente, em função da elevada dominância de Trichoptera (96,56\% - Tabela VII), condição esta que não se repete nas demais localidades (pontos 2, 4 e 5).

O ponto 8 também encontra-se isolado, também neste caso, em função de sua baixa riqueza, que conseqüentemente confere baixa similaridade.

As diferenças de valores de riquezas entre alto e baixo-gradientes em ambas as campanhas, assim como a redução da riqueza quando a caracterização física e química apontou redução da qualidade da água, permite afirmar que o índice EPT, em nível taxonômico de gênero, respondeu de forma satisfatória ao gradiente ambiental instalado entre as localidades amostradas. Contudo, 
verificou-se que a avaliação do ambiente aquático, por meio de dados meramente quantitativos de EPT, produziu menores riquezas, por estar condicionada a condições específicas de substrato, correnteza e profundidade, principalmente. CARLISLE e CLEMENTS (1999) constataram que o índice EPT apresentou sensibilidade moderada na distinção entre 3 localidades com diferentes graus de poluição, salientando que a avaliação da sensibilidade dos índices é limitada pela inexistência de uma série temporal de dados de campo e experimentais.

O aumento do esforço amostral, com coleta de dados semi-quantitativos e qualitativos, valendo-se de diversos tipos de amostradores, o que permite a contemplação de habitats com diversas complexidades estruturais, aumenta a riqueza observada em cada localidade, produzindo um resultado mais refinado.

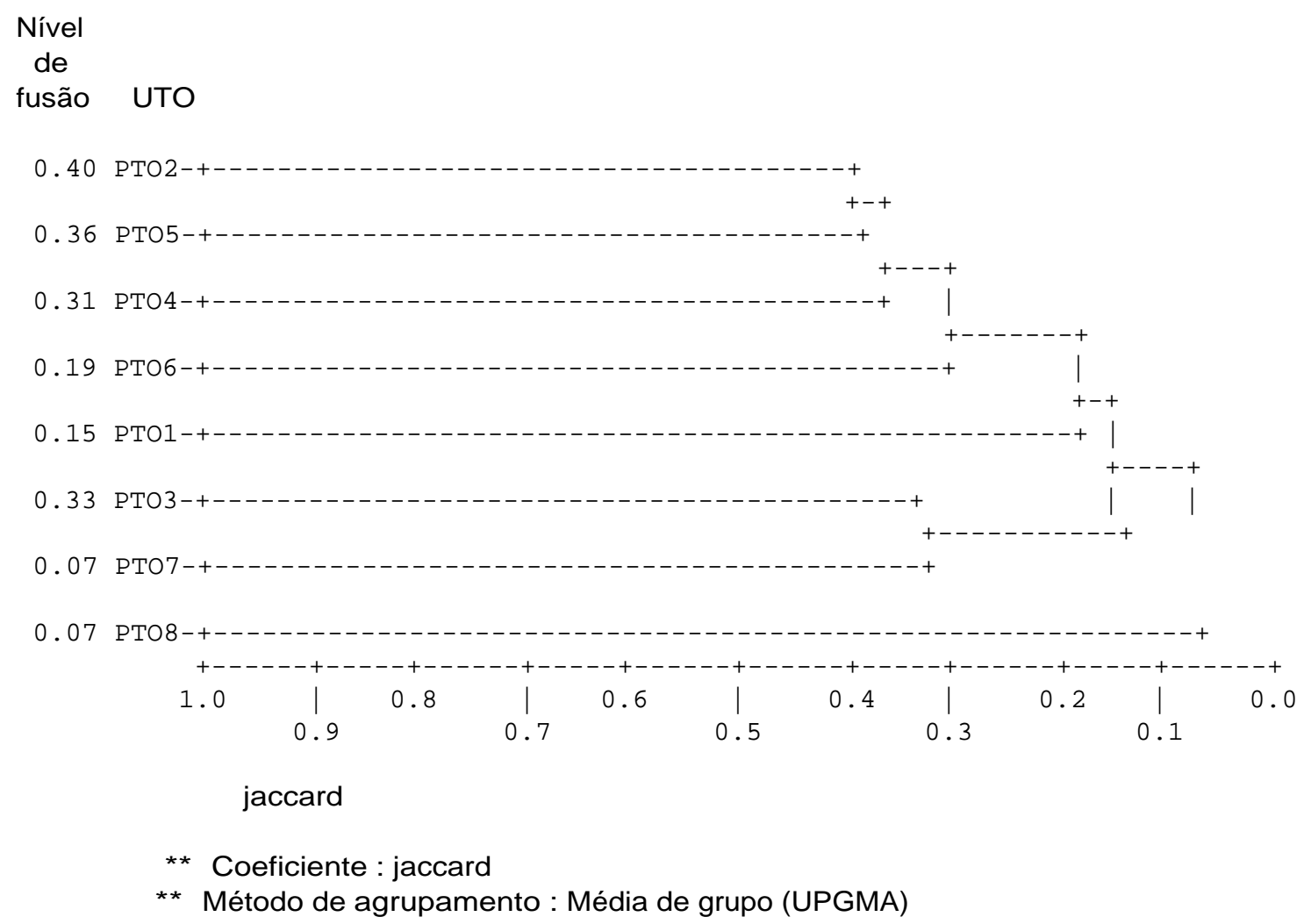

Figura 14 - Análise de agrupamento dos pontos de amostragem a partir da composição da comunidade de Ephemeroptera, Plecoptera e Trichoptera (dados qualitativos, por ponto de coleta) obtida na segunda campanha de amostragem. (correlação cofenética $=0,8238$ ) 


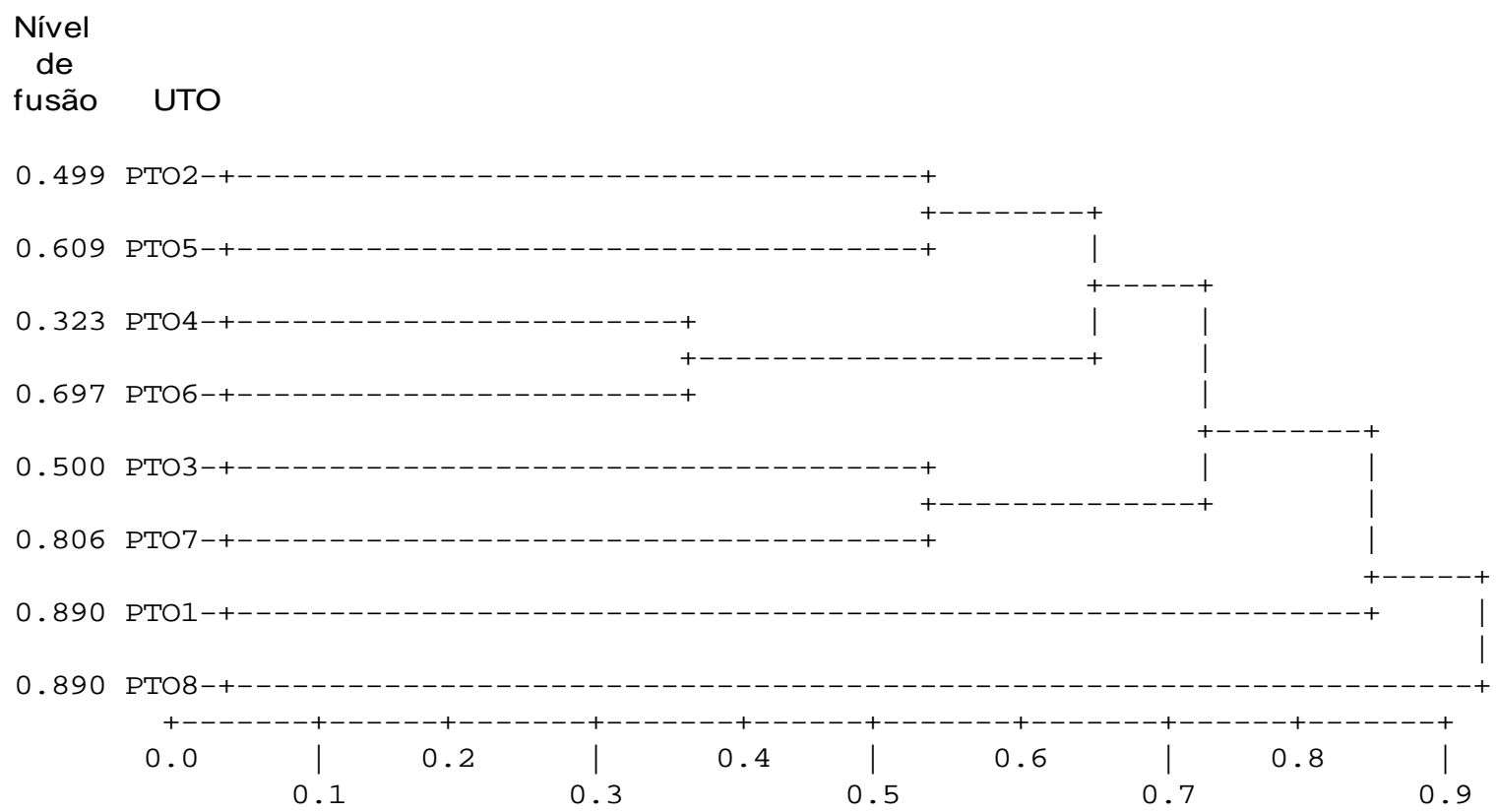

bray curtis

** Coeficiente : Bray Curtis

* * Método de agrupamento : Média de grupo (UPGMA)

Figura 15 - Análise de agrupamento dos pontos de amostragem a partir de dados quantitativos de EPT obtidos na segunda campanha de amostragem (correlação cofenética $=0,8561$ ). 
Quadro 1 - Composição das comunidades das ordens Ephemeroptera, Plecoptera e Trichoptera na primeira campanha de amostragem. Legenda: campo cinza = presença; campo branco = ausência. (a seqüência dos pontos foi alterada propositadamente de modo a separar alto e baixo-gradientes)

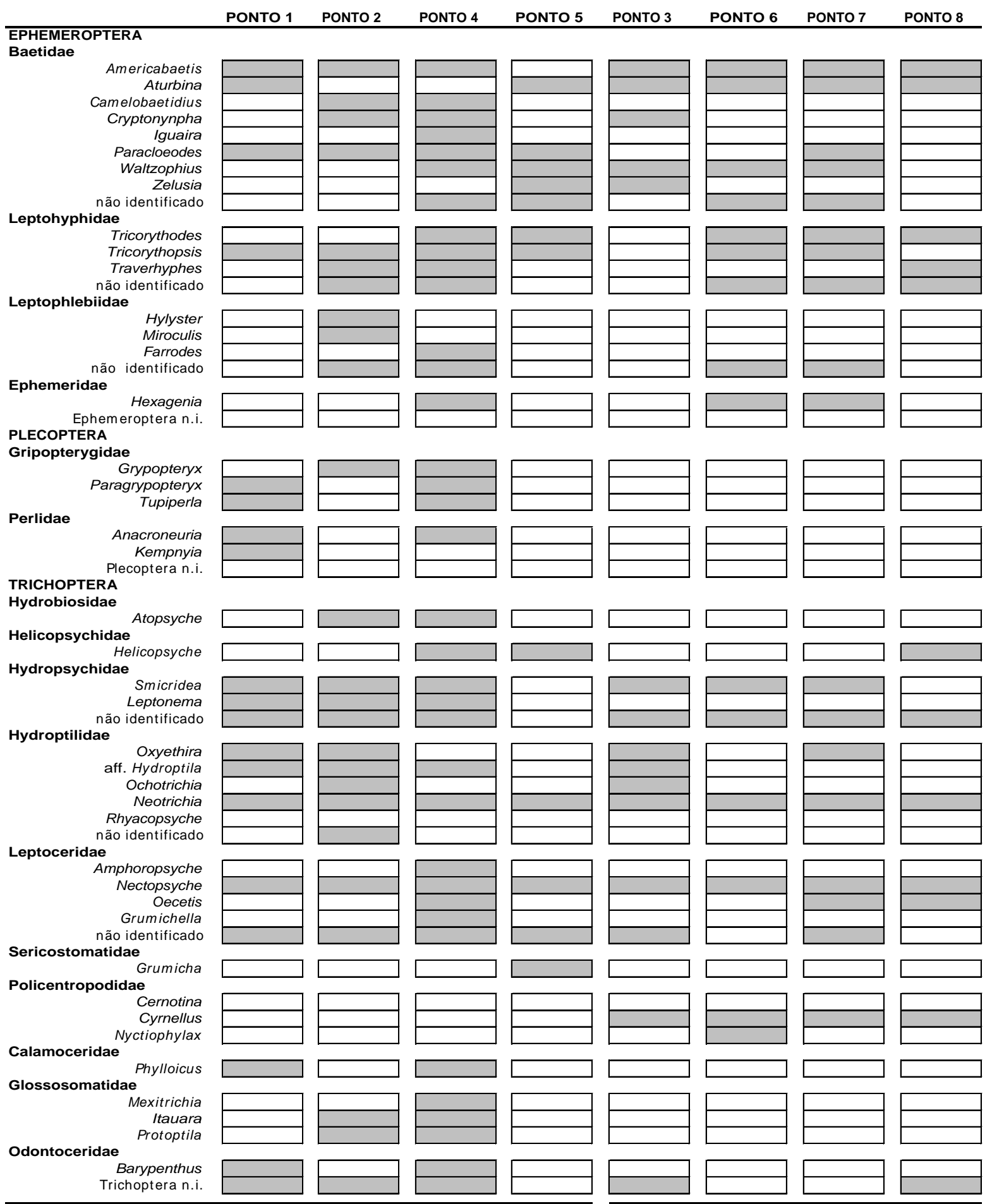


Quadro 2 - Composição das comunidades das ordens Ephemeroptera, Plecoptera e Trichoptera na segunda campanha de amostragem. Legenda: campo cinza= presença; campo branco = ausência. (a seqüência dos pontos foi alterada propositadamente de modo a separar alto e baixo-gradientes)

\section{EPHEMEROPTERA}

Baetidae

\begin{tabular}{rl|} 
Americabaetis & \\
Aturbina & \\
\cline { 2 - 2 } Camelobaetidius & \\
\cline { 2 - 2 } Cryptonynpha & \\
\cline { 2 - 2 } Iguaira & \\
\cline { 2 - 2 } Paracloeodes & \\
\cline { 2 - 2 } Waltzophius & \\
Zelusia & \\
\cline { 2 - 2 } não identificado & \\
\cline { 2 - 2 } &
\end{tabular}
Leptohyphidae

Tricorythodes

Tricorythopsis

Traverhyphes não identificado Leptophlebiidae
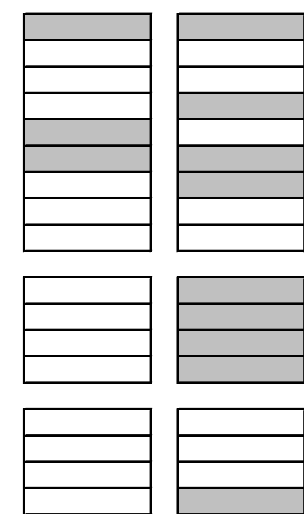

Ephemeridae

Hexagenia Ephemeroptera n.i. PLECOPTERA

Gripopterygidae

Grypopteryx
Paragrypopteryx
Tupiperla

$$
\text { Anacroneuria }
$$

Kempnyia

TRICHOPTERA

Hydrobiosidae Atopsyche

Helicopsyche

Hydropsychidae

Smicridea

Leptonema

não identificado

Hydroptilidae

Oxyethira

aff. Hydroptila

Ochotrichia

Neotrichia

Rhyacopsyche

não identificado

Leptoceridae

Amphoropsyche

Nectopsyche Oecetis

Grumichella

não identificado

Sericostomatidae

Grumicha

Policentropodidae

Cernotina

Nyctiophylax

Calamoceridae

Phylloicus

Glossosomatidae

Mexitrichia
Itauara

Itauara
Protoptila
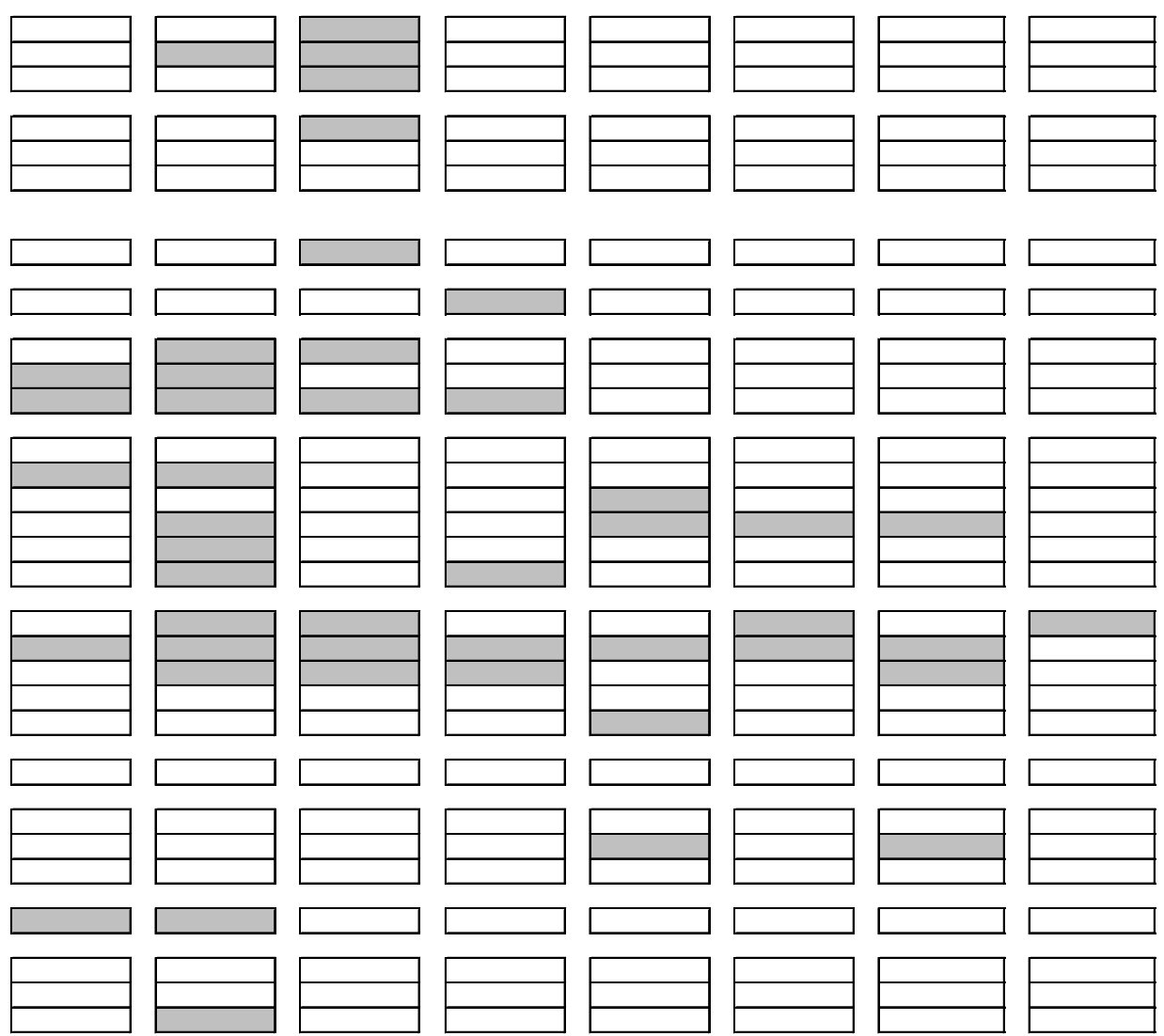

Odontoceridae

Barypenthus

Barypenthus
Trichoptera n.i.
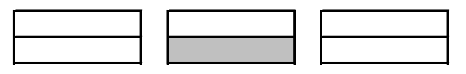

\begin{tabular}{|l|}
\hline \\
\hline
\end{tabular}
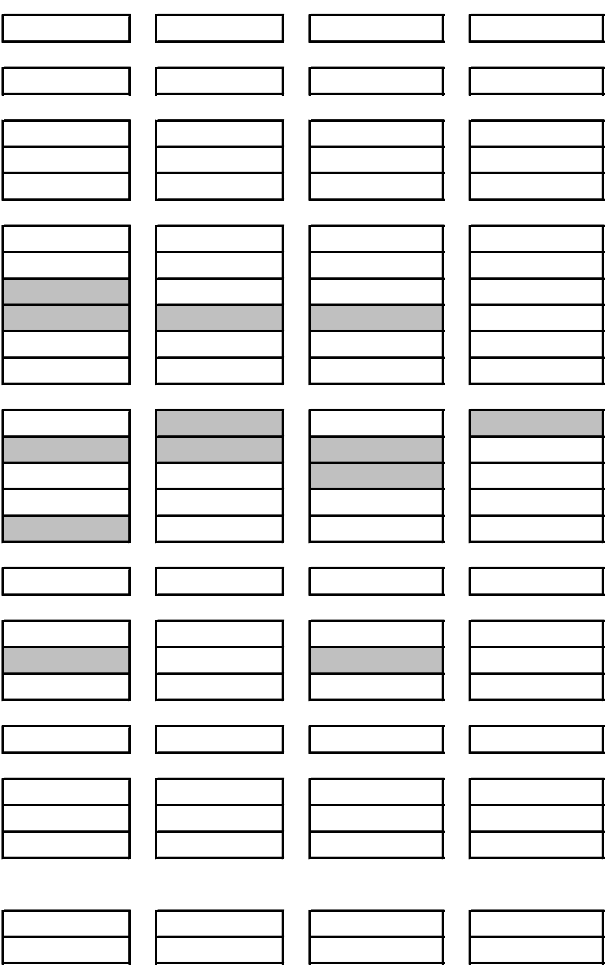
Considerando-se os dados em nível de família, como apresentados na Figura 16, verifica-se que as riquezas são consideravelmente inferiores, obviamente em função da ocorrência de algumas famílias com mais de um gênero registrado. No entanto, os valores, mesmo que diferentes, aparentemente refletem as mesmas condições. As correlações obtidas comparando-se riquezas em nível de gênero e família, foram significativa e altamente significativa. Para a primeira campanha, a correlação de Spearman foi $\rho=0,8571(\mathrm{p}=0,006)$ e para a segunda campanha $\rho=0,9762(\mathrm{p}=0,00001)$.

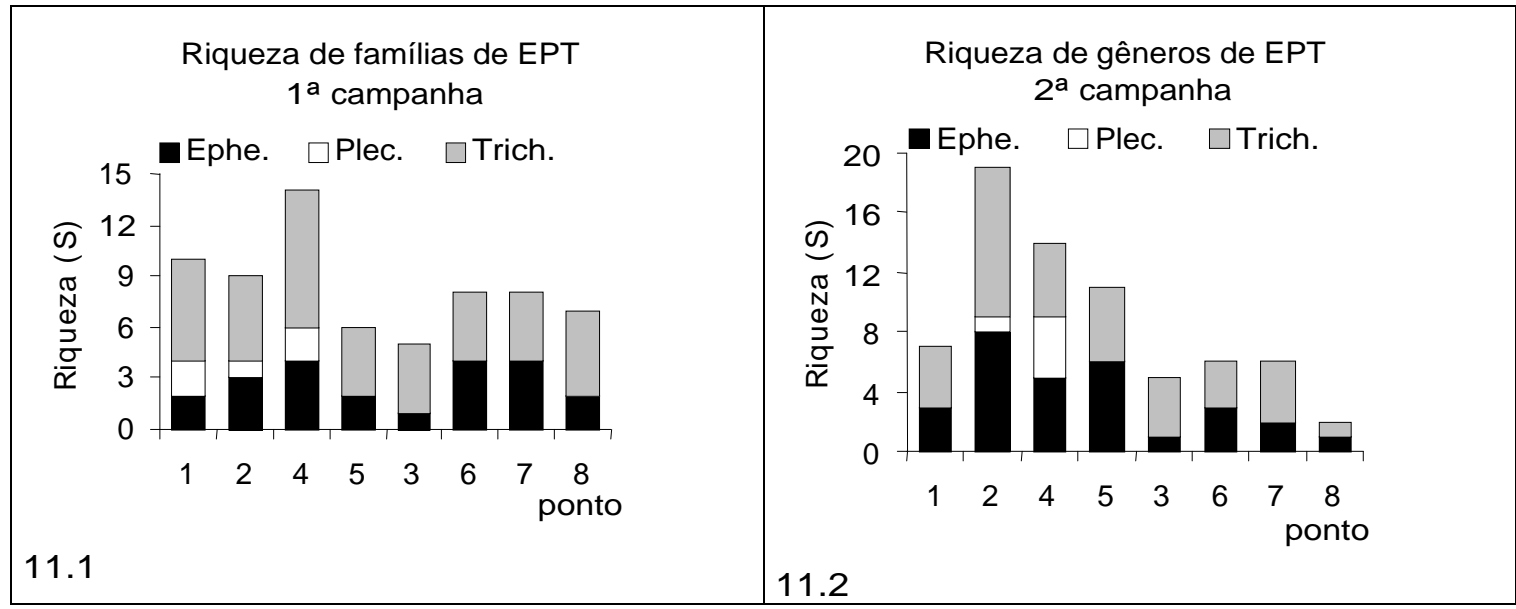

Figura 16- Riquezas das Ordens Ephemeroptera, Plecoptera e Trichoptera - EPT, em nível de família, obtidas na primeira (16.1) e segunda (16.2) campanhas. A seqüência de pontos foi propositadamente alterada, para facilitar a visualização.

Considerando-se a elevada correlação existente entre as riquezas de EPT em nível de gênero e família e sem dúvida, a semelhança dos gráficos obtidos (comparando-se a Figura $10 \mathrm{com}$ a Figura 16) pode-se afirmar que, adotando-se este último nível taxonômico pode-se obter um resultado satisfatório, principalmente em programas de monitoramento, os quais geralmente envolvem muitos pontos de amostragem, inclusive com replicatas. Tal fato justifica-se pela demanda de tempo, em função das dificuldades na identificação dos organismos em nível de gênero, principalmente em decorrência da falta de material de apoio para a identificação para gêneros exclusivos da região neotropical.

Em ambas as campanhas, a ordem Trichoptera foi a que mais contribuiu para a composição das riquezas, representando, aproximadamente $50 \%$ dos gêneros identificados na primeira campanha (fig. 17.1) e 55\% na segunda (fig. 17.2). A ordem Ephemeroptera contribuiu com $45 \%$ e $41 \%$, respectivamente na primeira e segunda campanhas. Nos pontos 5, e 7 a ordem Ephemeroptera foi 
mais representativa que Trichoptera nas duas campanhas de coleta. No ponto 6 o mesmo ocorre, no entanto apenas na primeira campanha.

A maior expressividade de Plecoptera foi registrada no ponto 4, segunda campanha, quando a ordem contribuiu com aproximadamente $29 \%$ dos taxons registrados (fig. 17.2).

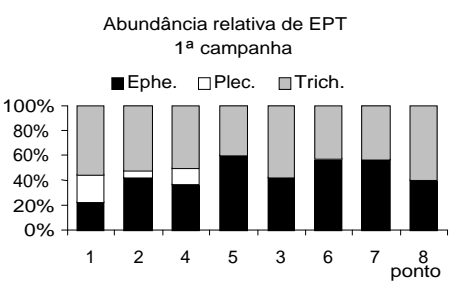

17.1

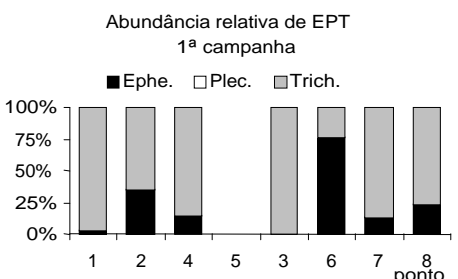

17.4

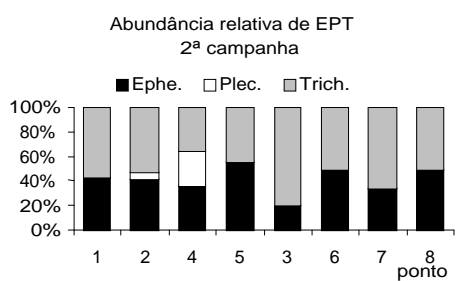

17.2

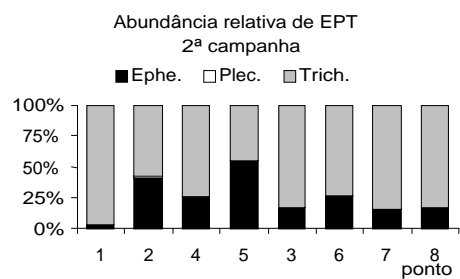

17.5

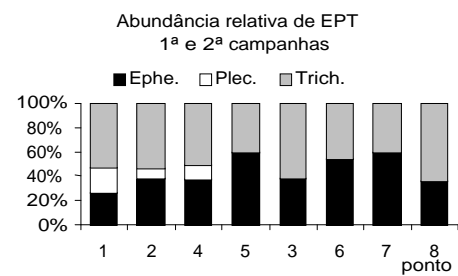

17.3

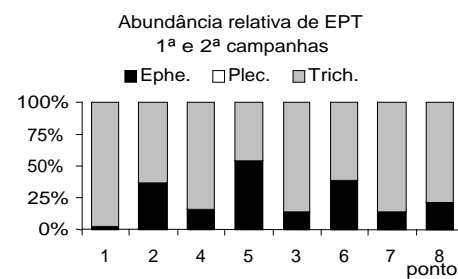

17.6

Figura 17- Abundância relativa com base em dados qualitativos $(17.1 ; 17.2$ e 17.3) e qualitativos $(17.4 ; 17.5$ e 17.6$)$ para a primeira e segunda campanhas e compilação de ambas, respectivamente. A seqüência de pontos foi propositadamente alterada, para facilitar a visualização.

Considerando o conjunto de dados obtidos nas duas campanhas de amostragem (fig. 17.3), a situação permanece praticamente inalterada continuando a maior expressividade de Trichoptera, exceto nos pontos 5, 6 e 7.

Em termos de densidade relativa, baseando-se apenas em dados originados de amostragens quantitativas, a ordem Trichoptera, dentre as três ordens consideradas foi dominante em praticamente todos os pontos de coleta, correspondendo a aproximadamente $75 \%$ dos organismos identificados. No ponto 1, em ambas as campanhas (figs. 17.4 a 17.6), a referida ordem correspondeu a mais de $95 \%$ dos organismos coletados. As exceções são o ponto 6 , primeira campanha e ponto 5, segunda campanha, localidades onde Ephemeroptera apresentou abundância relativa superior a Trichoptera.

Segundo Silva (1995, apud BISPO \& OLIVEIRA, 1998), em períodos chuvosos pode ocorrer a redução, em termos de riqueza e abundância, de Trichoptera. Isto deve-se à sua maior suscetibilidade ao deslocamento pela correnteza, em função de sua morfologia menos deprimida, se comparado às ordens Plecoptera e Ephemeroptera, e de hábitos como casulos e redes para captura de alimento, 
que provocam maior resistência à água. Contudo, no presente estudo, as maiores abundâncias e riquezas foram observadas na primeira campanha de amostragem, a qual corresponde ao período chuvoso.

A ordem Plecoptera, em termos de densidade relativa, com base dados quantitativos, foi completamente inexpressiva, correspondendo a, no máximo, $0,1 \%$ dos organismos, na segunda campanha, considerando-se também os dados qualitativos. Tal fato está associado à preferência de Plecoptera por águas mais frias e velocidade de corrente mais acentuada, comuns às regiões de cabeceira (COMPIN \& CÉRÉGHINO, 2003; BISPO et al., 2002).

Os valores de densidade relativa obtidos diferem daqueles obtidos por BISPO e OLIVEIRA (1998) em córregos do cerrado, no interior do Parque Ecológico de Goiânia - GO. Naquela localidade, a ordem Ephemeroptera foi dominante. Na estação seca, aproximadamente $73 \%$ da riqueza de EPT correspondia a Ephemeroptera e $26 \%$ a Trichoptera. Na estação chuvosa os valores foram de $57 \%$ e 42\% para Ephemeroptera e Trichoptera, respectivamente. Proporções semelhantes foram obtidas por GUALDONI e CORIGLIANO (2002) em um rio de altitude na Argentina.

Assim como no presente estudo, a ordem Plecoptera apresentou, em geral, baixa expressividade.

A família Hydropsychidae, pertencente à ordem Trichoptera é reconhecida como bastante tolerante à condições de degradação. Em função de sua maior tolerância, postula-se que, na medida em que diminui a qualidade ambiental, há uma tendência desta família aumentar sua dominância dentro da ordem. A relação Hydropsychidae/Trichoptera é proposta em um protocolo de avaliação da qualidade ambiental (BARBOUR et al., 1999), como potencial indicador de perturbação ambiental.

$\mathrm{Na}$ Tabela VII estão relacionados os valores correspondentes à relação Hydropsychidae/Trichoptera, para ambas as campanhas de amostragem e para a compilação dos dados de ambas.

Verifica-se que apenas nos pontos 1 e 2 (este último apenas na primeira campanha) a família Hydropsychidae correspondeu à quase totalidade dos Trichoptera amostrados. Verificando-se os dados obtidos com rede (semiquantitativo, neste caso, considerados apenas qualitativos), apresentados no Anexo e não considerados para o cálculo da referida relação, verifica-se a predominância de Hydropsychidae dentre os Trichoptera. 
Nos demais pontos amostrados, a família foi pouco representativa, conforma pode ser verificado na Tabela VII abaixo, inclusive nas amostras coletadas com rede.

Diante do exposto, o item proposto naquele protocolo não respondeu satisfatoriamente mediante o conjunto de dados obtidos e perante o gradiente ambiental configurado.

Tabela VII - Relação Hydropsychidae / Trichoptera para as campanhas de amostragem e compilação de ambas.

\begin{tabular}{|c|c|c|c|}
\hline \multicolumn{4}{|c|}{ RELAÇÃO HYDROPSYCHIDAE / TRICHOPTERA } \\
\hline PONTO & $1 \stackrel{\text { a } \text { CAMPANHA }}{ }$ & 2 a CAMPANHA & 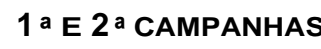 \\
\hline 1 & 0.960 & 0.976 & 0.968 \\
\hline 2 & 0.850 & 0.075 & 0.714 \\
\hline 3 & 0.022 & 0.000 & 0.019 \\
\hline 4 & - & 0.007 & 0.007 \\
\hline 5 & 0.000 & 0.000 & 0.000 \\
\hline 6 & 0.000 & 0.000 & 0.000 \\
\hline 7 & 0.000 & 0.000 & 0.000 \\
\hline 8 & 0.027 & 0.000 & 0.024 \\
\hline
\end{tabular}

Conforme mencionado no item 2.3.2, a possível associação de alguns gêneros com condições ambientais específicas, ou no mínimo como indicadores diretos de degradação ou menor grau de deterioração ambiental foi feito a partir de uma adaptação da análise nodal, empregando-se o método de agrupamentos. O resultado da análise encontra-se na Tabela VIII. Os grupos formados estão divididos através da diferença de cores (horizontal) e por colunas separadas por linhas cheias (vertical). Os gêneros e pontos de coleta foram divididos em sete grupos.

Para definir quais gêneros deveriam ser efetivamente considerados na análise utilizou-se como ferramenta o Índice de Valor de Importância - IVI (MEGURO, 2000), baseado em dados de freqüência e abundância. Serão considerados os gêneros cujo IVI for igual ou superior a $10 \%$ do maior IVI obtido. O resultado está graficamente representado na Figura 18. A linha cheia próxima da base do gráfico corresponde à "linha de corte", abaixo da qual estão os gêneros que não serão considerados na análise, em função de sua baixa densidade ou ocorrência muito esporádica. 
Tabela VIII - Ordenação dos gêneros de EPT e pontos de coleta a partir de análise por agrupamento.

\begin{tabular}{|c|c|c|c|c|c|c|c|c|c|c|c|c|c|c|}
\hline & 82 & 61 & 21 & 22 & 11 & 12 & 42 & 52 & 62 & 31 & 71 & 81 & 32 & 72 \\
\hline Americabaetis & 10.26 & 0.00 & 1026.19 & 108.02 & 19.64 & 44.19 & 0.00 & 10.26 & 0.00 & 0.00 & 0.00 & 0.00 & 0.00 & 0.00 \\
\hline Cryptonynpha & 0.00 & 0.00 & 14.73 & 39.28 & 0.00 & 0.00 & 0.00 & 0.00 & 0.00 & 0.00 & 0.00 & 0.00 & 0.00 & 0.00 \\
\hline Paracloeodes & 0.00 & 0.00 & 152.21 & 127.66 & 44.19 & 29.46 & 0.00 & 10.26 & 0.00 & 0.00 & 0.00 & 0.00 & 0.00 & 0.00 \\
\hline Waltzophius & 0.00 & 0.00 & 0.00 & 9.82 & 0.00 & 0.00 & 0.00 & 0.00 & 0.00 & 0.00 & 0.00 & 0.00 & 30.77 & 0.00 \\
\hline Tricorythopsis & 0.00 & 0.00 & 1669.40 & 628.48 & 9.82 & 0.00 & 10.26 & 451.29 & 10.26 & 0.00 & 0.00 & 0.00 & 0.00 & 0.00 \\
\hline Paragrypopteryx & 0.00 & 0.00 & 0.00 & 19.64 & 0.00 & 0.00 & 0.00 & 0.00 & 0.00 & 0.00 & 0.00 & 0.00 & 0.00 & 0.00 \\
\hline Smicridea & 0.00 & 0.00 & 4743.06 & 83.47 & 4.91 & 0.00 & 0.00 & 0.00 & 0.00 & 0.00 & 0.00 & 0.00 & 0.00 & 0.00 \\
\hline Leptonema & 0.00 & 0.00 & 29.46 & 7.37 & 903.44 & 1581.02 & 0.00 & 0.00 & 0.00 & 0.00 & 0.00 & 0.00 & 0.00 & 0.00 \\
\hline aff. Hydroptila & 0.00 & 0.00 & 702.13 & 672.67 & 44.19 & 14.73 & 0.00 & 0.00 & 0.00 & 0.00 & 0.00 & 0.00 & 0.00 & 0.00 \\
\hline Rhyacopsyche & 0.00 & 0.00 & 0.00 & 24.55 & 0.00 & 0.00 & 0.00 & 0.00 & 0.00 & 0.00 & 0.00 & 0.00 & 0.00 & 0.00 \\
\hline Phylloicus & 0.00 & 0.00 & 0.00 & 9.82 & 0.00 & 4.91 & 0.00 & 0.00 & 0.00 & 0.00 & 0.00 & 0.00 & 0.00 & 0.00 \\
\hline Protoptila & 0.00 & 0.00 & 14.73 & 9.82 & 0.00 & 0.00 & 0.00 & 0.00 & 0.00 & 0.00 & 0.00 & 0.00 & 0.00 & 0.00 \\
\hline Camelobaetius & 0.00 & 0.00 & 584.29 & 0.00 & 0.00 & 0.00 & 0.00 & 0.00 & 0.00 & 0.00 & 0.00 & 0.00 & 0.00 & 0.00 \\
\hline Hylyster & 0.00 & 0.00 & 73.65 & 0.00 & 0.00 & 0.00 & 0.00 & 0.00 & 0.00 & 0.00 & 0.00 & 0.00 & 0.00 & 0.00 \\
\hline Miroculis & 0.00 & 0.00 & 34.37 & 0.00 & 0.00 & 0.00 & 0.00 & 0.00 & 0.00 & 0.00 & 0.00 & 0.00 & 0.00 & 0.00 \\
\hline Grypopteryx & 0.00 & 0.00 & 19.64 & 0.00 & 0.00 & 0.00 & 0.00 & 0.00 & 0.00 & 0.00 & 0.00 & 0.00 & 0.00 & 0.00 \\
\hline Atopsyche & 0.00 & 0.00 & 29.46 & 0.00 & 0.00 & 0.00 & 0.00 & 0.00 & 0.00 & 0.00 & 0.00 & 0.00 & 0.00 & 0.00 \\
\hline Oxyethira & 0.00 & 0.00 & 14.73 & 0.00 & 0.00 & 0.00 & 0.00 & 0.00 & 0.00 & 0.00 & 0.00 & 0.00 & 0.00 & 0.00 \\
\hline Ochotrichia & 0.00 & 0.00 & 24.55 & 0.00 & 0.00 & 0.00 & 0.00 & 0.00 & 0.00 & 0.00 & 0.00 & 0.00 & 10.26 & 0.00 \\
\hline Itauara & 0.00 & 0.00 & 9.82 & 0.00 & 0.00 & 0.00 & 0.00 & 0.00 & 0.00 & 0.00 & 0.00 & 0.00 & 0.00 & 0.00 \\
\hline Tricorythodes & 0.00 & 0.00 & 0.00 & 39.28 & 0.00 & 0.00 & 102.57 & 1066.69 & 71.80 & 0.00 & 0.00 & 51.28 & 0.00 & 10.26 \\
\hline Traverhyphes & 0.00 & 0.00 & 58.92 & 34.37 & 0.00 & 0.00 & 0.00 & 41.03 & 0.00 & 0.00 & 0.00 & 30.77 & 0.00 & 10.26 \\
\hline Hexagenia & 0.00 & 102.57 & 0.00 & 0.00 & 0.00 & 0.00 & 0.00 & 133.34 & 0.00 & 0.00 & 123.08 & 0.00 & 0.00 & 0.00 \\
\hline Neotrichia & 0.00 & 0.00 & 4.91 & 14.73 & 0.00 & 0.00 & 0.00 & 0.00 & 82.05 & 0.00 & 153.85 & 20.51 & 41.03 & 30.77 \\
\hline Netopsyche & 0.00 & 0.00 & 103.11 & 535.19 & 24.55 & 34.37 & 246.16 & 1333.37 & 133.34 & 10.26 & 82.05 & 20.51 & 71.80 & 10.26 \\
\hline Oecetis & 0.00 & 0.00 & 0.00 & 14.73 & 0.00 & 0.00 & 61.54 & 112.82 & 0.00 & 0.00 & 10.26 & 20.51 & 0.00 & 41.03 \\
\hline Cyrnellus & 0.00 & 20.51 & 0.00 & 0.00 & 0.00 & 0.00 & 0.00 & 0.00 & 0.00 & 10.26 & 594.89 & 297.44 & 20.51 & 30.77 \\
\hline Amphoropsyche & 51.28 & 0.00 & 0.00 & 9.82 & 0.00 & 0.00 & 10.26 & 0.00 & 112.82 & 0.00 & 0.00 & 0.00 & 0.00 & 0.00 \\
\hline Helicopsyche & 0.00 & 0.00 & 0.00 & 0.00 & 0.00 & 0.00 & 0.00 & 10.26 & 0.00 & 0.00 & 0.00 & 0.00 & 0.00 & 0.00 \\
\hline Iguaira & 0.00 & 0.00 & 0.00 & 0.00 & 0.00 & 4.91 & 0.00 & 0.00 & 0.00 & 0.00 & 0.00 & 0.00 & 0.00 & 0.00 \\
\hline Nyctiophylax & 0.00 & 10.26 & 0.00 & 0.00 & 0.00 & 0.00 & 0.00 & 0.00 & 0.00 & 0.00 & 0.00 & 0.00 & 0.00 & 0.00 \\
\hline
\end{tabular}




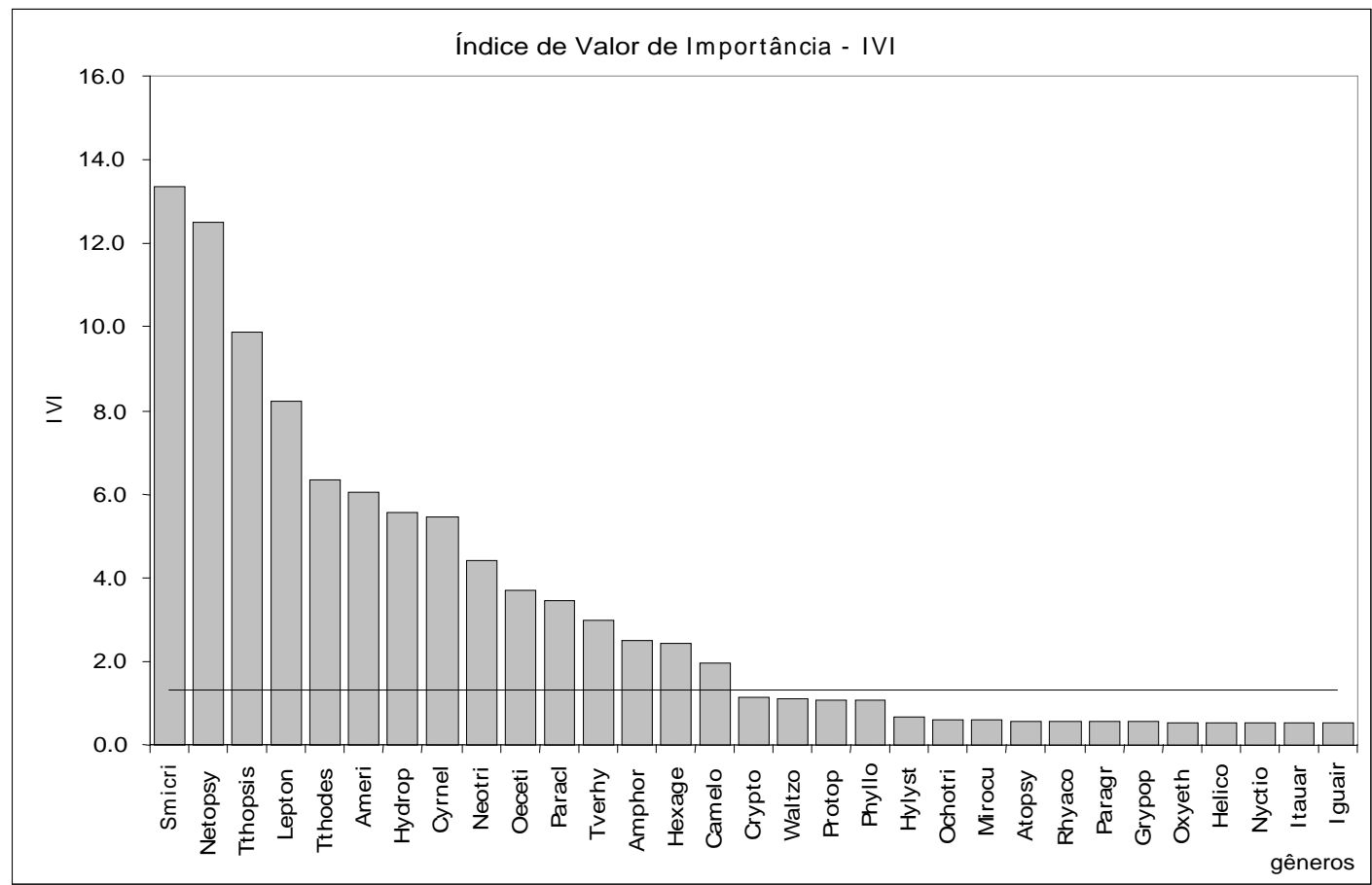

Figura 18 - Índice de Valor de Importância para os gêneros de EPT, primeira e segunda campanhas.

A partir do gráfico apresentado na Figura 18, fica estabelecido que serão considerados nas análise os seguintes gêneros abaixo relacionados:

Ordem TRICHOPTERA

Fam. Hydropsychidae

- Smicridea;

- Leptonema

Fam. Hydroptilidae

- aff. Hydroptila

- Neotrichia

Fam. Policentropodidae

- Cyrnellus

Fam. Leptoceridae

- Nectopsyche

- Oecetis

- Amphoropsyche

\section{Ordem EPHEMEROPTERA}

\section{Fam. Baetidae}

- Americabaetis

- Camelobaetidius

- Paracloeodes

Fam. Leptohyphidae

- Tricorythopsys

- Tricorythodes

- Traverhyphes

Fam. Ephemeridae

Serão considerados também, se identificados, os gêneros abaixo da linha de corte que apresentaram ocorrência significativa apenas em amostragens qualitativas, bem como aqueles abaixo da linha de corte que possam ter sido expressivos no mesmo tipo de amostragem. 
O grupo que mais se destaca na Tabela VIII é formado pelos gêneros Americabaetis, Paracloeodes, integrantes da família Baetidae, Trycorythopsis (fam. Leptohyphidae), e os gêneros Smicridea e Hidroptila, pertencentes às famílias Hydropsychidae e Hydroptilidae, respectivamente. Suas densidades mais elevadas foram observadas no ponto 2, primeira e segunda campanhas.

A partir dos gráficos obtidos pela Análise de Componente Principal (figs. 7 e 8), verificamos que o ponto 2 , na primeira campanha apresenta boas condições ambientais, sendo negativamente correlacionado com COD, condutividade, sólidos totais e voláteis, enfim, não está associado às variáveis relacionadas a enriquecimento orgânico. Os parâmetros que mais estão correlacionados ao ponto são o oxigênio dissolvido, o qual realmente é elevado em ambas as campanhas, a velocidade da correnteza e o nitrogênio orgânico. Conforme já apontado anteriormente, a fonte mais provável de nitrogênio orgânico é o trutário a localizado a montante do ponto 1, o qual pode estar contribuindo com restos de alimento e excretas de peixes que seguem rio abaixo.

A influência do trutário sobre a qualidade das águas nos pontos 1 e 2 , é mais evidente na segunda campanha. Naquele período, as variáveis mais correlacionadas ao ponto 2 foram nitrogênio amoniacal, ortofosfato, nitrato e clorofila. Na primeira campanha de amostragem foi observada toxicidade crônica na água. O sedimento no local é arenoso.

O gênero Americabaetis também ocorre nos demais pontos de amostragem, inclusive em coletas qualitativas com rede sobre macrófitas. Seus registros estão mais associados a ambientes com maior fluxo, como margem erosional ou canal.

Paracloeodes ocorre de forma mais concentrada nos ponto 2, em ambas as campanhas. No baixo gradiente é registrado apenas no ponto 7, sobre macrófitas, contudo, com poucos exemplares coletados. Em um estudo referente ao papel da deriva na distribuição da comunidade bentônica, em um rio da bacia do Paraná, GUALDONI e CORIGLIANO (2002) verificaram a ocorrência de Paracloeodes em ambientes de substrato arenoso, em rios de ordem elevada, portanto velocidade de corrente mais baixa e bastante degradados pela descarga de efluentes. Já GOULART e CALLISTO (2005) verificaram que Paracloeodes ocorreu na maioria dos substratos amostrados em seu trabalho em rios de cabeceira, desde sobre camada de folhiço sobre o leito do rio até areia, e em menor proporção sobre o sedimento mais fino. O aumento das frações mais finas no sedimento, nos pontos de baixo gradiente pode ser o fator limitante da 
ocorrência do gênero naqueles locais, visto que aparentemente é tolerante à níveis de poluição mais elevados que aqueles verificado no ponto 2.

Tricorythopsis ocorreu tanto no alto como no baixo-gradiente, principalmente na primeira campanha. Suas maiores densidades foram observadas nos pontos 2 e 5, primeira e segunda campanhas, respectivamente. No baixo-gradiente, foram observados apenas sobre macrófitas. No altogradiente, esteve associado somente a ambiente de maior velocidade (canal e margem erosional). GOULART e CALLISTO (2005) obtiveram a maior densidade de Tricorythopsis ( $87 \%$ ) sobre substrato com uma fina cobertura vegetal. A maioria dos Baetidae apesenta hábitos fragmentador, pastador e coletor. Assim como Paracloeodes e diferentemente de Americabaetis, no presente estudo, o referido gênero esteve associado ao alto-gradiente e suas características.

Também do mesmo grupo, o gênero Smicridea ocorreu apenas no ponto 2, primeira campanha. Assim como os demais, as ocorrências do gênero no baixo gradiente estão associadas à macrófitas e com baixa expressividade. Segundo WIGGINS (1998), a família Hydropsychidae é dominante dentre os Trichoptera em âmbito mundial. Os gêneros da família Hydropsychidae têm hábito filtrador, capturando as partículas por meio de uma rede confeccionada que submetem à correnteza. Em função desse hábito, são associados a concentrações mais elevadas de material em suspensão. Sua maior densidade foi observada no período chuvoso, mais favorável ao aumento de sólidos em suspensão.

O gênero Hydroptila apresentou maior densidade no ponto 2, ocorrendo também nas demais localidades e registrado também no ponto 3, sobre macrófitas. O gênero alimenta-se de algas unicelurares, filamentosas e diatomáceas (ANGRISANO \& KOROB, 2001, WIGGINS, 1998,). As correlação positiva entre o ponto 2 e as concentrações de nitrato e clorofila podem estar associadas à ocorrência do gênero, que tem hábito raspador/pastador.

O gênero Camelobaetidius foi exclusivo do ponto 2, primeira campanha. Sua ocorrência no ponto 4, na primeira e segunda campanhas corresponde a coleta de um único exemplar, em cada localidade por meio de amostragem qualitativa.

Integrante do mesmo grupo de Camelobaetidius, o gênero Oxyethira (fam. Hydroptilidae) também teve ocorrência restrita à primeira campanha. Segundo WIGGINS (1998), têm hábito raspador/pastador e preferencialmente habitam águas de menor velocidade de corrente. Foram amostrados sobre macrófitas, em detritos encalhados e no canal do rio Atibainha. Este último habitat, onde foi 
registrado com a maior densidade (ver planilhas no Anexo), é oposto à condição preferencial descrita na bibliografia.

A partir da Análise de Componente Principal, verifica-se que as variáveis mais correlacionadas com o ponto 1 são as mesmas apontadas para o ponto 2 , visto que estão próximos no gráfico, dentro de um mesmo quadrante. Contudo, verifica-se que as concentrações de nitrogênio amoniacal são superiores àquelas observadas no ponto 2. Foi observada toxicidade crônica no ponto 1, na primeira campanha apenas, contudo o efeito observado não pode ser atribuído exclusivamente ao nitrogênio amoniacal.

No ponto 1, a dominância é do gênero Leptonema (fam. Hydropsychidae), o qual corresponde a mais de $95 \%$ dos organismos coletados naquele local. Assim como Smicridea, dominante no ponto 2, pertencem a uma família caracteristicamente tolerante a níveis mais elevados de poluição. BAPTISTA et al. (1998) verificaram a preferência de Leptonema por depósitos de folhiço, equivalente ao habitat denominado "detritos", no presente estudo. Nesse mesmo tipo de habitat, e sob correnteza mais forte, HUAMANTINCO e NESSIMIAN (2000) verificaram a maior densidade de Smicridea, em um tributário do rio Paquequer, estado do Rio de Janeiro. Consultando os dados qualitativos, verifica-se que o gênero ocorre em detritos encalhados, no entanto sua ocorrência não é restrita a este habitat, sendo verificado também no canal e margem erosional do rio Atibainha. O baixo teor de sólidos voláteis obtido para o sedimento nestas localidades (fig. 4) sugere que este é composto essencialmente por areia, com pouca concentração de matéria orgânica, a qual poderia corresponder a restos de folhas. Portanto Leptonema, neste caso, não reproduz a preferência por detritos como tipo de substrato.

Os gêneros Smicridea e Leptonema, como apresentados, foram essencialmente restritos aos pontos 1 e 2 . Todavia, a família Hydropsychidae tem ampla distribuição e é muito abundante em rios de variadas características (HUAMANTINCO \& NESSIMIAN, 1999; VUORI \& KUKKONEN, 1996) e, de modo geral, associada a cargas moderadas de material particulado em suspensão (MACKAY, 1986).

ROBACK (1962), em uma avaliação da sensibilidade de gêneros da ordem Trichoptera, constatou que a restrição ambiental, com relação ao nitrogênio amoniacal dá-se em concentrações superiores a $1 \mathrm{mg} / \mathrm{L}$. Em concentração entre 10 e $20 \mathrm{mg} / \mathrm{L}$ somente foram tolerantes dois gêneros da família Hydropsychidae e um gênero da família Leptoceridae. O autor verificou ainda sensibilidade de 
Trichoptera ao íon nitrato, com significativa redução da riqueza da ordem em concentrações superiores a $0,5 \mathrm{mg} / \mathrm{L}$.

A elevada densidade dos gêneros Smicridea e Leptonema pode estar associada à carga de matéria orgânica em suspensão proveniente do criadouro de trutas. Segundo GoWEN et al. (1991 apud LOCH et al., 1996), aproximadamente $10 \%$ da massa adicionada ao sistema de criação na forma de alimento tem como destino final o efluente do criadouro.

Os Ephemeroptera Tricorythodes e Traverhyphes (fam. Leptohyphidae) ocorreram principalmente na segunda campanha, correspondente à estiagem tanto no alto como no baixo-gradiente, e nos habitats margem erosional, deposicional e canal. Esta distribuição mais ampla pode estar associada à pouca preferência um tipo específico de substrato (SALLES et al., 2004), como foi mencionado também por BAPTISTA et al. (1998), que verificaram a ocorrência do gênero Tricorythodes em trechos do rio de $4^{\underline{a}}$ a $6^{\underline{a}}$ ordens.

Hexagenia (Ephemeroptera, fam. Ephemeridae), esteve mais associado ao baixo-gradiente. O gênero tem hábito natatorial e é também encontrado em ambientes lênticos (LEONARD, 1962). A maior densidade observada no ponto 5 pode estar associada às velocidades mais baixas da corrente, pois neste ponto verificou-se a menor velocidade dentre os demais na segunda campanha. A ocorrência nos pontos 6 e 7 corrobora a velocidade como variável que influencia a distribuição do gênero.

Os pontos 6 e 7 estão mais associados a concentrações de nutrientes (principalmente fósforo total), COD, turbidez coliformes e demais indicadores de poluição do que os pontos de alto gradiente, e menores concentrações de oxigênio comparativamente (figs. 3, 7 e 8), revelando, portanto, a tolerância do gênero à poluição.

Semelhante preferência por pontos no baixo-gradiente foi observada nos gêneros Cyrnellus (Polycentropodidae) e Amphoropsyche (Leptoceridae). Os gêneros de Polycentropodidae e Leptoceridae têm por habito a construção de abrigos de seda, no caso de Polycentropodidade, ou de diversos materiais como areia, tecido vegetal, material particulado, etc., comuns a Leptoceridae. Ambas as famílias tem preferência por locais de menor velocidade de corrente. A maioria das larvas de Poycentropodidae é predadora, ocorrendo algumas espécies com hábito filtrador (WIGGINS, 1998). Segundo o mesmo autor, a análise do conteúdo de Cyrnellus revelou a presença de material particulado fino e restos de outros artrópodes. Os gêneros pertencentes à família Leptoceridae 
são essencialmente onívoros. No rio Peixe, MG, Cyrnellus foi registrado em trecho de rio moderadamente perturbado, composto por cascalho e depósitos de sedimento fino (GALDEAN et al., 2001).

Os gêneros Nectopsyche, Oecetis (ambos pertencentes à família Leptoceridae) e Neotrichia (Hydroptilidae), apresentaram hábito bastante generalista, ocorrendo na maioria dos locais amostrados, sem preferência por habitat. Diferentemente do que foi aqui observado, CRISCI-BISPO e outros (2004) e HUAMANTINCO e NESSIMIAN (2000) verificaram que Nectopsyche e Oecetis habitaram preferencialmente o ambiente de corredeira, em um riacho da Serra do Mar, tendo presença pouco expressiva nas zonas com menor velocidade de corrente.

Em termos de hábito alimentar, de modo geral Leptoceridae é onívoro e Hidroptilidae alimenta-se do conteúdo das algas, conforme já citado. O gênero Oecetis é morfologicamente adaptado ao hábito predador (ANGRISANO \& KOROB, 2001). Contudo, o grupo alimentar de Neotrichia ainda não foi definido (NEIFF et al., 1997). À medida que a ordem do rio aumenta, a tendência é o predomínio de espécies coletoras, filtradoras e carnívoras, sendo este último grupo o de menor representatividade. Portanto o que se verifica nos pontos de baixo-gradiente, em termos de hábitos alimentares, está coerente com o esperado.

A ocorrência desses gêneros nos pontos de baixo-gradiente, de hábito bastante generalista, sugere que os mesmos possuem tolerância às condições ambientais instaladas naquelas localidades, já citadas anteriormente, principalmente com referência aos pontos 7 e 8 , impossibilitando seu emprego como indicadores.

Dentre os gêneros com ocorrência registrada apenas qualitativamente, foi mais expressiva a ocorrência de Aturbina (Ephemeroptera - Baetidae), o qual foi registrado em praticamente todos os pontos de coleta, sobre macrófitas, principalmente. Em função disto, não é possível associar sua preferência quanto à granulometria do sedimento ou qualidade de habitat.

Segundo ALLAN (1995 apud GoulART \& CALLISTO, 2005) o substrato é o principal fator determinante do padrão de distribuição de invertebrados bentônicos ao longo de um rio. Em seu estudo, os autores também concluem que os principais fatores associados a distribuição de Baetidae nos rios estudados foram o histórico de ocupação da bacia, os padrões de uso e ocupação do solo e características do ambiente, como o tipo de substrato. HUAMANTINCO E NESSIMIAN (1999) apontam ainda a velocidade da correnteza como um segundo fator, a 
qual tem forte influência sobre o nível de oxigênio dissolvido no meio e sobre a qualidade do material disponível como alimento (tamanho de pacotes de folha e de partículas).

Pelo observado, os gêneros que mais se destacaram em termos de abundância têm hábitos mais generalistas e são relativamente tolerantes à poluição. Contudo, exibiram uma distribuição ao longo do gradiente que não é condizente com sua tolerância. Tal fato sugere que fatores como velocidade da corrente, tipo de substrato e disponibilidade de alimento são, juntamente com as condições físicas e químicas, igualmente importantes na definição do padrão de distribuição desses organismos.

Resultados mais conclusivos poderiam ter sido obtidos se o gradiente de poluição fosse mais drástico, selecionando-se pontos de baixo gradiente mais impactados e, portanto, mais restritivo.

A possibilidade de associação de determinados gêneros potencialmente existentes nestes locais estaria condicionada, talvez, a um conjunto de amostragens temporalmente regulares, com tomada de amostras quali e quantitativas, explorando-se a maior variedade possível de habitas. 


\section{CONCLUSÕES}

1. No corpo de água estudado, existe um gradiente ambiental entre os pontos 1 e 8 , evidenciado a partir do resultado da Análise de Componente Principal, no qual verifica-se o aumento da concentração nas variáveis relacionadas à poluição. No entanto, os pontos 1 e 2 sofrem interferência do criadouro de trutas situado a montante, principalmente dos parâmetros associados à carga de nutrientes.

2. O índice EPT, em nível de gênero respondeu satisfatoriamente ao gradiente ambiental estabelecido, sendo sensível, inclusive, às influências do trutário localizado a montante do ponto 1 .

3. O índice EPT, em nível de família também respondeu satisfatoriamente ao gradiente ambiental, portanto, a adoção deste nível taxonômico, em programas de biomonitoramento é recomendado, em função da demanda de tempo e das dificuldades inerentes à identificação dos exemplares em nível de gênero.

4. Não foi possível associar a ocorrência de gêneros em particular a condições ambientais específicas, pois os gêneros que apresentaram ocorrência restrita a determinadas localidades (característica de potencial bioindicador) são reconhecidamente, de acordo com a literatura, relativamente tolerantes a perturbações ambientais. Resultados mais representativos podem ser obtidos com a implantação de um programa regular de amostragem, visando buscar os fatores, além das condições ambientais, que determinam a distribuição dos organismos naquelas localidades.

\section{RECOMENDAÇÕES}

1. Em função da demanda de tempo e da dificuldade inerente à identificação dos exemplares em nível de gênero, recomenda-se empregar o índice EPT em nível de família em programas de biomonitoramento, pois este respondeu satisfatoriamente.

2. Implantar um programa regular de amostragem que investigue outros fatores associados à distribuição e abundância dos organismos bentônicos, além da poluição, para que se possa selecionar táxons indicadores de condições ambientais específicas. 


\section{REFERÊNCIAS BIBLIOGRÁFICAS}

AGOSTINHO, A.A.; VAZOLER, A.E.A.M. \& THOMAZ, S.M. 1995 The high river Paraná basin: limnological and ichthyological aspects. In: TUNDISI, J.G.; BICUDO, C.E.M. \& TUNDISI, T.M. (eds) Limnology in Brazil. Rio de Janeiro, ABC/SBL. p.59-104.

ANGRISANO, E.B. \& KOROB, P.G. 2001 Trichoptera. In: FERNÁNDEZ, H.R. \& DOMÍNGUEZ, E. (eds) Guía para la determinación de los artrópodos bentónicos sudamericanos. Serie Investigaciones de la UNT. volume I. Tucumán, EdUNT. p. 55-92.

APHA 1995 Standard Methods for the examination of water and wastewater. Washington, American Public Health Association/AWWA/WEF. $19^{\text {a }}$ ed.

ARAGÃO, M.A.; BURATINI, S.V. \& BERTOLETTI, E. 2003 Total hardness of surface waters in São Paulo state (Brazil). Acta Limnol. Bras. 15(1):1518.

ARAUJO, R.P.A. 1998 Avaliação da toxicidadede sedimentos ao anfípodo de água doce Hyalella meinerti Stebbing, 1899 (Crustacea, Amphioda). Dissertação (Mestrado - Ecologia), São Paulo, Instituto de Biociências, USP. 184p.

ASTM 1988 Proposed standard guide for conducting solid-phase sediment toxicity tests with freshwater invertebrates. Philadelphia, American Society for Testing and Materials. 51 p.+ anexos. (Draft $\mathrm{n} 02$, 09/01/1988).

BALLOCH, D.; DAVIES, C.E. \& JONES, F.H. 1976 Biological assessment of water quality in three British rivers: the North Esk (Scotland), The Ivel (England) and the Taf (Wales). Wat. Pollut. Control 75(1):92-114.

BAPTISTA, DF.; DORVILLE, F.F.M.; BUSS, D.F., NESSIMIAN, J.L. \& SOARES, L.H.J. 1998 Distribuição de comunidades de insetos aquáticos no gradiente longitudinal de uma bacia fluvial do sudeste brasileiro. In: ESTEVES, F.A. (ed) Ecologia de insetos aquáticos. Series Oecologia Brasiliensis. volume V. PPGE-UFRJ, p. 191-207. 
BARBOUR, M.T.; GERRITSEN, J.; SNYDER; B.D.; STRIBLING, J.B. 1999 Rapid bioassessment protocols for use in streams and wadeable rivers: periphyton, benthic macroinvertebrates and fish. Washington, U.S. Enviromental Protection Agency. $2^{\mathrm{a}}$ ed. (U.S.EPA 841-B-99-002)

BARGOS, T.; JESUS, M.M.; BASAGUREN, A. \& ORIVE, E. 1990 Assessing river water quality by means of multifactorial methods using macroinvertebrates. A comparative study of main water courses of Biscay. Wat. Res. 24(1):110.

BAUDO, R. 2001 Biological monitoring of aquatic ecosystems in Italy. J. Limnol. 60:49-52.

BAUMGARDNER, D.E.; BURIAN, S.K. \& BASS, D. 2003 Life stage descriptions, taxonomic notes, and new records for the mayfly Leptohyphidae (Ephemeroptera). Zootaxa 332:1-12.

BENSON, L.J. \& PEARSON, R.G. 1987 The role of drift and effect of season on macroinvertebrate colonization of implanted substrata in a tropical Australian stream. Freshwat. Biol. 18:109-116.

BISPO, P.C; FROEHLICH, C. G; \& OLIVEIRA, L. G. 2002 Spatial distribution of Plecoptera nymphs in streams of a mountainous area of central Brazil. Braz. J. Biol. 62(3): 409-417.

BISPO, P.C.; OLIVEIRA, L.G.; CRISCI, V.L. \& SILVA, M.M. 2001 A pluviosidade como fator de alteração da entomofauna bentônica (Ephemeroptera, Plecoptera e Trichoptera) em córregos do Planalto Central do Brasil. Acta Limnol. Bras. 13(2):1-9.

BISPO, P.C. \& OLIVEIRA, L.G. 1998 Distribuição espacial de insetos aquáticos (Ephemeroptera, Plecoptera e Trichoptera) em córregos do cerrado do Parque ecológico de Goiânia, Estado de Goiás. In: NESSIMIAM, J.L. \& CARVALHO, A.L. (ed). Ecologia de insetos aquáticos. Series Oecologia brasiliensis, volume V. PPGE-UFRJ, p.175-190.

BONADA, N.; PRAT, N.; RESH, V.H. \& STATZNER, B. 2006 Developments in aquatic insect biomonitoring: A comparative analysis of recent approaches.

Annu. Rev. Entomol. 51:495-523 
BORROR, D.J. \& DE LONG, D.M. 1988 I ntrodução ao Estudo dos I nsetos. São Paulo Edusp 653p.

BRANDIMARTE, A.L. \& ANAYA, M. 1995 Flotation of bottom fauna using chloride solution. I n: Congress of International Association of theoretical and applied limnology, 26; São Paulo, 1995. Abstracts. São Paulo, International Association of theoretical and applied limnology. p.227.

BRANDIMARTE, A.L.; SHIMIZU, G.Y.; ANAYA, M. \& KUHLMANN 2004 Amostragem de invertebrados bentônicos. In: BICUDO, C.E.M. \& BICUDO, D.C (eds) Amostragem em limnologia. São Carlos, RIMA Editora. p. 213230.

BUSS, D.F.; BAPTISTA, D.F.; NESSIMIAN, J.L. \& EGLER, M 2004 Substrate specificity, environmental degradation and disturbance structuring macroinvertebrate assemblages in neotropical streams. Hydrobiologia 518:179-188.

BUTCHER, J.T.; STEWART, P.M. \& SIMON, T.P. 2003 A benthic community index for streams in the Northern lakes and forests ecoregion. Ecological Indicators 3:181-193.

CALLISTO, M. \& ESTEVES, F. A. 1995 Distribuição da comunidade de macroinvertebrados bentônicos em um lago amazônico impactado por rejeito de bauxita, Lago Batata (Pará, Brasil). In: ESTEVES, F.A. (ed.) Estrutura, Funcionamento e Manejo de Ecossistemas Brasileiros. Series Oecologia Brasiliensis. volume I. PPGE-UFRJ, p.281-291.

CARLISLE, D.M. \& CLEMENTS, W.H. 1999 Sensitivity and variability of metrics used in biological assessments. of running waters Environmental Toxicology and Chemistry 18(2):285-291.

CETESB 1988 Guia de coleta e preservação de amostras de águas. São Paulo, Companhia de Tecnologia de Saneamento Ambiental. 150p.

CETESB 1989a Determinação de cádmio nas águas: método de espectrofotometria de absorção atômica. São Paulo, Companhia de Tecnologia de Saneamento Ambiental. 11p. (Norma Técnica L5.160). 
CETESB 1989b Determinação de chumbo nas águas: método de espectrofotometria de absorção atômica. São Paulo, Companhia de Tecnologia de Saneamento Ambiental. 11p. (Norma Técnica L5.116).

CETESB 1989c Determinação de cobre nas águas: método de espectrofotometria de absorção atômica. São Paulo, Companhia de Tecnologia de Saneamento Ambiental. 11p. (Norma Técnica L5.116).

CETESB 1989a Determinação de zinco nas águas: método de espectrofotometria de absorção atômica. São Paulo, Companhia de Tecnologia de Saneamento Ambiental. 11p. (Norma Técnica L5.158).

CETESB 1990a Determinação de cromo nas águas: método de espectrofotometria de absorção atômica. São Paulo, Companhia de Tecnologia de Saneamento Ambiental. 9p. (Norma Técnica L5.193).

CETESB 1990b Determinação de níquel nas águas: método de espectrofotometria de absorção atômica. São Paulo, Companhia de Tecnologia de Saneamento Ambiental. 11p. (Norma Técnica L5.135).

CETESB 1990c Determinação de pigmentos fotossintetizantes: Clorofilaa, b e c e feofitina-a. São Paulo, Companhia de Tecnologia de Saneamento Ambiental. 19p. (Norma Técnica L5.306).

CETESB 1991 Água. Avaliação de toxicidade crônica utilizando Ceriodaphnia dubia Richard 1894 (Cladocera- Crustacea). São Paulo, Companhia de Tecnologia de Saneamento Ambiental.. 25p. (Norma Técnica L5.022).

CETESB 1992 Coliformes fecais: determinação em amostras de água pela técnica de tubos múltiplos com meio A1 - método de ensaio. São Paulo, Companhia de Tecnologia de Saneamento Ambiental. 20p. (Norma Técnica L5.406).

CETESB 1992a Implementação de testes de toxicidade no controle de efluentes líquidos. São Paulo: CETESB, Série Manuais. 7p.

CETESB 1995 Sedimentos - determinação da distribuição granulométrica. São Paulo, Companhia de Tecnologia de Saneamento Ambiental. 15p. (Norma Técnica L6.160). 
CETESB. 1998 Relatório de Qualidade das Águas Interiores do Estado de São Paulo - 1996. São Paulo, Companhia de Tecnologia de Saneamento Ambiental. 268p. (Série Relatórios).

CETESB/DE IB-USP 2000 Uso de índices biológicos no biomonitoramento de ambientes aquáticos continentais - riachos e corredeiras na bacia hidrográfica do rio Atibaia. São Paulo, Companhia de Tecnologia de Saneamento Ambiental. 112p. (no prelo).

CETESB Relatório Uso de índices biológicos no biomonitoramento de ambientes aquáticos continentais - riachos e corredeiras na bacia hidrográfica do rio Atibaia. Fase II. São Paulo, Companhia de Tecnologia de Saneamento Ambiental. (no prelo).

CHACÓN, M.M. \& SEGNINI, S. 1996 Reconocimiento taxonomico de las nayades del orden Ephemeroptera en la deriva de dos rios de alta montaña en el estado Merida, Venezuela. Bol. Entomol. Venez. 11(2):103-122.

CHAPMAN, P. M.; WANG, F; JANSSEN, C.R.; GOULET, R.R. \& KAMUNDE, C.N. 2003 Conducting ecological risk assessments of inorganic metals and metalloids: current status. Human and Ecological Risk Assessment. $9(4): 641-697$.

CLEMENTS, W.H. 1999 Metal tolerance and predator-prey interactions in benthic macroinvertebrates stream communities. Ecological Applications $9(3): 1073-1084$.

COMPIM, A. \& CÉRÉGHINO, R. 2003 Sensitivity of aquatic insect species richness to disturbance in the Adour-Garonne stream system (France). Ecological Indicators 3:135-142.

CRISCI-BISPO, V.L.; BISPO, P.C. \& FROEHLICH , C.G. 2004 Triplectides larvae in empty cases of Nectopsyche (Trichoptera, Leptoceridae) at Parque Estadual Intervales, São Paulo State, Brazil. Revista Brasileira de Entomologia 48(1): 133-134,

CUNHA-SANTINO, M.B. \& BIANCINI-JÚNIOR, I. 2004 Humic substances mineralization: the variation of $\mathrm{pH}$, electrical conductivity and optical density. Acta Liminol. Bras. 16(1):63-75. 
DAHL, J. 2004 Detection of human-induced stress in streams: comparison of bioassessment approaches using macroinvertebrates. Tese (Doutorado), Uppsala, Swedish University of Agricultural Sciences. 43p.

DANIEL, M.H.B.; MONTEBELO, A.A.; BERNARDES, M.C.; OMETTO, J.P.H.B.; CAMARGO, P.B.; KRUSCHE, A.V.; BALLESTER, M.V.; VICTORIA, R.L. \& MARTINELLI, L.A. 2002 Effects of urban sewage on dissolved oxygen, dissolved inorganic and organic carbon, and electrical conductivity of small streams along a gradient of urbanization in the Piracicaba river basin. Water, Air, and Soil Pollution 136:189-206.

DA-SILVA, E.R. 1998 Estratégias de adaptação das espécies de Ephemeroptera às condições ambientais da restinga de Maricá, Estado do Rio de Janeiro In: NESSIMIAM, J.L.. \& CARVALHO, A.L. (eds). Ecologia de insetos aquáticos. Series Oecologia brasiliensis, volume V. PPGE-UFRJ, p.29-40.

DEL GRANDE, M.; REZENDE, M.O.O. \& ROCHA, O. 2003 Distribuição de compostos organoclorados nas águas e sedimentos da bacia do rio Piracicaba/SP - Brasil. Quim. Nova 26(5):678-686.

DIAZ R.J. \& ERSÉUS, C. 1994 Habitat preferences and species associations of shallow-water marine Tubificidae (Oligochaeta) from the barrier reef ecosystems off Belize, Central America Hydrobiologia 278(1):93-105

DICKSON, K.L.; CAIRNS Jr, J. \& ARNOLD, J.C. 1971 An evaluation of the use of a basket type artificial substrate for sampling macroinvertebrate organisms. Trans. Am. Fish. Soc. 100(3):553-559.

DOMÍNGUEZ, E; HUBBARD, M.D.; PESCADOR, M.L. \& MOLINERI, C. 2001 Ephemeroptera. In: Fernández, H.R. \& Domínguez, E. (eds) Guía para la determinación de los artrópodos bentónicos sudamericanos. Serie Investigaciones de la UNT. volume I. Tucumán, EdUNT. p.55-92.

EDMUNDS, G.F.Jr. 1984 Ephemeroptera. In: MERRITT, R.W.; CUMMINS, K.W. (eds) An introduction to the aquatic insects of North America. Dubuque, Kendall/Hunt Publ. p.94-125. $2^{\mathrm{a}}$ ed. 
EGLER, M. 2002 Utilizando a Comunidade de Macroinvertebrados Bentônicos na Avaliação da Degradação de Ecossistemas de Rios em Áreas Agrícolas. Dissertação (Mestrado - Saúde Pública), Rio de Janeiro Fundação Oswaldo Cruz. 116p.

ESTEVES, F.A. 1988 Fundamentos de Limnologia. Rio de Janeiro, Interciência/Finep. 575p.

FAVARO, P.C.; DE NADAI FERNANDES, E.A.; FERRAZ, E.S.B. \& FALÓTICO, M.H.B. 2004 Time still to restore the polluted Piracicaba river basin. Journal of Radioanalytical and Nuclear Chemistry 259(2):217-221.

FERREIRA-PERUQUETTI, P.S. \& FONSECA-GESSNER, A. A. 2003 A comunidade de Odonata (Insecta) em áreas naturais de cerrado e monocultura no nordeste do Estado de São Paulo, Brasil: relação entre o uso do solo e a riqueza faunística. Revista Brasileira de Zoologia 20(2):219-224.

FLINT, O; HOLZENTHAL, R.W \& HARRIS, S.C. 1999 Nomenclatural and systematic changes in the Neotropical caddsflies (Insecta: Trichoptera). Insecta Mundi 13(1-2):73-84.

FROEHLICH, C.G. 1999 Insetos Plecópteros. In: JOLY, C.A.\& BICUDO, C.E.M., O. (eds) Biodiversidade do Estado de São Paulo, Brasil: síntese do conhecimento ao final do século $\mathbf{X X}$. volume 4: Invertebrados de água doce. São Paulo, FAPESP 176p.

FROEHLICH, C.G. 1999a Outros insetos. In: JOLY, C.A.\& BICUDO, C.E.M., O. (eds) Biodiversidade do Estado de São Paulo, Brasil: síntese do conhecimento ao final do século $\mathbf{X X}$. volume 4: Invertebrados de água doce. São Paulo, FAPESP 176p.

GALDEAN, N.; CALLISTO, M. \& BARBOSA, F.A.R. 2001 Biodiversity assessment of benthic macroinvertebrates in altitudinal lotic ecosystems of Serra do Cipó (MG, Brazil). Rev. Brasil. Biol. 61(2):239-248.

GOULART, M. \& CALLISTO, M. 2005 Mayfly Diversity in the Brazilian Tropical Headwaters of Serra do Cipó. Brazilian Archives of Biology and Technlogy 48(6):983-996. 
GUAHYBA, R.R. 1988 Contribuição ao estudo das formas imaturas da ordem Trichoptera Kirby, 1813, da Represa dos Ciganos, RJ (Insecta). Acta Limnol. Bras. 2:751-769.

GUALDONI, C.M. \& CORIGLIANO, M.C. 2002 Distribución del bentos y la deriva de macroinvertebrados em tramos fluviales con diferentes condiciones de estres ambiental. Acta Liminol. Bras. 14(1):1-13.

HARPER, P.P. \& STEWART, K.W. 1984 Plecoptera. In: MERRITT, R.W.; CUMMINS, K.W. (eds) An introduction to the aquatic insects of North America. Dubuque, Kendall/Hunt Publ. p.182-225 $2^{\mathrm{a}}$ ed.

HELIÖVAARA, K. \& VÄISÄNEN, R. 1993 Insects and pollution. Boca Raton, CRC Press, Inc. 393p.

HICKEY, C.W. \& CLEMENTS, W.H. 1998 Effects of heavy metals on benthic macroinvertebrates communities in New Zealand streams. Environmental Toxicology and Chemistry 17(11):2238-2346.

HYNES, H.B.N. 1970 The ecology of running waters. Liverpool, Liverpool Univerity Press. 555p.

JOHNSON, R.K.; WIEDERHOLM, T. \& ROSENBERG, D.M. 1993 Freshwater biomonitoring using individual organisms, populations and species assemblages of benthic macroinvertebrates. In: ROSENBERG, D.M. \& RESH, V.H (eds) Freshwater biomonitoring and benthic macroinvertebrates substrates. New York, Chapman \& Hall, Inc. p.234-286.

HUAMANTINCO, A.A. \& NESSIMIAN, J.L. 1999 Estrutura e distribuição espacial da comunidade de larvas de Trichoptera (Insecta) em um tributário de primeira ordem do rio Paquequer, Teresópolis, RJ. Acta Limnol. Bras. 11(2):1-16.

HUAMANTINCO, A.A. \& NESSIMIAN, J.L. 2000 Variation and life strategies of the Trichoptera (Insecta) larvae community in a first order tributary of the Paquequer River, Southeastern Brazil. Rev. Brasil. Biol. 60(1):73-82. 
JUNQUEIRA, M.V., AMARANTE, M.C., DIA, C.F.S. \& FRANÇA, E.S. 2000 Biomonitoramento da qualidade das águas da bacia do Alto Rio das Velhas (MG/Brasil) através de macroinvertebrados. Acta Limnol. Bras. 12(1):7387.

LEONARD, J.W. 1962. Environmental requirements of Ephemeroptera. In: Tarzwell, C. M. (ed.), Third Seminar in Biological Problems in Water Pollution. No. 999-WP-25, U.S. Public Health Service, Cincinnati. p.110117.

LOCH, D.D.; WEST, J.L. \& PERLMUTTER, D.G. 1996 The effect of trout farm effluent on the taxa richness of benthic macroinvertebrates. Aquaculture 147:37-55.

LUGO-ORTIZ, C.R. \& McCAFFERTY, W.P. 1996 Taxonomy of the Neotropical genus Americabaetis, new status (Insecta: Ephemeroptera: Baetidae). Stud. Neotrop. Fauna \& Environm. 31:156-169.

MACKAY, R.J 1986 Life cycles of Hydropsiche riola, H. slossonae and Cheumatopsyche pettiti (Trichoptera: Hydropsychidae) in a spring-fed stream in Minnesota. American Midland Naturalist 115(1):19-24.

MACKAY, R.J. \& WIGGINS, G.B. 1979 Ecological diversity in Trichoptera. Ann. Rev. Entomol. 24:185-208.

MANDAVILLE 2002 (http: // lakes.chebucto.org/ZOOBENTH/BENTHOS/ benthos. html)

MARTINELLI, LA, KRUSCHE, A.V.; VICTORIA, R.L.; DE CAMARGO, P.B., BERNARDES, M.; FERRAZ, E.S., DE MORAES, J.M. \& BALLESTER, M.V. 1999 Effects of sewage on the chemical composition of Piracicaba river, Brazil. Water, Air, and Soil Pollution 110: 67-79.

McCABE, D.J. \& GOTELLI, N.J. 2000 Effects of disturbance frequency, intensity, and area on assemblages of stream macroinvertebrates. Oecologia 124:270-279.

MEGURO, M. 2000 Métodos em ecologia vegetal. São Paulo, IB/USP. 118p. 
MERRITT, R.W.; CUMMINS, K.W. (eds) 1996 An introduction to the aquatic insects of North America. Dubuque, Kendall/Hunt Publ. 862p. $3^{\mathrm{a}}$ ed.

METCALFE, J. 1989 Biological water quality assessment of running waters based on macroinvertebrate communities: history and present status in Europe. Environ. Pollut. 60: 101-139.

MOLINERI, C. 1999 Revision of the genus Tricorythopsis (Ephemeropter: Leptohyphidae) with description of four new species. Aquatic Insects 21: 285-300.

MOLINERI, C. 2003 Revision of the South American species of Leptohyphes Eaton (Ephemeroptera: Leptohyphidae) with a key to the nymphs. Stud. Neotrop. Fauna and Environm. 38(1):47-70.

MOULTON, T.P. 1998 Saúde e integridade do ecossistema e o papel dos insetos aquáticos. In: NESSIMIAM, J.L.. \& CARVALHO, A.L. (eds) Ecologia de insetos aquáticos. Series Oecologia brasiliensis, volume V. PPGE-UFRJ, p.281- 298 .

NEIFF, A.P \& CARIGNAN, R. 1997 Macroinvertebrates on Eichhornia crassipes roots in two lakes of the Paraná river floodplain. Hydrobiologia 345: 185196.

NELSON, S. M., ROLINE, R.A, THULLEN, J.S., SARTORIS, J.J. \& BOUTWELL,J.E. 2000 Invertebrate assemblages and trace element bioaccumulation associated with constructed wetlands. Wetlands 20(2):406-415.

NIEMI, G.J. \& McDONALD, M.E. 2004 Application of ecological indicators. Annu. Rev. Ecol. Syst. 35:89-111.

NIMER, E. 1989 Climatologia do Brasil. Rio de Janeiro, IBGE. 422p.

NORRIS, R.H. \& GEORGES, A. 1993 Analysis and interpretation of benthic macroinvertebrate surveys. In: ROSENBERG, D.M. \& RESH, V.H (eds) Freshwater biomonitoring and benthic macroinvertebrates substrates. New York, Chapman \& Hall, Inc. p.234-286. 
OLIFIERS, M.H.; DORVILLÉ, L.F.M; NESSIMIAN, J.L. \& HAMADA, N. 2004 A key to Brazilian genera of Plecoptera (Insecta) based on nymphs. Zootaxa $651: 1-15$.

OLIVEIRA, L.G.; BISPO, P.C.; CRISCI, V.L. \& SOUSA, K.G. 1999 Distribuições de categorias funcionais alimentares de larvas de Trichoptera (Insecta) em uma região serrana do Brasil Central. Acta Limnol. Bras. 11(2):173-183.

PAYNE, A. I. 1986 The ecology of tropical lakes and rivers. New York, John Wiley \& Sons. 301p.

PENNAK, R.W. 1989 Fresh-water invertebrates of the United States. New York, John Wiley. 628p. $3^{\mathrm{a}} \mathrm{ed}$.

PEREIRA, D. \& DE LUCA, S.J. 2003 Benthic macroinvertebrates and the quality of the hydric resources in Maratá creek basin (Rio Grande so Sul, Brazil). Acta Limnol. Bras. 15(2):57-68.

PÉREZ, G.R. 1988 Guía para el estudio de los macroinvertebrados acuáticos del Departamento de Antioquia. Bogotá, Editorial Presencia. $217 p$.

REICE, S.R.; WOHLENBERG, M. 1993 Monitoring freshwater benthic macroinvertebrates and benthic processes: measures for assessment of ecosystem health. In: ROSENBERG, D.M. \& RESH, V.H (eds) Freshwater biomonitoring and benthic macroinvertebrates. New York, Chapman \& Hall, Inc. p. 287-305.

RESH, V.H. \& JACKSON, J.K. 1992 Rapid assessment approaches to biomonitoring using benthic macroinvertebrates. In: ROSENBERG, D.M. \& RESH, V.H (eds) Freshwater biomonitoring and benthic macroinvertebrates. New York, Chapman \& Hall, Inc. p. 195-233.

ROBACK S. S. 1962. Environmental requirements of Trichoptera. In: Tarzwell, C. M. (ed.), Third Seminar in Biological Problems in Water Pollution. No. 999-WP-25, U.S. Public Health Service, Cincinnati. p.118-126. 
ROMERO, F. 2001 Plecoptera. In: FERNÁNDEZ, H.R. \& DOMÍNGUEZ, E. (eds) Guía para la determinación de los artrópodos bentónicos sudamericanos. Serie Investigaciones de la UNT. volume I. Tucumán, EdUNT. pp. 93-110.

ROSENBERG, D.M. \& RESH, V.H. 1992 Introduction to freshwater biomonitoringand benthic macroinvertebrates. In: ROSENBERG, D.M. \& RESH, V.H (eds) Freshwater biomonitoring and benthic macroinvertebrates. New York, Chapman \& Hall, Inc. p.195-233.

ROSS, J.L.S. \& MOROZ, I.C. 1997 Mapa geomorfológico do estado de Sâo Paulo - escala 1:500.000. São Paulo, Laboratório de Geomorfologia Depto. de Geografia - FFLCH/ USP - Laboratório de Cartografia Geotécnica Geologia Aplicada - IPT/ FAPESP.

SALLES, F.F. \& FRANCISCHETI, C.N. 2004 Cryptonynpha dasilvai sp. nov. (Ephemeroptera: Baetidae) do Brasil. Neotropical Entomology 33(2)213216.

SALLES, F.F.; Da-SILVA, E.; SERRÃO, J.E. \& FRANCISCHETTI, C.N. 2004 Baetidae (Ephemeroptera) na região sudeste do Brasil: novos registros e chave para os gêneros no estágio ninfal. Neotropical Entomology 33(6):725-735.

SALOMÃO, M.S.M.B.; MOLISANI, M.M.; OVALLE, A.R.C., REZENDE, C.E.; LACERDA, L.D. \& CARVALHO, C.E.V. 2001 Particulate heavy metal transport in the lower Paraíba do Sul River basin, southeastern, Brazil. Hydrol. Process. 15:587-593.

SHEPHERD, G.J. 1995 FI TOPAC 1.0 UNICAMP. Campinas. Software de classificação e ordenação.

SILVA, A.M.M. \& SACOMANI, L.B. 2001 Using chemical and physical parameters to define the quality of Pardo River water (Botucatu-SP-Brazil). Wat. Res. 35(6):1609-1616.

SIMÕES, L.B. 2003 A importância das matas ripárias no controle da poluição difusa. In: HENRY, R (ed) Ecótonos nas interfaces dos ecossistemas aquáticos. São Carlos, Rima Editora, p.339-349. 
SMA. 1998 Entre Serras e Águas - Plano de desenvolvimento sustentável para a área de influência da duplicação da rodovia Fernão Dias. Caderno de Subsídios no 4. Relatório de Qualidade Ambiental 1998. 127p.

SMITH, S.L.; MACDONALD,D.D.; KEENLEYSIDE, K.A; INGERSOLL, C.G. \& FIELD, L.J. 1996 A preliminary evaluation of sediment quality assessment values for freshwater ecosystems. J. Great Lakes Res. 22(3):557-564.

SMITH, W.S. \& PETRERE JR., M. 2000 Caracterização limnológica da bacia de drenagem do rio Sorocaba, São Paulo, Brasil. Acta Limnol. Bras. 12(2):15-27.

SWIFT, MC. 2002 Stream ecosystem response to, and recovery from, experimental exposure to selenium. Journal of Aquatic Ecosystem Stress and Recovery 9:159-184.

THORNE, R. St. J. \& WILLIAMS, W.P. 1997 The response of benthic macroinvertebrates to pollution in developing countries: a multimetric system of bioassessment. Freshwat. Biol. 37:671-686.

THORP, J.H.; COVICH, A.P. (eds.) 1991 Ecology and classification of North America freshwater invertebrates. San Diego, Academic Press. 911p.

TOMAZELLI, A.C. \& MARTINELLI, L.A. 2003 Heavy metals in six Brazilian watersheds: levels of contamination in the state of São Paulo. J. Phys. IV 107:1305-1308.

VALENTIN, J.L. 2000 Ecologia numérica. Uma introdução à análise multivariada de dados ecológicos. Rio de Janeiro, Ed. Interciência. $117 p$.

VARIOLI, P.; BARTOLI, M.; GIORDANI, G.; MAGNI, P. \& WELSH, D. 2004 Biogeochemical indicators as tools for assessing sediment quality/vulnerability in transitional aquatic ecosystems. Aquatic Conserv.: Mar.Freshw.Ecosyst. 14:S19 -S29.

VON DER OHE, P.C. \& LIESS, M. 2004 Relative sensitivity distribution of aquatic invertebrates to organic and metal compounds. Environmental Toxicology and Chemistry 23(1):150-156. 
VUORI, K.M. \& KUKKONEN, J. 1996 Metal concentrations in Hydropsyche pellucidula larvae (Trichoptera, Hydropsychidae) in relation to the anal papillae abnormalities and age of exocuticle. Wat. Res. 30(10):2265-2272.

WIEDENBRUG, S.; NOLTE, U. \& WÜRDIG, N. L. 1997 Macrozoobenthos of a coastal lake in southern Brazil Archiv für Hydrobiologie 140(4):533-548

WIERSEMA, N.A. \& McCAFFERTY, W.P. 2000 Generic revision of the North Central American Leptohyphidae (Ephemeroptera: Pannota). Trans. Am. Entomol. Soc. 126(3-4):337-371.

WIGGINS, G.B. 1984 Trichoptera. In: MERRITT, R.W.; CUMMINS, K.W. (eds) An introduction to the aquatic insects of North America. Dubuque, Kendall/Hunt Publ. p.271-347. $2^{\text {a }}$ ed.

WIGGINS, G.B. \& MACKAY, R.J. 1978 Some relationships between systematics and trophic ecology in Neartic aquatic insects, with special reference to Trichoptera. Ecology 59(6):1211-1220.

WIGGINS, G.B. 1998.. Larvae of the North American caddisfly genera (Trichoptera). Toronto, Univ. Toronto Press. 457p. $2^{\mathrm{a}} \mathrm{ed}$.

WILLIAMS, M.R.; FILOSO, S.; MARTINELLI, L.A.; LARA, L.B. \& CAMARGO, P.B.C. 2001 Precipitation and river water chemistry of the Piracicaba River Basin, Southeast Brazil. J. Environ. Qual. 30:967-981.

YAMASHIKI, Y.; NAKAMURA, T.; KUROSAWA, M.; \& AND MATSUI, S. 2006 Ecosystem approach to mitigate impacts of sedimentation on the hydrological cycle and aquatic ecosystem. Hydrol. Process. 20:12731291. 
ANEXOS 


\begin{tabular}{|c|c|c|c|c|}
\hline $\begin{array}{l}\text { PONTO } 1 \\
\text { HÄBITATS } \\
\text { EQUIPAMENTO }\end{array}$ & $\begin{array}{l}\text { DETRITOS (D) } \\
\text { REDE }\end{array}$ & $\begin{array}{l}\text { CANAL (C) } \\
\text { HESS }\end{array}$ & $\begin{array}{l}\text { M. DEP. (DE) } \\
\text { HESS }\end{array}$ & $\begin{array}{l}\text { M. ERO. (ER) } \\
\text { HESS }\end{array}$ \\
\hline \multicolumn{5}{|l|}{$\begin{array}{l}\text { EPHEMEROPTERA } \\
\text { Baetidae }\end{array}$} \\
\hline Americabaetis & 137.00 & 14.73 & 0.00 & 4.91 \\
\hline Aturbina & 2.00 & 0.00 & 0.00 & 0.00 \\
\hline Camelobaetidius & 0.00 & 0.00 & 0.00 & 0.00 \\
\hline Cryptonynpha & 0.00 & 0.00 & 0.00 & 0.00 \\
\hline Iguaira & 0.00 & 0.00 & 0.00 & 0.00 \\
\hline Paracloeodes & 37.00 & 0.00 & 29.46 & 14.73 \\
\hline Waltzophius & 0.00 & 0.00 & 0.00 & 0.00 \\
\hline Zelusia & 0.00 & 0.00 & 0.00 & 0.00 \\
\hline não identificado & 0.00 & 0.00 & 0.00 & 0.00 \\
\hline \multicolumn{5}{|l|}{ Leptohyphidae } \\
\hline Tricorythodes & 0.00 & 0.00 & 0.00 & 0.00 \\
\hline Tricorythopsis & 4.00 & 4.91 & 0.00 & 4.91 \\
\hline Traverhyphes & 0.00 & 0.00 & 0.00 & 0.00 \\
\hline não identificado & 0.00 & 0.00 & 0.00 & 0.00 \\
\hline \multicolumn{5}{|l|}{ Leptophlebiidae } \\
\hline Hylyster & 0.00 & 0.00 & 0.00 & 0.00 \\
\hline Miroculis & 0.00 & 0.00 & 0.00 & 0.00 \\
\hline Farrodes & 0.00 & 0.00 & 0.00 & 0.00 \\
\hline \multirow{2}{*}{\multicolumn{5}{|c|}{ Ephemeridae }} \\
\hline & & & & \\
\hline Hexagenia & 0.00 & 0.00 & 0.00 & 0.00 \\
\hline $\begin{array}{l}\text { Ephemeroptera n.i. } \\
\text { PLECOPTERA }\end{array}$ & \multicolumn{3}{|c|}{ PLECOPTERA } & 0.00 \\
\hline Gripopterygidae & & & 0.00 & 0.00 \\
\hline Grypopteryx & 0.00 & 0.00 & 0.00 & 0.00 \\
\hline Paragrypopteryx & 4.00 & 0.00 & 0.00 & 0.00 \\
\hline Tupiperla & 15.00 & 0.00 & 0.00 & 0.00 \\
\hline \multicolumn{5}{|l|}{ Perlidae } \\
\hline Anacroneuria & 3.00 & 0.00 & 0.00 & 0.00 \\
\hline Kempnyia & 2.00 & 0.00 & 0.00 & 0.00 \\
\hline Plecoptera n.i. & & 0.00 & 0.00 & 0.00 \\
\hline \multicolumn{5}{|l|}{$\begin{array}{l}\text { TRICHOPTERA } \\
\text { Hydrobiosidae }\end{array}$} \\
\hline Atopsyche & 0.00 & 0.00 & 0.00 & 0.00 \\
\hline \multicolumn{5}{|l|}{ Helicopsychidae } \\
\hline $\begin{array}{l}\text { Helicopsyche } \\
\text { Hydropsychidae }\end{array}$ & \multicolumn{3}{|c|}{ Hydropsychidae } & 0.00 \\
\hline Smicridea & 9.00 & 4.91 & 0.00 & 0.00 \\
\hline Leptonema & 426.00 & 49.10 & 230.77 & 623.57 \\
\hline não identificado & 387.00 & 51.56 & 360.89 & 584.29 \\
\hline \multicolumn{5}{|l|}{ Hydroptilidae } \\
\hline Oxyethira & 6.00 & 0.00 & 0.00 & 0.00 \\
\hline aff. Hydroptila & 2.00 & 9.82 & 19.64 & 14.73 \\
\hline Ochotrichia & 0.00 & 0.00 & 0.00 & 0.00 \\
\hline Neotrichia & 3.00 & 0.00 & 0.00 & 0.00 \\
\hline Rhyacopsyche & 0.00 & 0.00 & 0.00 & 0.00 \\
\hline não identificado & 0.00 & 0.00 & 0.00 & 0.00 \\
\hline \multicolumn{5}{|l|}{ Leptoceridae } \\
\hline Amphoropsyche & 0.00 & 0.00 & 0.00 & 0.00 \\
\hline Nectopsyche & 15.00 & 4.91 & 9.82 & 9.82 \\
\hline Oecetis & 1.00 & 0.00 & 0.00 & 0.00 \\
\hline Grumichella & 0.00 & 0.00 & 0.00 & 0.00 \\
\hline não identificado & 1.00 & 0.00 & 0.00 & 0.00 \\
\hline \multicolumn{5}{|l|}{ Sericostomatidae } \\
\hline Grumicha & 0.00 & 0.00 & 0.00 & 0.00 \\
\hline \multicolumn{5}{|l|}{ Policentropodidae } \\
\hline Cernotina & 1.00 & 0.00 & 0.00 & 0.00 \\
\hline Cyrnellus & 0.00 & 0.00 & 0.00 & 0.00 \\
\hline Nyctiophylax & 0.00 & 0.00 & 0.00 & 0.00 \\
\hline Calamoceridae & & & & \\
\hline Phylloicus & 1.00 & 0.00 & 0.00 & 0.00 \\
\hline Glossosomatidae & & & & \\
\hline Mexitrichia & 0.00 & 0.00 & 0.00 & 0.00 \\
\hline Itauara & 0.00 & 0.00 & 0.00 & 0.00 \\
\hline Protoptila & 0.00 & 0.00 & 0.00 & 0.00 \\
\hline Odontoceridae & & & & \\
\hline Barypenthus & 2.00 & 0.00 & 0.00 & 0.00 \\
\hline Trichoptera n.i. & 0.00 & 0.00 & 0.00 & 9.82 \\
\hline
\end{tabular}

Dados quali e quantitativos - $1^{\text {a }}$ campanha 


\begin{tabular}{|c|c|c|c|}
\hline $\begin{array}{l}\text { PONTO } 2 \\
\text { HÁBITATS } \\
\text { EQUIPAMENTO }\end{array}$ & $\begin{array}{l}\text { CANAL (C) } \\
\text { HESS }\end{array}$ & $\begin{array}{c}\text { CORREDEIRA (CO) } \\
\text { HESS }\end{array}$ & $\begin{array}{l}\text { M. DEP. (DE) } \\
\text { HESS }\end{array}$ \\
\hline \multicolumn{4}{|l|}{$\begin{array}{l}\text { EPHEMEROPTERA } \\
\text { Baetidae }\end{array}$} \\
\hline Americabaetis & 957.45 & 68.74 & 0.00 \\
\hline Aturbina & 0.00 & 0.00 & 0.00 \\
\hline Camelobaetidius & 530.28 & 54.01 & 0.00 \\
\hline Cryptonynpha & 14.73 & 0.00 & 0.00 \\
\hline Iguaira & 0.00 & 0.00 & 0.00 \\
\hline Paracloeodes & 147.30 & 0.00 & 4.91 \\
\hline Waltzophius & 0.00 & 0.00 & 0.00 \\
\hline Zelusia & 0.00 & 0.00 & 0.00 \\
\hline não identificado & 0.00 & 0.00 & 0.00 \\
\hline \multicolumn{4}{|l|}{ Leptohyphidae } \\
\hline Tricorythodes & 0.00 & 0.00 & 0.00 \\
\hline Tricorythopsis & 1369.89 & 289.69 & 9.82 \\
\hline Traverhyphes & 58.92 & 0.00 & 0.00 \\
\hline não identificado & 132.57 & 63.83 & 4.91 \\
\hline \multicolumn{4}{|l|}{ Leptophlebiidae } \\
\hline Hylyster & 73.65 & 0.00 & 0.00 \\
\hline Miroculis & 29.46 & 4.91 & 0.00 \\
\hline Farrodes & 0.00 & 0.00 & 0.00 \\
\hline não identificado & 58.92 & 0.00 & 0.00 \\
\hline \multicolumn{4}{|l|}{ Ephemeridae } \\
\hline Ephemeroptera n.i. & 0.00 & 0.00 & 0.00 \\
\hline \multicolumn{4}{|l|}{$\begin{array}{l}\text { PLECOPTERA } \\
\text { Gripopterygidae }\end{array}$} \\
\hline Grypopteryx & 14.73 & 4.91 & 0.00 \\
\hline Paragrypopteryx & 0.00 & 0.00 & 0.00 \\
\hline Tupiperla & 0.00 & 0.00 & 0.00 \\
\hline \multicolumn{4}{|l|}{ Perlidae } \\
\hline Anacroneuria & 0.00 & 0.00 & 0.00 \\
\hline Kempnyia & 0.00 & 0.00 & 0.00 \\
\hline Plecoptera n.i. & 0.00 & 0.00 & 0.00 \\
\hline \multicolumn{4}{|l|}{$\begin{array}{l}\text { TRICHOPTERA } \\
\text { Hydrobiosidae }\end{array}$} \\
\hline \multicolumn{3}{|l|}{ Helicopsychidae } & 0.00 \\
\hline Helicopsyche & 0.00 & 0.00 & 0.00 \\
\hline \multicolumn{4}{|l|}{ Hydropsychidae } \\
\hline Smicridea & 4256.97 & 476.27 & 9.82 \\
\hline Smicridea & 29.46 & 0.00 & 0.00 \\
\hline não identificado & 1090.02 & 44.19 & 0.00 \\
\hline \multicolumn{4}{|l|}{ Hydroptilidae } \\
\hline Oxyethira & 14.73 & 0.00 & 0.00 \\
\hline aff. Hydroptila & 545.01 & 142.39 & 14.73 \\
\hline Ochotrichia & 0.00 & 19.64 & 4.91 \\
\hline Neotrichia & 0.00 & 4.91 & 0.00 \\
\hline Rhyacopsyche & 0.00 & 0.00 & 0.00 \\
\hline não identificado & 44.19 & 9.82 & 0.00 \\
\hline \multicolumn{4}{|l|}{ Leptoceridae } \\
\hline Amphoropsyche & 0.00 & 0.00 & 0.00 \\
\hline Nectopsyche & 88.38 & 14.73 & 0.00 \\
\hline Oecetis & 0.00 & 0.00 & 0.00 \\
\hline Grumichella & 0.00 & 0.00 & 0.00 \\
\hline não identificado & 73.65 & 0.00 & 0.00 \\
\hline \multicolumn{4}{|l|}{ Sericostomatidae } \\
\hline \multicolumn{3}{|l|}{ Policentropodidae } & 0.00 \\
\hline Cernotina & 0.00 & 0.00 & 0.00 \\
\hline Cyrnellus & 0.00 & 0.00 & 0.00 \\
\hline Nyctiophylax & 0.00 & 0.00 & 0.00 \\
\hline \multicolumn{4}{|l|}{ Calamoceridae } \\
\hline Phylloicus & 0.00 & 0.00 & 0.00 \\
\hline \multicolumn{4}{|l|}{ Glossosomatidae } \\
\hline Mexitrichia & 0.00 & 0.00 & 0.00 \\
\hline Itauara & 0.00 & 9.82 & 0.00 \\
\hline Protoptila & 0.00 & 14.73 & 0.00 \\
\hline Odontoceridae & & & \\
\hline Barypenthus & 0.00 & 0.00 & 0.00 \\
\hline Trichoptera n.i. & 0.00 & 9.82 & 0.00 \\
\hline
\end{tabular}

Dados quali e quantitativos - $1^{\text {a }}$ campanha 
PONTO 3

HÁBITATS

MACRÓFITAS (M)

CANAL (C)

M. DEP. (DE)

M. ERO. (ER)

QUIPAMENTO

REDE

PETERSEN USP PETERSEN USP

PETERSEN USP

EPHEMER
Baetidae

Americabaetis
Aturbina
Camelobaetidius
Cryptonynpha
Iguaira
Paracloeodes
Waltzophius
Zelusia
não identificado

13.33

19.00

0.00

0.00

0.00

0.00

5.00

0.00

0.00

0.67

4.00

0.00

0.00

0.00

0.00

0.00

0.00

Leptohyphidae

Tricorythopsis

Traverhyphes

não identificado

Leptophlebiidae

\subsection{0}

0.00

0.00

0.00

0.00

0.00

Hylyster

Miroculis

0.00

Farrodes

não identificado

0.00

0.00

0.00

0.00

0.00

0.00

0.00

0.00

0.00

0.00

0.00

Hexagenia

Ephemeroptera n.i.

0.00

0.00

0.00

0.00

0.00

0.00

0.00

0.00

0.00

Perlidae

Grypopteryx
Paragrypopteryx

Tupiperla

0.00

0.00

0.00

0.00

Kempnyia

0.00

0.00

TRICHOPTERA

Pleco
PTERA

Hydrobiosidae
Atopsyche

Helicopsychidae

Helicopsyche

0.00

0.00

\subsection{0}

0.00

0.00

0.00

0.00

0.00

0.00

0.00

0.00

0.00

$$
0.00
$$

0.00

0.00

0.00
0.00

0.00

0.00

$0.00 \quad 0.00$

$\begin{array}{ll}0.00 & 0.00 \\ 0.00 & 0.00\end{array}$

$\begin{array}{ll}0.00 & 0.00 \\ 0.00 & 0.00\end{array}$

$0.00 \quad 0.00$

$0.00 \quad 0.00$

$\begin{array}{ll}0.00 & 0.00 \\ 0.00 & 0.00\end{array}$

$0.00 \quad 0.00$

$0.00 \quad 0.00$

$\begin{array}{ll}0.00 & 0.00\end{array}$

Hydropsychidae

Smicridea

0.00

0.00

0.00

0.00

0.00

0.00

$0.00 \quad 0.00$

Leptonema

6.33

0.00

0.00

0.00

0.00

0.00

$\begin{array}{ll}0.00 & 0.00\end{array}$

Hydroptilidae

não identificado

0.00

0.00

0.00

0.00

0.00

3.33

0.00

0.33

0.00

0.00

0.00

0.00

0.00

não identificado

72.00

0.00

0.00

0.00

0.00

0.00

0.00

0.00

0.00

0.00

0.00

0.00

0.00

$\begin{array}{ll}0.00 & 0.00 \\ 0.00 & 0.00\end{array}$

0.00

0.00

0.33

0.00

0.00

0.00

0.00

0.00
0.00

0.00

0.00

0.00

0.00

0.00

0.00

0.00

0.00

0.00

0.00

$$
0.00
$$

0.00

0.00

0.00

0.00

10.26

0.00

0.00

0.00

0.00

0.00

0.00

0.00

0.00

0.00

0.00
10.26

0.00

Cyrnellus

0.00

0.00

Calamoceridae

Phylloicus

0.00

0.00

0.00

0.00

$0.00 \quad 0.00$

0.00
0.00

0.00

0.00

0.00

0.00

0.00

0.00

0.00

Protoptila

Odontoceridae

Barypenthus

0.00

0.00

0.00

0.00

0.00

0.00

0.00

0.00

10.26

Dados quali e quantitativos $-1^{\underline{a}}$ campanha 
PONTO 4

HÁBITATS

EQUIPAMENTO

DETRITOS (D) CORREDEIRA (CO)

REDE

M. DEP (DE)

EPHEMEROPTERA

Baetidae

Americabaetis Aturbina

Camelobaetidius

Cryptonynpha Iguaira

Paracloeodes

Waltzophius

Zelusia

não identificado

Leptohyphidae

Tricorythodes

Tricorythopsis

Traverhyphes

não identificado

Leptophlebiidae

Hylyster

Miroculis

Farrodes

não identificado

Ephemeridae

Hexagenia

Ephemeroptera n.i.

PLECOPTERA

Gripopterygidae

Grypopteryx

REDE

PETERSEN CETESB

Paragrypopteryx
Pupiperla

TRICHOPTERA

Hydrobiosidae

Helicopsychidae

Atopsyche

Helicopsyche

Hydropsychidae

Smicridea

Leptonema

não identificado

Hydroptilidae

Oxyethira

aff. Hydroptila

Ochotrichia

Neotrichia

Rhyacopsyche

não identificado

Leptoceridae

Amphoropsyche

Nectopsyche

Oecetis

Grumichella

não identificado

Sericostomatidae

Grumicha

0.00

0.00

0.00

0.00

0.00

0.00

0.00

0.00

0.00

0.00

0.00

0.00

0.00

0.00

0.00

0.00

0.00

0.00

0.00

2.33

0.00

1.00

0.00

16.33

0.33

3.00

0.00

0.00

0.33

0.00

0.00

0.00

5.59

0.00

0.00

$14.33 \quad 39.15$

$14.67 \quad 5.59$

$1.67 \quad 5.59$

$\begin{array}{ll}4.33 & 0.00\end{array}$

0.00

0.00

0.00

0.00

0.00

2.67

0.00

0.00

27.97

$0.00 \quad 0.00$

0.00

0.00

0.00

3.33

0.00

0.00

0.00

0.00

1.00

0.00

0.67

0.00

0.33

0.00

0.00

0.00

0.00

0.00

0.33

0.00

0.00

0.33

5.59

0.00

0.00

0.00

3.00

0.33

0.00

0.00

0.00

2.33

11.19

0.00

0.00

0.00

0.00

0.00

0.00

0.00

0.00

0.00

0.00

0.00

0.00

4.33

0.00

0.00

44.75

3.33

$\begin{array}{ll}0.00 & 0.00 \\ 0.00 & 0.00\end{array}$

Policentropodidae

0.00

0.33

0.00

15.67

85.26

0.00

27.97

0.00

$\begin{array}{ll}1.00 & 95.09\end{array}$

Cernotina

Cyrnellus

Nyctiophylax

0.00

0.00

0.00

0.00

0.00

0.00

0.00

0.00

0.00

0.00

0.00

Calamoceridae

Phylloicus

0.00

0.00

11.19

Glossosomatidae

Mexitrichia $\quad 0.00$

Itauara

Protoptila

Odontoceridae

Barypenthus

0.00

1.33

0.00

0.33

0.00

1.33

0.00

Trichoptera n.i.

0.00

0.33

0.00

$\begin{array}{ll}0.33 & 16.78\end{array}$

Dados quali e quantitativos $-1^{\text {a }}$ campanha 


\begin{tabular}{|c|c|c|}
\hline $\begin{array}{l}\text { PONTO } 5 \\
\text { HÁBITATS } \\
\text { EQUIPAMENTO }\end{array}$ & $\begin{array}{l}\text { MACRÓFITAS (M) } \\
\text { REDE }\end{array}$ & $\begin{array}{c}\text { M. DEP.(DE) } \\
\text { PETERSEN CETESB }\end{array}$ \\
\hline \multicolumn{3}{|l|}{$\begin{array}{l}\text { EPHEMEROPTERA } \\
\text { Baetidae }\end{array}$} \\
\hline Americabaetis & 0.00 & 0.00 \\
\hline Aturbina & 1.67 & 0.00 \\
\hline Camelobaetidius & 0.00 & 0.00 \\
\hline Cryptonynpha & 0.00 & 0.00 \\
\hline Iguaira & 0.00 & 0.00 \\
\hline Paracloeodes & 1.00 & 0.00 \\
\hline Waltzophius & 4.67 & 0.00 \\
\hline Zelusia & 1.33 & 0.00 \\
\hline não identificado & 1.67 & 0.00 \\
\hline \multicolumn{3}{|l|}{ Leptohyphidae } \\
\hline Tricorythodes & 23.00 & 0.00 \\
\hline Tricorythopsis & 0.33 & 0.00 \\
\hline Traverhyphes & 0.00 & 0.00 \\
\hline não identificado & 0.00 & 0.00 \\
\hline \multicolumn{3}{|l|}{ Leptophlebiidae } \\
\hline Hylyster & 0.00 & 0.00 \\
\hline Miroculis & 0.00 & 0.00 \\
\hline Farrodes & 0.00 & 0.00 \\
\hline não identificado & 0.00 & 0.00 \\
\hline \multicolumn{3}{|l|}{ Ephemeridae } \\
\hline Hexagenia & 0.00 & 0.00 \\
\hline Ephemeroptera n.i. & 0.00 & 0.00 \\
\hline \multicolumn{3}{|l|}{$\begin{array}{l}\text { PLECOPTERA } \\
\text { Gripopterygidae }\end{array}$} \\
\hline Grypopteryx & 0.00 & 0.00 \\
\hline Paragrypopteryx & 0.00 & 0.00 \\
\hline Tupiperla & 0.00 & 0.00 \\
\hline Perlidae & 0.00 & 0.00 \\
\hline Anacroneuria & 0.00 & 0.00 \\
\hline Kempnyia & 0.00 & 0.00 \\
\hline Plecoptera n.i. & 0.00 & 0.00 \\
\hline \multicolumn{3}{|l|}{$\begin{array}{l}\text { TRICHOPTERA } \\
\text { Hydrobiosidae }\end{array}$} \\
\hline Atopsyche & 0.00 & 0.00 \\
\hline \multicolumn{3}{|l|}{ Helicopsychidae } \\
\hline Helicopsyche & 6.00 & 0.00 \\
\hline \multicolumn{3}{|l|}{ Hydropsychidae } \\
\hline Smicridea & 0.00 & 0.00 \\
\hline Leptonema & 0.00 & 0.00 \\
\hline não identificado & 0.00 & 0.00 \\
\hline \multicolumn{3}{|l|}{ Hydroptilidae } \\
\hline Oxyethira & 0.00 & 0.00 \\
\hline aff. Hydroptila & 0.00 & 0.00 \\
\hline Ochotrichia & 0.00 & 0.00 \\
\hline Neotrichia & 2.00 & 0.00 \\
\hline Rhyacopsyche & 0.00 & 0.00 \\
\hline não identificado & 0.00 & 0.00 \\
\hline \multicolumn{3}{|l|}{ Leptoceridae } \\
\hline Amphoropsyche & 0.00 & 0.00 \\
\hline Nectopsyche & 169.67 & 0.00 \\
\hline Oecetis & 0.00 & 0.00 \\
\hline Grumichella & 0.00 & 0.00 \\
\hline não identificado & 0.33 & 0.00 \\
\hline \multicolumn{3}{|l|}{ Sericostomatidae } \\
\hline \multirow{2}{*}{\multicolumn{3}{|c|}{ Policentropodidae }} \\
\hline & & \\
\hline Cernotina & 0.00 & 0.00 \\
\hline Cyrnellus & 0.00 & 0.00 \\
\hline \multirow{2}{*}{\multicolumn{3}{|c|}{ Calamoceridae }} \\
\hline & & \\
\hline Phylloicus & 0.00 & 0.00 \\
\hline \multicolumn{3}{|l|}{ Glossosomatidae } \\
\hline Mexitrichia & 0.00 & 0.00 \\
\hline Itauara & 0.00 & 0.00 \\
\hline Protoptila & 0.00 & 0.00 \\
\hline Odontoceridae & & \\
\hline Barypenthus & 0.00 & 0.00 \\
\hline Trichoptera n.i. & 0.00 & 0.00 \\
\hline
\end{tabular}

Dados quali e quantitativos $-1^{\text {a }}$ campanha 
PONTO 6

HÁBITATS

EQUIPAMENTO

MACRÓFITAS(M)

CANAL (C)

M. DEP. (DE)

M. ERO.(ER)

EPHEMEROPTERA

Baetidae

Americabaetis REDE

PETERSEN USP PETERSEN USP

PETERSEN USP

\begin{tabular}{|c|c|c|c|c|}
\hline & & & & \\
\hline Americabaetis & 60.00 & 0.00 & 0.00 & 0.00 \\
\hline Aturbina & 14.00 & 0.00 & 0.00 & 0.00 \\
\hline Camelobaetidius & 0.00 & 0.00 & 0.00 & 0.00 \\
\hline Cryptonynpha & 0.00 & 0.00 & 0.00 & 0.00 \\
\hline Iguaira & 0.00 & 0.00 & 0.00 & 0.00 \\
\hline Paracloeodes & 0.00 & 0.00 & 0.00 & 0.00 \\
\hline Waltzophius & 2.00 & 0.00 & 0.00 & 0.00 \\
\hline Zelusia & 0.00 & 0.00 & 0.00 & 0.00 \\
\hline não identificado & 11.00 & 0.00 & 0.00 & 0.00 \\
\hline Leptohyphidae & & & & \\
\hline Tricorythodes & 2.00 & 0.00 & 0.00 & 0.00 \\
\hline Tricorythopsis & 6.00 & 0.00 & 0.00 & 0.00 \\
\hline Traverhyphes & 0.00 & 0.00 & 0.00 & 0.00 \\
\hline não identificado & 2.00 & 0.00 & 0.00 & 0.00 \\
\hline Leptophlebiidae & & & & \\
\hline Hylyster & 0.00 & 0.00 & 0.00 & 0.00 \\
\hline Miroculis & 0.00 & 0.00 & 0.00 & 0.00 \\
\hline Farrodes & 0.00 & 0.00 & 0.00 & 0.00 \\
\hline não identificado & 2.00 & 0.00 & 0.00 & 0.00 \\
\hline Ephemeridae & & & & \\
\hline Hexagenia & 0.00 & 0.00 & 0.00 & 102.57 \\
\hline Ephemeroptera n.i. & & 0.00 & 0.00 & 0.00 \\
\hline PLECOPTERA & & & & \\
\hline Gripopterygidae & & & & \\
\hline Grypopteryx & 0.00 & 0.00 & 0.00 & 0.00 \\
\hline Paragrypopteryx & 0.00 & 0.00 & 0.00 & 0.00 \\
\hline Tupiperla & 0.00 & 0.00 & 0.00 & 0.00 \\
\hline Perlidae & & & & \\
\hline Anacroneuria & 0.00 & 0.00 & 0.00 & 0.00 \\
\hline Kempnyia & 0.00 & 0.00 & 0.00 & 0.00 \\
\hline Plecoptera n.i. & 0.00 & 0.00 & 0.00 & 0.00 \\
\hline $\begin{array}{l}\text { TRICHOPTERA } \\
\text { Hydrobiosidae }\end{array}$ & & & & \\
\hline Atopsyche & 0.00 & 0.00 & 0.00 & 0.00 \\
\hline Helicopsychidae & & & & \\
\hline Helicopsyche & 0.00 & 0.00 & 0.00 & 0.00 \\
\hline Hydropsychidae & & & & \\
\hline Smicridea & 2.00 & 0.00 & 0.00 & 0.00 \\
\hline Leptonema & 0.00 & 0.00 & 0.00 & 0.00 \\
\hline não identificado & 1.00 & 0.00 & 0.00 & 0.00 \\
\hline Hydroptilidae & & & & \\
\hline Oxyethira & 0.00 & 0.00 & 0.00 & 0.00 \\
\hline aff. Hydroptila & 0.00 & 0.00 & 0.00 & 0.00 \\
\hline Ochotrichia & 0.00 & 0.00 & 0.00 & 0.00 \\
\hline Neotrichia & 79.00 & 0.00 & 0.00 & 0.00 \\
\hline Rhyacopsyche & 0.00 & 0.00 & 0.00 & 0.00 \\
\hline não identificado & 0.00 & 0.00 & 0.00 & 0.00 \\
\hline Leptoceridae & & & & \\
\hline Amphoropsyche & 0.00 & 0.00 & 0.00 & 0.00 \\
\hline Nectopsyche & 4.00 & 0.00 & 0.00 & 0.00 \\
\hline Oecetis & 0.00 & 0.00 & 0.00 & 0.00 \\
\hline Grumichella & 0.00 & 0.00 & 0.00 & 0.00 \\
\hline não identificado & 0.00 & 0.00 & 0.00 & 0.00 \\
\hline Sericostomatidae & & & & \\
\hline Grumicha & 0.00 & 0.00 & 0.00 & 0.00 \\
\hline Policentropodidae & & & & \\
\hline Cernotina & 0.00 & 0.00 & 0.00 & 0.00 \\
\hline Cyrnellus & 4.00 & 0.00 & 0.00 & 20.51 \\
\hline Nyctiophylax & 0.00 & 10.26 & 0.00 & 0.00 \\
\hline Calamoceridae & & & & \\
\hline Phylloicus & 0.00 & 0.00 & 0.00 & 0.00 \\
\hline Glossosomatidae & & & & \\
\hline Mexitrichia & 0.00 & 0.00 & 0.00 & 0.00 \\
\hline Itauara & 0.00 & 0.00 & 0.00 & 0.00 \\
\hline Protoptila & 0.00 & 0.00 & 0.00 & 0.00 \\
\hline Odontoceridae & & & & \\
\hline Barypenthus & 0.00 & 0.00 & 0.00 & 0.00 \\
\hline Trichoptera n.i. & 0.00 & 0.00 & 0.00 & 0.00 \\
\hline
\end{tabular}

Dados quali e quantitativos $-1^{\underline{a}}$ campanha 
PONTO 7

HÁBITATS

EQUIPAMENTO

MACRÓFITAS (M)

CANAL (C)

M. DEP. (DE)

M. ERO. (ER)

EPHEMEROPTERA

Baetidae

Americabaetis
Aturbina
Camelobaetidius
Cryptonynpha
Iguaira
Paracloeodes
Waltzophius
Zelusia
não identificado

126.00
116.00
0.00
0.00
0.00
0.67
0.67
0.00
PETERSEN USP

PETERSEN USP

PETERSEN USP

Leptohyphidae

Tricorythodes

Tricorythopsis

Traverhyphes

não identificado

Leptophlebiidae

Hylyster

Miroculis

Farrodes

não identificado

Ephemeridae

Hexagenia

Ephemeroptera n.i.

PLECOPTERA

Gripopterygidae

Grypopteryx

Paragrypopteryx

Perlidae Tupiperla

Anacroneuria

Kempnyia

Plecoptera n.i.

TRICHOPTERA

Hydrobiosidae

Helicopsychidae

Atopsyche

5.00

0.00

0.00

0.00

0.00

0.00

0.00

0.00

0.00

0.00

0.33

0.33

0.00

0.00

0.00

0.00

0.00

0.00

0.00

0.00

0.00

0.00

0.33

0.00

0.00

0.00

0.00

0.00

0.00

0.00

0.00

0.00

0.00

0.00

0.00

0.00

0.00

0.00

0.33

0.00

.

0.00

0.00

0.00

0.00

0.00

0.00

0.00

0.00

0.00

0.00

0.00

0.00

0.00

0.00

0.00

10.26

0.00

0.00

0.00

0.00

123.08

0.00

0.00

0.00

0.00

0.00

0.00

0.00

0.00

0.00

0.00

0.00

0.00

0.00

0.00
0.00

0.00

0.00

0.00

0.00

0.00

0.00

0.00

0.00

0.00

0.00

$0.00 \quad 0.00$

0.00

0.00

Helicopsyche

0.00

0.00

0.00

0.00

0.00

0.00

0.00

8.67

0.00

0.67

0.00

0.00

0.00

0.00

0.00

Leptonema

não identificado

Hydroptilidae

Oxyethira

\subsection{7}

0.00

0.00

0.00

0.00

0.00

0.00

Rhyacopsyche

55.33

0.00

0.00

0.00

10.26

0.00

0.00

0.00

0.00

0.00

0.00

$0.00 \quad 0.00$

0.00

0.33
0.00

0.00

0.33

0.00

0.00

0.00

0.00

41.03

0.00

0.00

0.00

0.00

112.82

0.00

0.00
0.00

Sericostomatidae

$$
\text { Grumicha }
$$

0.00

0.00

0.00

0.00

0.00

0.00

0.00

0.00

$0.00 \quad 0.00$

$10.26 \quad 61.54$

$0.00 \quad 10.26$

$0.00 \quad 0.00$

$0.00 \quad 0.00$

Calamoceridae

Cyrnellus
Nyctiophylax

Phylloicus

0.00

0.00

0.00

0.00

Glossosomatidae

Mexitrichia $\quad 0.00$

Itauara

0.00

0.00

0.00

0.00

0.00

0.00

41.03

553.86

Protoptila

0.00

0.00

0.00

0.00

Odontoceridae

Barypenthus

0.00

0.00

$\begin{array}{lc}0.00 & 0.00 \\ & \\ 0.00 & 0.00 \\ 0.00 & 0.00 \\ 0.00 & 0.00 \\ & \\ 0.00 & 0.00 \\ 0.00 & 10.26\end{array}$

Dados quali e quantitativos $-1^{\underline{a}}$ campanha 


\begin{tabular}{|c|c|c|c|c|}
\hline $\begin{array}{l}\text { PONTO } 8 \\
\text { HABITATS } \\
\text { EQUIPAMENTO }\end{array}$ & $\begin{array}{l}\text { MACRÓFITAS (M) } \\
\text { REDE }\end{array}$ & $\begin{array}{l}\text { CANAL (C) } \\
\text { PETERSEN USP }\end{array}$ & $\begin{array}{l}\text { M. DEP.(DE) } \\
\text { PETERSEN USP }\end{array}$ & $\begin{array}{l}\text { M. ERO. (ER) } \\
\text { PETERSEN USP }\end{array}$ \\
\hline \multicolumn{5}{|l|}{$\begin{array}{l}\text { EPHEMEROPTERA } \\
\text { Baetidae }\end{array}$} \\
\hline Americabaetis & 79.00 & 0.00 & 0.00 & 0.00 \\
\hline Aturbina & 160.00 & 0.00 & 0.00 & 0.00 \\
\hline Camelobaetidius & 0.00 & 0.00 & 0.00 & 0.00 \\
\hline Cryptonynpha & 0.00 & 0.00 & 0.00 & 0.00 \\
\hline Iguaira & 0.00 & 0.00 & 0.00 & 0.00 \\
\hline Paracloeodes & 0.00 & 0.00 & 0.00 & 0.00 \\
\hline Waltzophius & 0.00 & 0.00 & 0.00 & 0.00 \\
\hline Zelusia & 0.00 & 0.00 & 0.00 & 0.00 \\
\hline não identificado & 0.00 & 0.00 & 0.00 & 0.00 \\
\hline \multicolumn{5}{|l|}{ Leptohyphidae } \\
\hline Tricorythodes & 0.33 & 41.03 & 0.00 & 10.26 \\
\hline Tricorythopsis & 0.00 & 0.00 & 0.00 & 0.00 \\
\hline Traverhyphes & 18.00 & 0.00 & 0.00 & 30.77 \\
\hline não identificado & 0.00 & 30.77 & 0.00 & 0.00 \\
\hline \multicolumn{5}{|l|}{ Leptophlebiidae } \\
\hline Hylyster & 0.00 & 0.00 & 0.00 & 0.00 \\
\hline Miroculis & 0.00 & 0.00 & 0.00 & 0.00 \\
\hline Farrodes & 0.00 & 0.00 & 0.00 & 0.00 \\
\hline não identificado & 0.00 & 0.00 & 0.00 & 0.00 \\
\hline \multicolumn{5}{|l|}{ Ephemeridae } \\
\hline Hexagenia & 0.00 & 0.00 & 0.00 & 0.00 \\
\hline Ephemeroptera n.i. & 0.00 & 0.00 & 0.00 & 0.00 \\
\hline \multicolumn{5}{|l|}{$\begin{array}{l}\text { PLECOPTERA } \\
\text { Gripopterygidae }\end{array}$} \\
\hline Grypopteryx & 0.00 & 0.00 & 0.00 & 0.00 \\
\hline Paragrypopteryx & 0.00 & 0.00 & 0.00 & 0.00 \\
\hline Tupiperla & 0.00 & 0.00 & 0.00 & 0.00 \\
\hline \multicolumn{5}{|l|}{ Perlidae } \\
\hline Anacroneuria & 0.00 & 0.00 & 0.00 & 0.00 \\
\hline Kempnyia & 0.00 & 0.00 & 0.00 & 0.00 \\
\hline Plecoptera n.i. & 0.00 & 0.00 & 0.00 & 0.00 \\
\hline \multicolumn{5}{|l|}{$\begin{array}{l}\text { TRICHOPTERA } \\
\text { Hydrobiosidae }\end{array}$} \\
\hline Atopsyche & 0.00 & 0.00 & 0.00 & 0.00 \\
\hline \multicolumn{5}{|l|}{ Helicopsychidae } \\
\hline Helicopsyche & 0.33 & 0.00 & 0.00 & 0.00 \\
\hline \multicolumn{5}{|l|}{ Hydropsychidae } \\
\hline Smicridea & 0.00 & 0.00 & 0.00 & 0.00 \\
\hline Leptonema & 0.00 & 0.00 & 0.00 & 0.00 \\
\hline não identificado & 0.00 & 10.26 & 0.00 & 0.00 \\
\hline \multicolumn{5}{|l|}{ Hydroptilidae } \\
\hline Oxyethira & 0.00 & 0.00 & 0.00 & 0.00 \\
\hline aff. Hydroptila & 0.00 & 0.00 & 0.00 & 0.00 \\
\hline Ochotrichia & 0.00 & 0.00 & 0.00 & 0.00 \\
\hline Neotrichia & 5.33 & 10.26 & 0.00 & 10.26 \\
\hline Rhyacopsyche & 0.00 & 0.00 & 0.00 & 0.00 \\
\hline não identificado & 0.00 & 0.00 & 0.00 & 0.00 \\
\hline \multicolumn{5}{|l|}{ Leptoceridae } \\
\hline Amphoropsyche & 0.00 & 0.00 & 0.00 & 0.00 \\
\hline Nectopsyche & 0.67 & 20.51 & 0.00 & 0.00 \\
\hline Oecetis & 0.00 & 20.51 & 0.00 & 0.00 \\
\hline Grumichella & 0.00 & 0.00 & 0.00 & 0.00 \\
\hline não identificado & 0.00 & 0.00 & 0.00 & 0.00 \\
\hline \multicolumn{5}{|l|}{ Sericostomatidae } \\
\hline Grumicha & 0.00 & 0.00 & 0.00 & 0.00 \\
\hline \multicolumn{5}{|l|}{ Policentropodidae } \\
\hline Cernotina & 0.00 & 0.00 & 0.00 & 0.00 \\
\hline Cyrnellus & 2.00 & 0.00 & 0.00 & 297.44 \\
\hline Nyctiophylax & 0.00 & 0.00 & 0.00 & 0.00 \\
\hline Calamoceridae & & & & \\
\hline Phylloicus & 0.00 & 0.00 & 0.00 & 0.00 \\
\hline Glossosomatidae & & & & \\
\hline Mexitrichia & 0.00 & 0.00 & 0.00 & 0.00 \\
\hline Itauara & 0.00 & 0.00 & 0.00 & 0.00 \\
\hline Protoptila & 0.00 & 0.00 & 0.00 & 0.00 \\
\hline Odontoceridae & & & & \\
\hline Barypenthus & 0.00 & 0.00 & 0.00 & 0.00 \\
\hline Trichoptera n.i. & 0.33 & 10.26 & 0.00 & 0.00 \\
\hline
\end{tabular}




\begin{tabular}{|c|c|c|c|}
\hline $\begin{array}{l}\text { PONTO } 1 \\
\text { HÁBITATS } \\
\text { EQUIPAMENTO }\end{array}$ & $\begin{array}{l}\text { CANAL } \\
\text { HESS }\end{array}$ & $\begin{array}{l}\text { M. DEP. } \\
\text { HESS }\end{array}$ & $\begin{array}{l}\text { M. ERO. } \\
\text { HESS }\end{array}$ \\
\hline \multicolumn{4}{|l|}{$\begin{array}{l}\text { EPHEMEROPTERA } \\
\text { Baetidae }\end{array}$} \\
\hline Americabaetis & 19.64 & 4.91 & 19.64 \\
\hline Aturbina & 0.00 & 0.00 & 0.00 \\
\hline Camelobaetidius & 0.00 & 0.00 & 0.00 \\
\hline Cryptonynpha & 0.00 & 0.00 & 0.00 \\
\hline Iguaira & 4.91 & 0.00 & 0.00 \\
\hline Paracloeodes & 9.82 & 0.00 & 19.64 \\
\hline Waltzophius & 0.00 & 0.00 & 0.00 \\
\hline Zelusia & 0.00 & 0.00 & 0.00 \\
\hline não identificado & 0.00 & 0.00 & 0.00 \\
\hline \multicolumn{4}{|l|}{ Leptohyphidae } \\
\hline Tricorythodes & 0.00 & 0.00 & 0.00 \\
\hline Tricorythopsis & 0.00 & 0.00 & 0.00 \\
\hline Traverhyphes & 0.00 & 0.00 & 0.00 \\
\hline não identificado & 0.00 & 0.00 & 0.00 \\
\hline \multicolumn{4}{|l|}{ Leptophlebiidae } \\
\hline Hylyster & 0.00 & 0.00 & 0.00 \\
\hline Miroculis & 0.00 & 0.00 & 0.00 \\
\hline Farrodes & 0.00 & 0.00 & 0.00 \\
\hline não identificado & 0.00 & 0.00 & 0.00 \\
\hline \multicolumn{4}{|l|}{ Ephemeridae } \\
\hline Hexagenia & 0.00 & 0.00 & 0.00 \\
\hline Ephemeroptera n.i. & 0.00 & 0.00 & 0.00 \\
\hline \multicolumn{4}{|l|}{$\begin{array}{l}\text { PLECOPTERA } \\
\text { Gripopterygidae }\end{array}$} \\
\hline Grypopteryx & 0.00 & 0.00 & 0.00 \\
\hline Paragrypopteryx & 0.00 & 0.00 & 0.00 \\
\hline Tupiperla & 0.00 & 0.00 & 0.00 \\
\hline \multicolumn{4}{|l|}{ Perlidae } \\
\hline Anacroneuria & 0.00 & 0.00 & 0.00 \\
\hline Kempnyia & 0.00 & 0.00 & 0.00 \\
\hline Plecoptera n.i. & 0.00 & 0.00 & 0.00 \\
\hline \multicolumn{4}{|l|}{$\begin{array}{l}\text { TRICHOPTERA } \\
\text { Hydrobiosidae }\end{array}$} \\
\hline $\begin{array}{l}\text { Hydrobiosidae } \\
\text { Atopsyche }\end{array}$ & 0.00 & 0.00 & 0.00 \\
\hline \multicolumn{4}{|l|}{ Helicopsychidae } \\
\hline Helicopsyche & 0.00 & 0.00 & 0.00 \\
\hline \multicolumn{4}{|l|}{ Hydropsychidae } \\
\hline Smicridea & 0.00 & 0.00 & 0.00 \\
\hline Leptonema & 368.25 & 0.00 & 1212.77 \\
\hline não identificado & 348.61 & 0.00 & 220.95 \\
\hline \multicolumn{4}{|l|}{ Hydroptilidae } \\
\hline Oxyethira & 0.00 & 0.00 & 0.00 \\
\hline aff. Hydroptila & 14.73 & 0.00 & 0.00 \\
\hline Ochotrichia & 0.00 & 0.00 & 0.00 \\
\hline Neotrichia & 0.00 & 0.00 & 0.00 \\
\hline Rhyacopsyche & 0.00 & 0.00 & 0.00 \\
\hline não identificado & 0.00 & 0.00 & 0.00 \\
\hline \multicolumn{4}{|l|}{ Leptoceridae } \\
\hline Amphoropsyche & 0.00 & 0.00 & 0.00 \\
\hline Nectopsyche & 4.91 & 9.82 & 19.64 \\
\hline Oecetis & 0.00 & 0.00 & 0.00 \\
\hline Grumichella & 0.00 & 0.00 & 0.00 \\
\hline não identificado & 0.00 & 0.00 & 0.00 \\
\hline \multicolumn{4}{|l|}{ Sericostomatidae } \\
\hline \multicolumn{3}{|l|}{ Policentropodidae } & 0.00 \\
\hline Cernotina & 0.00 & 0.00 & 0.00 \\
\hline Cyrnellus & 0.00 & 0.00 & 0.00 \\
\hline Nyctiophylax & 0.00 & 0.00 & 0.00 \\
\hline \multicolumn{4}{|l|}{ Calamoceridae } \\
\hline Phylloicus & 4.91 & 0.00 & 0.00 \\
\hline Glossosomatidae & & & \\
\hline Mexitrichia & 0.00 & 0.00 & 0.00 \\
\hline Itauara & 0.00 & 0.00 & 0.00 \\
\hline Protoptila & 0.00 & 0.00 & 0.00 \\
\hline Odontoceridae & & & \\
\hline Barypenthus & 0.00 & 0.00 & 0.00 \\
\hline Trichoptera n.i. & 0.00 & 0.00 & 0.00 \\
\hline
\end{tabular}

Dados quali e quantitativos $-2^{\mathrm{a}}$ campanha 


\begin{tabular}{|c|c|c|c|}
\hline $\begin{array}{l}\text { PONTO } 2 \\
\text { HÁBITATS } \\
\text { EQUIPAMENTO }\end{array}$ & $\begin{array}{l}\text { CANAL } \\
\text { HESS }\end{array}$ & $\begin{array}{l}\text { M. DEP. } \\
\text { HESS }\end{array}$ & $\begin{array}{l}\text { M. ERO. } \\
\text { HESS }\end{array}$ \\
\hline \multicolumn{4}{|l|}{$\begin{array}{l}\text { EPHEMEROPTERA } \\
\text { Baetidae }\end{array}$} \\
\hline Americabaetis & 108.02 & 0.00 & 0.00 \\
\hline Aturbina & 0.00 & 0.00 & 0.00 \\
\hline Camelobaetidius & 0.00 & 0.00 & 0.00 \\
\hline Cryptonynpha & 39.28 & 0.00 & 0.00 \\
\hline Iguaira & 0.00 & 0.00 & 0.00 \\
\hline Paracloeodes & 127.66 & 0.00 & 0.00 \\
\hline Waltzophius & 9.82 & 0.00 & 0.00 \\
\hline Zelusia & 0.00 & 0.00 & 0.00 \\
\hline não identificado & 0.00 & 0.00 & 0.00 \\
\hline \multicolumn{4}{|l|}{ Leptohyphidae } \\
\hline Tricorythodes & 39.28 & 0.00 & 0.00 \\
\hline Tricorythopsis & 623.57 & 0.00 & 4.91 \\
\hline Traverhyphes & 34.37 & 0.00 & 0.00 \\
\hline não identificado & 54.01 & 0.00 & 0.00 \\
\hline \multicolumn{4}{|c|}{ Leptophlebiidae } \\
\hline Hylyster & 0.00 & 0.00 & 0.00 \\
\hline Miroculis & 0.00 & 0.00 & 0.00 \\
\hline Farrodes & 0.00 & 0.00 & 0.00 \\
\hline não identificado & 19.64 & 0.00 & 0.00 \\
\hline \multicolumn{4}{|l|}{ Ephemeridae } \\
\hline Hexagenia & 0.00 & 0.00 & 0.00 \\
\hline Ephemeroptera n.i. & 0.00 & 0.00 & 0.00 \\
\hline \multicolumn{4}{|l|}{$\begin{array}{l}\text { PLECOPTERA } \\
\text { Gripoptervaidae }\end{array}$} \\
\hline Grypopteryx & 0.00 & 0.00 & 0.00 \\
\hline Paragrypopteryx & 19.64 & 0.00 & 0.00 \\
\hline Tupiperla & 0.00 & 0.00 & 0.00 \\
\hline \multicolumn{4}{|l|}{ Perlidae } \\
\hline Anacroneuria & 0.00 & 0.00 & 0.00 \\
\hline Kempnyia & 0.00 & 0.00 & 0.00 \\
\hline Plecoptera n.i. & 0.00 & 0.00 & 0.00 \\
\hline \multicolumn{4}{|l|}{ TRICHOPTERA } \\
\hline Hydrobiosidae & & & \\
\hline \multicolumn{3}{|l|}{ Helicopsychidae } & 0.00 \\
\hline Helicopsyche & 0.00 & 0.00 & 0.00 \\
\hline \multicolumn{4}{|l|}{ Hydropsychidae } \\
\hline Smicridea & 78.56 & 0.00 & 4.91 \\
\hline Leptonema & 7.37 & 0.00 & 0.00 \\
\hline não identificado & 14.73 & 0.00 & 4.91 \\
\hline \multicolumn{4}{|l|}{ Hydroptilidae } \\
\hline Oxyethira & 0.00 & 0.00 & 0.00 \\
\hline aff. Hydroptila & 672.67 & 0.00 & 0.00 \\
\hline Ochotrichia & 0.00 & 0.00 & 0.00 \\
\hline Neotrichia & 14.73 & 0.00 & 0.00 \\
\hline Rhyacopsyche & 24.55 & 0.00 & 0.00 \\
\hline não identificado & 63.83 & 0.00 & 4.91 \\
\hline \multicolumn{4}{|l|}{ Leptoceridae } \\
\hline Amphoropsyche & 9.82 & 0.00 & 0.00 \\
\hline Nectopsyche & 530.28 & 4.91 & 0.00 \\
\hline Oecetis & 14.73 & 0.00 & 0.00 \\
\hline Grumichella & 0.00 & 0.00 & 0.00 \\
\hline não identificado & 0.00 & 0.00 & 0.00 \\
\hline \multicolumn{4}{|l|}{ Sericostomatidae } \\
\hline \multicolumn{4}{|l|}{ Policentropodidae } \\
\hline Cernotina & 0.00 & 0.00 & 0.00 \\
\hline Cyrnellus & 0.00 & 0.00 & 0.00 \\
\hline Nyctiophylax & 0.00 & 0.00 & 0.00 \\
\hline \multicolumn{4}{|l|}{ Calamoceridae } \\
\hline $\begin{array}{l}\text { Phylloicus } \\
\text { Glossosomatidae }\end{array}$ & 9.82 & 0.00 & 0.00 \\
\hline Mexitrichia & 0.00 & 0.00 & 0.00 \\
\hline Itauara & 0.00 & 0.00 & 0.00 \\
\hline Protoptila & 9.82 & 0.00 & 0.00 \\
\hline Odontoceridae & & & \\
\hline Barypenthus & 0.00 & 0.00 & 0.00 \\
\hline Trichoptera n.i. & 0.00 & 4.91 & 0.00 \\
\hline
\end{tabular}

Dados quali e quantitativos - $2^{\mathrm{a}}$ campanha 


\begin{tabular}{|c|c|c|c|}
\hline $\begin{array}{l}\text { PONTO } 3 \\
\text { HÁBITATS } \\
\text { EQUIPAMENTO }\end{array}$ & $\begin{array}{c}\text { CANAL } \\
\text { PETERSEN USP }\end{array}$ & $\begin{array}{c}\text { M. DEP. } \\
\text { PETERSEN USP }\end{array}$ & $\begin{array}{l}\text { M. ERO. } \\
\text { PETERSEN USP }\end{array}$ \\
\hline \multicolumn{4}{|l|}{$\begin{array}{l}\text { EPHEMEROPTERA } \\
\text { Baetidae }\end{array}$} \\
\hline Americabaetis & 0.00 & 0.00 & 0.00 \\
\hline Aturbina & 0.00 & 0.00 & 0.00 \\
\hline Camelobaetidius & 0.00 & 0.00 & 0.00 \\
\hline Cryptonynpha & 0.00 & 0.00 & 0.00 \\
\hline Iguaira & 0.00 & 0.00 & 0.00 \\
\hline Paracloeodes & 0.00 & 0.00 & 0.00 \\
\hline Waltzophius & 0.00 & 0.00 & 30.77 \\
\hline Zelusia & 0.00 & 0.00 & 0.00 \\
\hline não identificado & 0.00 & 0.00 & 0.00 \\
\hline \multicolumn{4}{|l|}{ Leptohyphidae } \\
\hline Tricorythodes & 0.00 & 0.00 & 0.00 \\
\hline Tricorythopsis & 0.00 & 0.00 & 0.00 \\
\hline Traverhyphes & 0.00 & 0.00 & 0.00 \\
\hline não identificado & 0.00 & 0.00 & 0.00 \\
\hline \multicolumn{4}{|l|}{ Leptophlebiidae } \\
\hline Hylyster & 0.00 & 0.00 & 0.00 \\
\hline Miroculis & 0.00 & 0.00 & 0.00 \\
\hline Farrodes & 0.00 & 0.00 & 0.00 \\
\hline não identificado & 0.00 & 0.00 & 0.00 \\
\hline \multicolumn{4}{|l|}{ Ephemeridae } \\
\hline Hexagenia & 0.00 & 0.00 & 0.00 \\
\hline Ephemeroptera n.i. & 0.00 & 0.00 & 0.00 \\
\hline \multicolumn{4}{|l|}{$\begin{array}{l}\text { PLECOPTERA } \\
\text { Gripopterygidae }\end{array}$} \\
\hline Grypopteryx & 0.00 & 0.00 & 0.00 \\
\hline Paragrypopteryx & 0.00 & 0.00 & 0.00 \\
\hline Tupiperla & 0.00 & 0.00 & 0.00 \\
\hline \multicolumn{4}{|l|}{ Perlidae } \\
\hline Anacroneuria & 0.00 & 0.00 & 0.00 \\
\hline Kempnyia & 0.00 & 0.00 & 0.00 \\
\hline Plecoptera n.i. & 0.00 & 0.00 & 0.00 \\
\hline \multicolumn{4}{|l|}{$\begin{array}{l}\text { TRICHOPTERA } \\
\text { Hydrobiosidae }\end{array}$} \\
\hline $\begin{array}{l}\text { Atopsyche } \\
\text { Helicopsychidae }\end{array}$ & 0.00 & 0.00 & 0.00 \\
\hline Helicopsyche & 0.00 & & \\
\hline \multicolumn{4}{|l|}{ Hydropsychidae } \\
\hline Smicridea & 0.00 & 0.00 & 0.00 \\
\hline Leptonema & 0.00 & 0.00 & 0.00 \\
\hline não identificado & 0.00 & 0.00 & 0.00 \\
\hline \multicolumn{4}{|l|}{ Hydroptilidae } \\
\hline Oxyethira & 0.00 & 0.00 & 0.00 \\
\hline aff. Hydroptila & 0.00 & 0.00 & 0.00 \\
\hline Ochotrichia & 10.26 & 0.00 & 0.00 \\
\hline Neotrichia & 10.26 & 20.51 & 10.26 \\
\hline Rhyacopsyche & 0.00 & 0.00 & 0.00 \\
\hline não identificado & 0.00 & 0.00 & 0.00 \\
\hline \multicolumn{4}{|l|}{ Leptoceridae } \\
\hline Amphoropsyche & 0.00 & 0.00 & 0.00 \\
\hline Nectopsyche & 10.26 & 61.54 & 0.00 \\
\hline Oecetis & 0.00 & 0.00 & 0.00 \\
\hline Grumichella & 0.00 & 0.00 & 0.00 \\
\hline não identificado & 10.26 & 0.00 & 0.00 \\
\hline \multicolumn{4}{|l|}{ Sericostomatidae } \\
\hline Grumicha & 0.00 & 0.00 & 0.00 \\
\hline \multicolumn{4}{|l|}{ Policentropodidae } \\
\hline Cernotina & 0.00 & 0.00 & 0.00 \\
\hline Cyrnellus & 20.51 & 0.00 & 0.00 \\
\hline Nyctiophylax & 0.00 & 0.00 & 0.00 \\
\hline \multicolumn{4}{|l|}{ Calamoceridae } \\
\hline Phylloicus & 0.00 & 0.00 & 0.00 \\
\hline Glossosomatidae & & & \\
\hline Mexitrichia & 0.00 & 0.00 & 0.00 \\
\hline Itauara & 0.00 & 0.00 & 0.00 \\
\hline Protoptila & 0.00 & 0.00 & 0.00 \\
\hline Odontoceridae & & & \\
\hline Barypenthus & 0.00 & 0.00 & 0.00 \\
\hline Trichoptera n.i. & 0.00 & 0.00 & 0.00 \\
\hline
\end{tabular}

Dados quali e quantitativos - $2^{\mathrm{a}}$ campanha 


\begin{tabular}{|c|c|c|c|c|}
\hline $\begin{array}{l}\text { PONTO } 4 \\
\text { HABBITATS } \\
\text { EQUIPAMENTO }\end{array}$ & $\begin{array}{l}\text { CANAL } \\
\text { PETERSEN USP }\end{array}$ & $\begin{array}{l}\text { M. DEP. } \\
\text { PETERSEN USP }\end{array}$ & $\begin{array}{l}\text { M. ERO. } \\
\text { PETERSEN USP }\end{array}$ & $\begin{array}{l}\text { DETRITOS } \\
\text { CATAÇÃO }\end{array}$ \\
\hline \multicolumn{5}{|l|}{$\begin{array}{l}\text { EPHEMEROPTERA } \\
\text { Baetidae }\end{array}$} \\
\hline Americabaetis & 0.00 & 0.00 & 0.00 & 1.00 \\
\hline Aturbina & 0.00 & 0.00 & 0.00 & 0.00 \\
\hline Camelobaetidius & 0.00 & 0.00 & 0.00 & 0.33 \\
\hline Cryptonynpha & 0.00 & 0.00 & 0.00 & 0.00 \\
\hline Iguaira & 0.00 & 0.00 & 0.00 & 0.00 \\
\hline Paracloeodes & 0.00 & 0.00 & 0.00 & 0.00 \\
\hline Waltzophius & 0.00 & 0.00 & 0.00 & 0.00 \\
\hline Zelusia & 0.00 & 0.00 & 0.00 & 0.00 \\
\hline não identificado & 0.00 & 0.00 & 0.00 & 0.00 \\
\hline \multicolumn{5}{|l|}{ Leptohyphidae } \\
\hline Tricorythodes & 10.26 & 61.54 & 30.77 & 1.67 \\
\hline Tricorythopsis & 0.00 & 0.00 & 10.26 & 0.33 \\
\hline Traverhyphes & 0.00 & 0.00 & 0.00 & 0.00 \\
\hline não identificado & 0.00 & 0.00 & 0.00 & 0.33 \\
\hline \multicolumn{5}{|l|}{ Leptophlebiidae } \\
\hline Hylyster & 0.00 & 0.00 & 0.00 & 0.00 \\
\hline Miroculis & 0.00 & 0.00 & 0.00 & 0.00 \\
\hline Farrodes & 0.00 & 0.00 & 0.00 & 0.00 \\
\hline não identificado & 0.00 & 0.00 & 0.00 & 1.67 \\
\hline \multicolumn{5}{|l|}{ Ephemeridae } \\
\hline Hexagenia & 0.00 & 0.00 & 0.00 & 0.00 \\
\hline Ephemeroptera n.i. & 0.00 & 0.00 & 0.00 & 0.00 \\
\hline \multicolumn{5}{|l|}{$\begin{array}{l}\text { PLECOPTERA } \\
\text { Gripopterygidae }\end{array}$} \\
\hline Grypopteryx & 0.00 & 0.00 & 0.00 & 6.33 \\
\hline Paragrypopteryx & 0.00 & 0.00 & 0.00 & 5.67 \\
\hline Tupiperla & 0.00 & 0.00 & 0.00 & 5.67 \\
\hline \multicolumn{5}{|l|}{ Perlidae } \\
\hline Anacroneuria & 0.00 & 0.00 & 0.00 & 0.33 \\
\hline Kempnyia & 0.00 & 0.00 & 0.00 & 0.00 \\
\hline Plecoptera n.i. & 0.00 & 0.00 & 0.00 & 0.00 \\
\hline \multicolumn{5}{|l|}{$\begin{array}{l}\text { TRICHOPTERA } \\
\text { Hydrobiosidae }\end{array}$} \\
\hline \multirow{2}{*}{\multicolumn{5}{|c|}{ Helicopsychidae }} \\
\hline & & & & \\
\hline $\begin{array}{l}\text { Helicopsyche } \\
\text { Hydropsychidae }\end{array}$ & 0.00 & 0.00 & 0.00 & 0.00 \\
\hline Smicridea & 0.00 & 0.00 & 0.00 & 0.33 \\
\hline Leptonema & 0.00 & 0.00 & 0.00 & 0.00 \\
\hline não identificado & 0.00 & 0.00 & 0.00 & 0.67 \\
\hline \multicolumn{5}{|l|}{ Hydroptilidae } \\
\hline Oxyethira & 0.00 & 0.00 & 0.00 & 0.00 \\
\hline aff. Hydroptila & 0.00 & 0.00 & 0.00 & 0.00 \\
\hline Ochotrichia & 0.00 & 0.00 & 0.00 & 0.00 \\
\hline Neotrichia & 0.00 & 0.00 & 0.00 & 0.00 \\
\hline Rhyacopsyche & 0.00 & 0.00 & 0.00 & 0.00 \\
\hline não identificado & 0.00 & 0.00 & 0.00 & 0.00 \\
\hline \multicolumn{5}{|l|}{ Leptoceridae } \\
\hline Amphoropsyche & 0.00 & 0.00 & 10.26 & 0.00 \\
\hline Nectopsyche & 10.26 & 112.82 & 123.08 & 5.67 \\
\hline Oecetis & 0.00 & 30.77 & 30.77 & 0.00 \\
\hline Grumichella & 0.00 & 0.00 & 0.00 & 0.00 \\
\hline não identificado & 0.00 & 0.00 & 0.00 & 0.00 \\
\hline \multicolumn{5}{|l|}{ Sericostomatidae } \\
\hline $\begin{array}{l}\text { Grumicha } \\
\text { Policentronodidae }\end{array}$ & 0.00 & 0.00 & 0.00 & 0.00 \\
\hline \multicolumn{5}{|l|}{ Policentropodidae } \\
\hline Cernotina & 0.00 & 0.00 & 0.00 & 0.00 \\
\hline Cyrnellus & 0.00 & 0.00 & 0.00 & 0.00 \\
\hline Nyctiophylax & 0.00 & 0.00 & 0.00 & 0.00 \\
\hline Calamoceridae & & & & \\
\hline Phylloicus & 0.00 & 0.00 & 0.00 & 0.00 \\
\hline Glossosomatidae & & & & \\
\hline Mexitrichia & 0.00 & 0.00 & 0.00 & 0.00 \\
\hline Itauara & 0.00 & 0.00 & 0.00 & 0.00 \\
\hline Protoptila & 0.00 & 0.00 & 0.00 & 0.00 \\
\hline Odontoceridae & & & & \\
\hline Barypenthus & 0.00 & 0.00 & 0.00 & 0.00 \\
\hline Trichoptera n.i. & 0.00 & 0.00 & 0.00 & 0.00 \\
\hline
\end{tabular}

Dados quali e quantitativos $-2^{\underline{a}}$ campanha 


\begin{tabular}{|c|c|c|}
\hline $\begin{array}{l}\text { PONTO } 5 \\
\text { HABITATS } \\
\text { EQUIPAMENTO }\end{array}$ & $\begin{array}{l}\text { M. DEP. } \\
\text { PETERSEN USP }\end{array}$ & $\begin{array}{l}\text { M. ERO. } \\
\text { PETERSEN USP }\end{array}$ \\
\hline \multicolumn{3}{|l|}{$\begin{array}{l}\text { EPHEMEROPTERA } \\
\text { Baetidae }\end{array}$} \\
\hline Americabaetis & 0.00 & 10.26 \\
\hline Aturbina & 0.00 & 0.00 \\
\hline Camelobaetidius & 0.00 & 0.00 \\
\hline Cryptonynpha & 0.00 & 0.00 \\
\hline Iguaira & 0.00 & 0.00 \\
\hline Paracloeodes & 0.00 & 10.26 \\
\hline Waltzophius & 0.00 & 0.00 \\
\hline Zelusia & 0.00 & 0.00 \\
\hline não identificado & 0.00 & 0.00 \\
\hline \multicolumn{3}{|l|}{ Leptohyphidae } \\
\hline Tricorythodes & 51.28 & 1015.41 \\
\hline Tricorythopsis & 10.26 & 441.04 \\
\hline Traverhyphes & 0.00 & 41.03 \\
\hline não identificado & 0.00 & 71.80 \\
\hline \multicolumn{3}{|l|}{ Leptophlebiidae } \\
\hline Hylyster & 0.00 & 0.00 \\
\hline Miroculis & 0.00 & 0.00 \\
\hline Farrodes & 0.00 & 0.00 \\
\hline não identificado & 0.00 & 0.00 \\
\hline \multicolumn{3}{|l|}{ Ephemeridae } \\
\hline Hexagenia & 41.03 & 92.31 \\
\hline Ephemeroptera n.i. & 0.00 & 0.00 \\
\hline \multicolumn{3}{|l|}{$\begin{array}{l}\text { PLECOPTERA } \\
\text { Gripopterygidae }\end{array}$} \\
\hline Grypopteryx & 0.00 & 0.00 \\
\hline Paragrypopteryx & 0.00 & 0.00 \\
\hline Tupiperla & 0.00 & 0.00 \\
\hline \multicolumn{3}{|l|}{ Perlidae } \\
\hline Anacroneuria & 0.00 & 0.00 \\
\hline Kempnyia & 0.00 & 0.00 \\
\hline Plecoptera n.i. & 0.00 & 0.00 \\
\hline \multicolumn{3}{|l|}{$\begin{array}{l}\text { TRICHOPTERA } \\
\text { Hydrobiosidae }\end{array}$} \\
\hline Atopsyche & 0.00 & 0.00 \\
\hline \multicolumn{3}{|l|}{ Helicopsychidae } \\
\hline \multicolumn{3}{|l|}{ Hydropsychidae } \\
\hline Smicridea & 0.00 & 0.00 \\
\hline Leptonema & 0.00 & 0.00 \\
\hline não identificado & 0.00 & 10.26 \\
\hline \multicolumn{3}{|l|}{ Hydroptilidae } \\
\hline Oxyethira & 0.00 & 0.00 \\
\hline aff. Hydroptila & 0.00 & 0.00 \\
\hline Ochotrichia & 0.00 & 0.00 \\
\hline Neotrichia & 0.00 & 0.00 \\
\hline Rhyacopsyche & 0.00 & 0.00 \\
\hline não identificado & 0.00 & 10.26 \\
\hline \multicolumn{3}{|l|}{ Leptoceridae } \\
\hline Amphoropsyche & 0.00 & 0.00 \\
\hline Nectopsyche & 164.11 & 1169.26 \\
\hline Oecetis & 0.00 & 112.82 \\
\hline Grumichella & 0.00 & 0.00 \\
\hline não identificado & 0.00 & 0.00 \\
\hline \multicolumn{3}{|l|}{ Sericostomatidae } \\
\hline Grumicha & 0.00 & 0.00 \\
\hline \multicolumn{3}{|l|}{ Policentropodidae } \\
\hline Cernotina & 0.00 & 0.00 \\
\hline Cyrnellus & 0.00 & 0.00 \\
\hline Nyctiophylax & 0.00 & 0.00 \\
\hline \multicolumn{3}{|l|}{ Calamoceridae } \\
\hline Phylloicus & 0.00 & 0.00 \\
\hline Glossosomatidae & & \\
\hline Mexitrichia & 0.00 & 0.00 \\
\hline Itauara & 0.00 & 0.00 \\
\hline Protoptila & 0.00 & 0.00 \\
\hline Odontoceridae & & \\
\hline Barypenthus & 0.00 & 0.00 \\
\hline Trichoptera n.i. & 0.00 & 0.00 \\
\hline
\end{tabular}

Dados quali e quantitativos $-2^{\underline{a}}$ campanha 


\begin{tabular}{|c|c|c|c|}
\hline $\begin{array}{l}\text { PONTO } 6 \\
\text { HÁBITATS } \\
\text { EQUIPAMENTO }\end{array}$ & $\begin{array}{c}\text { CANAL } \\
\text { PETERSEN USP }\end{array}$ & $\begin{array}{c}\text { M. DEP. } \\
\text { PETERSEN USP }\end{array}$ & $\begin{array}{c}\text { M. ERO. } \\
\text { PETERSEN USP }\end{array}$ \\
\hline \multicolumn{4}{|l|}{$\begin{array}{l}\text { EPHEMEROPTERA } \\
\text { Baetidae }\end{array}$} \\
\hline Americabaetis & 0.00 & 0.00 & 0.00 \\
\hline Aturbina & 0.00 & 0.00 & 0.00 \\
\hline Camelobaetidius & 0.00 & 0.00 & 0.00 \\
\hline Cryptonynpha & 0.00 & 0.00 & 0.00 \\
\hline Iguaira & 0.00 & 0.00 & 0.00 \\
\hline Paracloeodes & 0.00 & 0.00 & 0.00 \\
\hline Waltzophius & 0.00 & 0.00 & 0.00 \\
\hline Zelusia & 0.00 & 0.00 & 0.00 \\
\hline não identificado & 0.00 & 0.00 & 0.00 \\
\hline \multicolumn{4}{|l|}{ Leptohyphidae } \\
\hline Tricorythodes & 71.80 & 0.00 & 0.00 \\
\hline Tricorythopsis & 10.26 & 0.00 & 0.00 \\
\hline Traverhyphes & 0.00 & 0.00 & 0.00 \\
\hline não identificado & 0.00 & 10.26 & 0.00 \\
\hline \multicolumn{4}{|l|}{ Leptophlebiidae } \\
\hline Hylyster & 0.00 & 0.00 & 0.00 \\
\hline Miroculis & 0.00 & 0.00 & 0.00 \\
\hline Farrodes & 0.00 & 0.00 & 0.00 \\
\hline não identificado & 30.77 & 0.00 & 0.00 \\
\hline \multicolumn{4}{|l|}{ Ephemeridae } \\
\hline Hexagenia & 0.00 & 0.00 & 0.00 \\
\hline Ephemeroptera n.i. & 0.00 & 0.00 & 0.00 \\
\hline \multicolumn{4}{|l|}{$\begin{array}{l}\text { PLECOPTERA } \\
\text { Gripopterygidae }\end{array}$} \\
\hline Grypopteryx & 0.00 & 0.00 & 0.00 \\
\hline Paragrypopteryx & 0.00 & 0.00 & 0.00 \\
\hline Tupiperla & 0.00 & 0.00 & 0.00 \\
\hline \multicolumn{4}{|l|}{ Perlidae } \\
\hline Anacroneuria & 0.00 & 0.00 & 0.00 \\
\hline Kempnyia & 0.00 & 0.00 & 0.00 \\
\hline Plecoptera n.i. & 0.00 & 0.00 & 0.00 \\
\hline \multicolumn{4}{|l|}{$\begin{array}{l}\text { TRICHOPTERA } \\
\text { Hydrobiosidae }\end{array}$} \\
\hline Atopsyche & 0.00 & 0.00 & 0.00 \\
\hline \multicolumn{4}{|l|}{ Helicopsychidae } \\
\hline $\begin{array}{l}\text { Helicopsyche } \\
\text { Hydropsychidae }\end{array}$ & 0.00 & 0.00 & 0.00 \\
\hline Smicridea & \multicolumn{3}{|c|}{ Hydropsychidae } \\
\hline Leptonema & $\begin{array}{l}0.00 \\
0.00\end{array}$ & 0.00 & 0.00 \\
\hline não identificado & 0.00 & 0.00 & 0.00 \\
\hline \multicolumn{4}{|l|}{ Hydroptilidae } \\
\hline Oxyethira & 0.00 & 0.00 & 0.00 \\
\hline aff. Hydroptila & 0.00 & 0.00 & 0.00 \\
\hline Ochotrichia & 0.00 & 0.00 & 0.00 \\
\hline Neotrichia & 0.00 & 82.05 & 0.00 \\
\hline Rhyacopsyche & 0.00 & 0.00 & 0.00 \\
\hline \multirow{2}{*}{\multicolumn{4}{|c|}{ Leptoceridae }} \\
\hline & & & \\
\hline Amphoropsyche & 0.00 & 30.77 & 82.05 \\
\hline Nectopsyche & 10.26 & 123.08 & 0.00 \\
\hline Oecetis & 0.00 & 0.00 & 0.00 \\
\hline Grumichella & 0.00 & 0.00 & 0.00 \\
\hline não identificado & 0.00 & 0.00 & 0.00 \\
\hline \multicolumn{4}{|l|}{ Sericostomatidae } \\
\hline Grumicha & 0.00 & 0.00 & 0.00 \\
\hline \multicolumn{4}{|l|}{ Policentropodidae } \\
\hline Cernotina & 0.00 & 0.00 & 0.00 \\
\hline Cyrnellus & 0.00 & 0.00 & 0.00 \\
\hline Nyctiophylax & 0.00 & 0.00 & 0.00 \\
\hline \multicolumn{4}{|l|}{ Calamoceridae } \\
\hline Phylloicus & 0.00 & 0.00 & 0.00 \\
\hline Glossosomatidae & & & \\
\hline Mexitrichia & 0.00 & 0.00 & 0.00 \\
\hline Itauara & 0.00 & 0.00 & 0.00 \\
\hline Protoptila & 0.00 & 0.00 & 0.00 \\
\hline Odontoceridae & & & \\
\hline Barypenthus & 0.00 & 0.00 & 0.00 \\
\hline Trichoptera n.i. & 0.00 & 0.00 & 0.00 \\
\hline
\end{tabular}

Dados quali e quantitativos $-2^{\mathrm{a}}$ campanha 
PONTO 7

HÁBITATS

CANAL

M. DEP.

M. ERO.

EQUIPAMENTO

PETERSEN US

PETERSEN US

PETERSEN USP

EPHEMER
Baetidae

Americabaetis Aturbina

Camelobaetidius

Cryptonynpha Iguaira

Paracloeodes

Waltzophius Zelusia

não identificado

Leptohyphidae

Tricorythodes

Tricorythopsis

Traverhyphes

Leptophlebiidae

ão identificado

0.00

0.00

0.00

0.00

0.00

0.00

0.00

0.00

0.00

0.00

0.00

0.00

0.00

0.00

0.00

0.00

0.00

0.00

0.00

Ephemeroptera $n$.

PLECOPTERA

Gripopterygidae

Grypopteryx Paragrypopteryx Tupiperla

Perlidae

Anacroneuria Kempnyia

TRICHOPTERA

Plecoptera n.i.

Hydrobiosidae

Helicopsychidae

Atopsyche

Helicopsyche

Hydropsychidae

Smicridea

Leptonema

não identificado

Hydroptilidae

Oxyethira

aff. Hydroptila

Ochotrichia

Neotrichia

Rhyacopsyche

não identificado

Leptoceridae

Amphoropsyche Nectopsyche Oecetis

Grumichella

não identificado

Sericostomatidae

Grumicha

Policentropodidae

Cernotina

Cyrnellus

Nyctiophylax

Calamoceridae

Phylloicus

Glossosomatidae

$\begin{array}{ll}\text { Mexitrichia } & 0.00 \\ \text { Itauara } & 0.00\end{array}$

Protoptila

Odontoceridae

Barypenthus

Trichoptera n.i.
$0.00 \quad 0.00$

$0.00-0.00$

$0.00 \quad 0.00$

$0.00-0.00$

$0.00 \quad 0.00$

$0.00 \quad 0.00$

$0.00-0.00$

$0.00 \quad 0.00$

$0.00 \quad 0.00$

$10.26 \quad 0.00$

$0.00 \quad 0.00$

$10.26 \quad 0.00$

$0.00 \quad 0.00$

$0.00 \quad 0.00$

$0.00 \quad 0.00$

$0.00-0.00$

$0.00 \quad 0.00$

$0.00 \quad 0.00$

$0.00 \quad 0.00$

$\begin{array}{lll}0.00 & 0.00 & 0.00\end{array}$

$0.00 \quad 0.00 \quad 0.00$

$\begin{array}{lll}0.00 & 0.00 & 0.00\end{array}$

$\begin{array}{lll}0.00 & 0.00 & 0.00\end{array}$

$\begin{array}{lll}0.00 & 0.00 & 0.00\end{array}$

$\begin{array}{lll}0.00 & 0.00 & 0.00\end{array}$

$\begin{array}{lll}0.00 & 0.00 & 0.00\end{array}$

$\begin{array}{lll}0.00 & 0.00 & 0.00\end{array}$

$\begin{array}{lll}0.00 & 0.00 & 0.00\end{array}$

$\begin{array}{lll}0.00 & 0.00 & 0.00\end{array}$

$\begin{array}{lll}0.00 & 0.00 & 0.00\end{array}$

$\begin{array}{lll}0.00 & 0.00 & 0.00\end{array}$

$\begin{array}{lll}0.00 & 0.00 & 0.00\end{array}$

$0.00 \quad 0.00 \quad 0.00$

$\begin{array}{lll}20.51 & 10.26 & 0.00\end{array}$

$\begin{array}{lll}0.00 & 0.00 & 0.00\end{array}$

$\begin{array}{lll}0.00 & 0.00 & 0.00\end{array}$

$\begin{array}{lll}0.00 & 0.00 & 0.00\end{array}$

$\begin{array}{lll}10.26 & 0.00 & 0.00\end{array}$

$10.26 \quad 30.77 \quad 0.00$

$\begin{array}{lll}0.00 & 0.00 & 0.00\end{array}$

$\begin{array}{lll}0.00 & 0.00 & 0.00\end{array}$

$\begin{array}{lll}0.00 & 0.00 & 0.00\end{array}$

$\begin{array}{lll}0.00 & 0.00 & 0.00\end{array}$

$\begin{array}{lll}10.26 & 0.00 & 20.51\end{array}$

$\begin{array}{lll}0.00 & 0.00 & 0.00\end{array}$

$\begin{array}{lll}0.00 & 0.00 & 0.00\end{array}$

$\begin{array}{lll}0.00 & 0.00 & 0.00\end{array}$

0.00

$0.00 \quad 0.00$

$\begin{array}{lll}0.00 & 0.00 & 0.00\end{array}$

$\begin{array}{lll}0.00 & 0.00 & 0.00\end{array}$

Dados quali e quantitativos $-2^{\underline{a}}$ campanha 


\begin{tabular}{|c|c|c|c|}
\hline $\begin{array}{l}\text { PONTO } 8 \\
\text { HÁBITATS } \\
\text { EQUIPAMENTO }\end{array}$ & $\begin{array}{c}\text { CANAL } \\
\text { PETERSEN USP }\end{array}$ & $\begin{array}{c}\text { M. DEP. } \\
\text { PETERSEN USP }\end{array}$ & $\begin{array}{c}\text { M. ERO. } \\
\text { PETERSEN USP }\end{array}$ \\
\hline \multicolumn{4}{|l|}{$\begin{array}{l}\text { EPHEMEROPTERA } \\
\text { Baetidae }\end{array}$} \\
\hline Americabaetis & 10.26 & 0.00 & 0.00 \\
\hline Aturbina & 0.00 & 0.00 & 0.00 \\
\hline Camelobaetidius & 0.00 & 0.00 & 0.00 \\
\hline Cryptonynpha & 0.00 & 0.00 & 0.00 \\
\hline Iguaira & 0.00 & 0.00 & 0.00 \\
\hline Paracloeodes & 0.00 & 0.00 & 0.00 \\
\hline Waltzophius & 0.00 & 0.00 & 0.00 \\
\hline Zelusia & 0.00 & 0.00 & 0.00 \\
\hline não identificado & 0.00 & 0.00 & 0.00 \\
\hline \multicolumn{4}{|l|}{ Leptohyphidae } \\
\hline Tricorythodes & 0.00 & 0.00 & 0.00 \\
\hline Tricorythopsis & 0.00 & 0.00 & 0.00 \\
\hline Traverhyphes & 0.00 & 0.00 & 0.00 \\
\hline não identificado & 0.00 & 0.00 & 0.00 \\
\hline \multicolumn{4}{|l|}{ Leptophlebiidae } \\
\hline Hylyster & 0.00 & 0.00 & 0.00 \\
\hline Miroculis & 0.00 & 0.00 & 0.00 \\
\hline Farrodes & 0.00 & 0.00 & 0.00 \\
\hline não identificado & 0.00 & 0.00 & 0.00 \\
\hline \multicolumn{4}{|l|}{ Ephemeridae } \\
\hline Hexagenia & 0.00 & 0.00 & 0.00 \\
\hline Ephemeroptera n.i. & 0.00 & 0.00 & 0.00 \\
\hline \multicolumn{4}{|l|}{ PLECOPTERA } \\
\hline \multicolumn{4}{|l|}{ Gripopterygidae } \\
\hline Grypopteryx & 0.00 & 0.00 & 0.00 \\
\hline Paragrypopteryx & 0.00 & 0.00 & 0.00 \\
\hline Tupiperla & 0.00 & 0.00 & 0.00 \\
\hline \multicolumn{4}{|l|}{ Perlidae } \\
\hline Anacroneuria & 0.00 & 0.00 & 0.00 \\
\hline Kempnyia & 0.00 & 0.00 & 0.00 \\
\hline Plecoptera n.i. & 0.00 & 0.00 & 0.00 \\
\hline \multicolumn{4}{|l|}{ TRICHOPTERA } \\
\hline Atopsyche & 0.00 & 0.00 & 0.00 \\
\hline \multicolumn{4}{|l|}{ Helicopsychidae } \\
\hline Helicopsyche & 0.00 & 0.00 & 0.00 \\
\hline \multicolumn{4}{|l|}{ Hydropsychidae } \\
\hline Smicridea & 0.00 & 0.00 & 0.00 \\
\hline Leptonema & 0.00 & 0.00 & 0.00 \\
\hline não identificado & 0.00 & 0.00 & 0.00 \\
\hline \multicolumn{4}{|l|}{ Hydroptilidae } \\
\hline Oxyethira & 0.00 & 0.00 & 0.00 \\
\hline aff. Hydroptila & 0.00 & 0.00 & 0.00 \\
\hline Ochotrichia & 0.00 & 0.00 & 0.00 \\
\hline Neotrichia & 0.00 & 0.00 & 0.00 \\
\hline Rhyacopsyche & 0.00 & 0.00 & 0.00 \\
\hline não identificado & 0.00 & 0.00 & 0.00 \\
\hline \multicolumn{4}{|l|}{ Leptoceridae } \\
\hline Amphoropsyche & 30.77 & 20.51 & 0.00 \\
\hline Nectopsyche & 0.00 & 0.00 & 0.00 \\
\hline Oecetis & 0.00 & 0.00 & 0.00 \\
\hline Grumichella & 0.00 & 0.00 & 0.00 \\
\hline não identificado & 0.00 & 0.00 & 0.00 \\
\hline Sericostomatidae & & & \\
\hline Grumicha & 0.00 & 0.00 & 0.00 \\
\hline Policentropodidae & & & \\
\hline Cernotina & 0.00 & 0.00 & 0.00 \\
\hline Cyrnellus & 0.00 & 0.00 & 0.00 \\
\hline Nyctiophylax & 0.00 & 0.00 & 0.00 \\
\hline Calamoceridae & & & \\
\hline Phylloicus & 0.00 & 0.00 & 0.00 \\
\hline Glossosomatidae & & & \\
\hline Mexitrichia & 0.00 & 0.00 & 0.00 \\
\hline Itauara & 0.00 & 0.00 & 0.00 \\
\hline Protoptila & 0.00 & 0.00 & 0.00 \\
\hline Odontoceridae & & & \\
\hline Barypenthus & 0.00 & 0.00 & 0.00 \\
\hline Trichoptera n.i. & 0.00 & 0.00 & 0.00 \\
\hline
\end{tabular}

Dados quali e quantitativos - $2^{\text {a }}$ campanha 


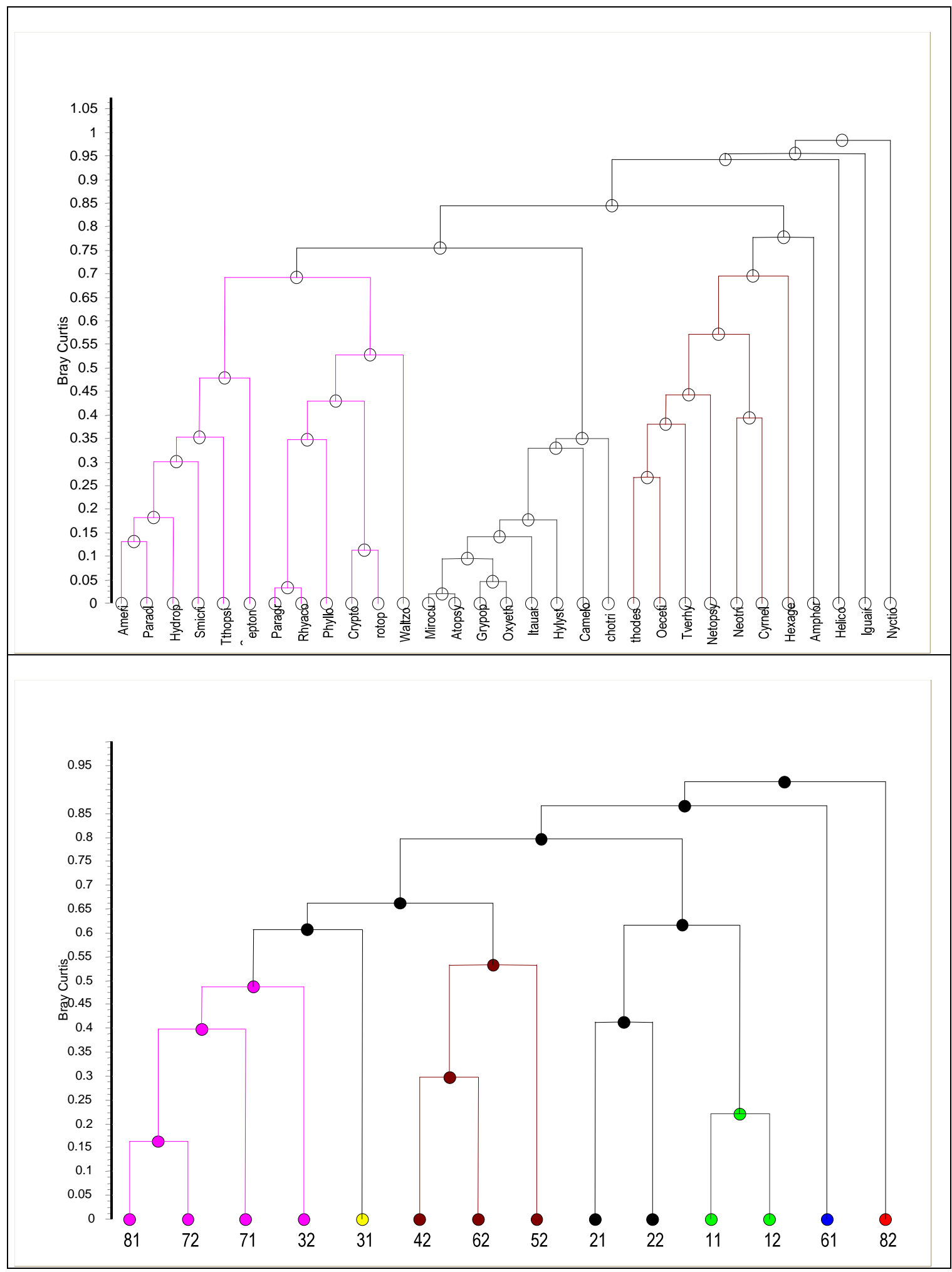

Dendrogramas proveniente de análise de agrupamento (Bray-Curtis / UPGMA) para os dados bióticos, como ferramenta para a análise nodal. 